\title{
Human capital in growth regressions: how much difference does data quality make?
}

\author{
Angel de la Fuente* \\ Instituto de Análisis Económico (CSIC) \\ and \\ Rafael Doménech \\ Universidad de Valencia
}

January 2000

\begin{abstract}
We construct a revised version of the Barro and Lee (1996) data set for a sample of OECD countries using previously unexploited sources and following a heuristic approach to obtain plausible time profiles for attainment levels by removing sharp breaks in the data that seem to reflect changes in classification criteria. It is then shown that these revised data perform much better than the Barro and Lee (1996) or Nehru et al (1995) series in a number of growth specifications. We interpret these results as an indication that poor data quality may be behind counterintuitive findings in the recent literature on the (lack of) relationship between educational investment and growth. Using our preferred empirical specificaction, we also show that the contribution of TFP to cross-country productivity differentials is substantial and that its importance relative to differences in factor stocks increases over time.
\end{abstract}

\footnotetext{
${ }^{*}$ We gratefully acknowledge financial support from the European Fund for Regional Development, the Spanish Ministry of Education through CICYT grants SEC99-1189 and SEC99-0820 and the European TNR "Specialization vs. diversification: the microeconomics of regional development and the propagation of macroeconomic shocks in Europe." We thank José Emilio Boscá, Anna Borkowsky (Swiss Federal Statistical Office) and Gunilla Dahlen (Statistics Sweden) for their helpful comments and suggestions, and María Jesús Freire and Juan Antonio Duro for their helpful research assistance.

Correspondence to: Angel de la Fuente, Instituto de Análisis Económico, Campus de la Universidad Autónoma de Barcelona, 08193, Bellaterra, Barcelona. Tel: 93-580-6612. Fax: 93-580-1452. E-Mail address: delafuente@cc.uab.es.

Rafael Domenech, Departamento de Análisis Económico, Universidad de Valencia, Campus de los Naranjos, 46022 Valencia, Spain; email: Rafael.Domenech@uv.es
} or 


\section{1.- Introduction}

Recent empirical investigations of the contribution of human capital accumulation to economic growth have often produced discouraging results. Educational variables frequently turn out to be insignificant or to have the "wrong" sign in growth regressions, particularly when these are estimated using firstdifferenced or panel specifications. The accumulation of such negative results in the recent literature has fueled a growing skepticism on the role of schooling in the growth process, and has even led some researchers (notably Pritchett (1995)) to seriously consider possible reasons why the contribution of educational investment to productivity growth may actually be negative.

In this paper we argue that counterintuitive results on human capital and growth may be due, at least in part, to deficiencies in the data or inadequacies of the econometric specification. When we compare the different studies in the recent empirical literature on human capital and growth, perhaps the clearest regularity we find is that results are typically much better when we focus on cross-section or pooled data estimates, and get considerably worse when we consider the results of first-differenced, fixed effects or within specifications -- which rely more heavily on the time-series variation of the data. ${ }^{1}$ To put it in a slightly different way, the data seem to be telling us that, controlling for other things, more educated countries do tend to be more productive than others, but that it is not true that productivity rises over time with human capital in the manner suggested by the cross-section profile.

This pattern of results, which is not unusual in panel data estimation, ${ }^{2}$ may reflect a number of (not mutually exclusive) problems that have nothing to do with the ineffectiveness of educational investment. One possibility is measurement error. If human capital stocks have been measured with error (and, as we will argue below, we have every reason to believe this is the case), their first differences will be even less accurate than their levels, a fact that could explain their lack of significance in some of the relevant studies. A second possibility has to do with the trends of the human capital variables and the growth rate of output. Since productivity growth has declined over time while both enrollment rates and schooling levels rose sharply in the last decades (especially in developing countries), a negative sign on the human capital variable is not really surprising when we eliminate the cross-section variation of the data, but it may simply reflect the omission of some other factors that may account for the growth slowdown.

We provide some evidence that data deficiencies are at least partially responsible for the poor empirical performance of human capital indicators in growth equations. On the other hand, correcting in a simple way for a potential "trends problem" does not significantly affect the results in the OECD sample we consider when a production function specification is used, although we suspect this may change in a broader sample or with a convergence equation specification.

\footnotetext{
1 See among others Mankiw, Romer and Weil (1992), Knight, Loayza and Villanueva (1993), Benhabib and Spiegel (1994), Barro and Lee (1994), Islam (1995), Caselli et al (1996) and Hamilton and Monteagudo (1998). De la Fuente (2000) surveys this literature.

2 See for example Griliches and Hausman (1986).
} 
The paper is organized as follows. In Section 2 we briefly review the available data on educational attainment levels and document some of the problems they display. In Section 3 we describe the construction of new schooling series for a sample of 21 OECD countries. These series are essentially a revised version of (a subset of) Barro and Lee's (1996) data set that incorporates a greater amount of national information than the original series and tries to avoid implausible breaks in the data by correcting for what appear to be changes in classification criteria. We focus on the OECD in part for reasons of data availability and in part because this is the sample for which Mankiw, Romer and Weil (MRW 1992) find weakest support for their human capital-augmented Solow model. ${ }^{3}$ In Section 4 we show that our revised data perform much better than Barro and Lee's (1996) or Nehru et al's (1995) series in a number of fairly standard growth accounting specifications. Our best results are obtained with a specification in first differences that allows for a technological catch-up effect following de la Fuente (1996). We use this model to explore the relative importance of total factor productivity (TFP) and factor stocks as sources of crosscountry productivity differences and find that the contribution of the first factor is substantial and increasing over time. Section 5 concludes.

\section{2.- International data on educational attainment: a brief survey and some worrisome features}

The basic source of schooling data is a diverse set of indicators provided by national agencies on the basis of population censuses and educational and labour force surveys. Various international organizations collect this information and compile comparative statistics that provide easily accessible and (supposedly) homogeneous information for a large number of countries. Perhaps the most comprehensive regular source of international educational statistics is UNESCO's Statistical Yearbook. This publication provides reasonably complete yearly time series on school enrollment rates by level of education for most countries in the world and contains some data on the educational attainment of the adult population, government expenditures on education, teacher/pupil ratios and other variables of interest. Other UNESCO publications contain additional information on educational stocks and flows and some convenient compilations. Other useful sources include the UN's Demographic Yearbook, which also reports educational attainment levels by age group and the IMF's Government Finance Statistics, which provides data on public expenditures on education. Finally, the OECD also compiles educational statistics both for its member states (e.g. OECD (1995)) and occasionally for larger groups of countries.

The UNESCO enrollment series have been used in a large number of empirical studies of the link between education and productivity. In many cases this choice reflects the easy availability and broad coverage of these data rather than their theoretical suitability for the purpose of the study. Enrollment rates can probably be considered an acceptable, although imperfect, proxy for the flow of educational investment. On the other hand, these variables are not necessarily a good indicator of the existing stock of human capital since average educational attainment (which is often the more interesting variable from a theoretical point of view) responds to investment flows only gradually and with a very considerable lag.

\footnotetext{
${ }^{3}$ MRW's schooling variable is not significant at the usual $5 \%$ level in this subsample, but does become significant in broader samples.
} 
In an attempt to remedy these shortcomings, a number of researchers have constructed data sets that attempt to measure directly the educational stock embodied in the population or labour force of large samples of countries. One of the earliest attempts in this direction is due to Psacharopoulos and Arriagada (PA, 1986) who, drawing on earlier work by Kaneko (1986), report data on the educational composition of the labour force in 99 countries and provide estimates of the average years of schooling. In most cases, however, PA provide only one observation per country.

More recently, there have been various attempts to construct more complete data sets on educational attainment that provide broader temporal coverage and can therefore be used in growth accounting and other empirical exercises. This requires panel data for as many countries and years as possible.

\subsection{Educational data bases: coverage and construction}

The existing data sets on educational attainment have been constructed by combining the available data on attainment levels with the UNESCO enrollment figures to obtain series of average years of schooling and the educational composition of the population or labour force. Enrollment data are transformed into attainment figures through a perpetual inventory method or some short-cut procedure that attempts to approximate it. We are aware of the following studies:

Kyriacou (1991) provides estimates of the average years of schooling of the labour force $(h)$ for a sample of 111 countries. His data cover the period 1965-1985 at five-year intervals. He uses UNESCO data and PA's attainment figures to estimate an equation linking $h$ to lagged enrollment rates. This equation is then used to construct an estimate of $h$ for other years and countries.

Lau, Jamison and Louat (1991) and Lau, Bhalla and Louat (1991). These studies use a perpetual inventory method and annual data on enrollment rates to construct estimates of attainment levels for the working-age population. Their perpetual inventory method uses age-specific survival rates constructed for representative countries in each region but does not seem to correct enrollment rates for dropouts or repeaters. "Early" school enrollment rates are estimates constructed through backward extrapolation of post-1960 figures. They do not use or benchmark against available census figures.

Barro and Lee (B\&L 1993) construct education indicators combining census data and enrollment rates. To estimate attainment levels in years for which census data are not available, they use a combination of interpolation between available census observations (where possible) and a perpetual inventory method that can be used to estimate changes from nearby (either forward or backward) benchmark observations. Their version of the perpetual inventory method makes use of data on gross enrollments ${ }^{4}$ and the age composition of the population (to estimate survival rates). The data set contains observations for 129 countries and covers the period 1960-85 at five-year intervals. Besides the average years of education of the population over 25, Barro and Lee report information on the fraction of the (male and female) population

4 The gross enrollment rate is defined as the ratio between the total number of students enrolled in a given educational level and the size of the population which, according to its age, "should" be enrolled in the course. The net enrollment rate is defined in an analogous manner but counting only those students who belong to the relevant age group. Hence, older students (typically repeaters) are excluded in this second case. 
that has reached and completed each educational level. In a more recent paper (B\&L, 1996), the same authors present an update of their previous work. The revised database, which is constructed following the same procedure as the previous one (except for the use of net rather than gross enrollment rates), extends the attainment series up to 1990, provides data for the population over 15 years of age and incorporates some new information on quality indicators such as the pupil/teacher ratio, public educational expenditures per student and the length of the school year.

Nehru, Swanson and Dubey (NSD 1995) follow roughly the same procedure as Lau, Jamison and Louat (1991) but introduce several improvements. The first one is that Nehru et al collect a fair amount of enrollment data prior to 1960 and do not therefore need to rely as much on the backward extrapolation of enrollment rates. Secondly, they make some adjustment for grade repetition and drop-outs using the limited information available on these variables.

We can divide these studies into two groups according to whether they make use of both census attainment data and enrollment series or only the latter. The first set of papers (Kyriacou and Barro and Lee) relies on census figures where available and then uses enrollment data to fill in the missing values. Kyriacou's is the least sophisticated of the two studies. This author uses a simple regression of educational stocks on lagged flows to estimate the unavailable levels of schooling. This procedure is valid only when the relationship between these two variables is stable over time and across countries, which seems unlikely although it may not be a bad rough approximation, particularly within groups of countries with similar population age structures. In principle, Barro and Lee's procedure should be superior to Kyriacou's because it makes use of more information and does not rely on such strong implicit assumptions. In addition, these authors also choose their method for filling in missing observations on the basis of an accuracy test based on a sample of 30 countries for which relatively complete census data are available.

The second group of papers (Louat et al and Nehru et al) uses only enrollment data to construct time series of educational attainment. The version of the perpetual inventory method used in these studies is a bit more sophisticated than the one in Barro and Lee, particularly in the case of Nehru et al. Both Nehru et al and Louat et al use estimates of age-specific survival probabilities constructed for a representative country in each region. This procedure should be more accurate than Barro and Lee's rough estimate of survival probabilities (which is not really age-specific and therefore can bias the results if attainment levels differ significantly across age groups, as seems likely). Unlike Barro and Lee (1993), Nehru et al also make a potentially important correction for repeaters and drop-outs using (limited) country-specific information on these variables. ${ }^{5}$ On the other hand, these studies completely ignore census data on attainment levels. To justify this decision, Nehru et al observe that census publications typically do not report the actual years of schooling of individuals (only whether or not they have completed a certain level of education and/or whether they have started it) and often provide information only for the population aged 25 and over. As a result, there will be some arbitrariness in estimates of average years of schooling based on this data and the

\footnotetext{
${ }^{5}$ Barro and Lee's (1996) estimates, however, partially account for these factors by using estimates of net enrollment rates. The paper, however, gives no details on how net enrollment rates are estimated.
} 
omission of the younger segments of the population may bias the results, particularly in LDCs, where this age group is typically very large and much more educated than older cohorts. While this is certainly true and may call for some adjustment of the census figures on the basis of other sources, in our opinion it hardly justifies discarding the only direct information available on the variables of interest.

\subsection{A closer look at the OECD data}

Methodological differences across different studies would be of relatively little concern if they all gave us a consistent and reasonable picture of educational attainment levels across countries and their evolution over time. As we will see presently, this is not the case. Different sources show very significant variations in terms of the relative positions of different countries. Although the various studies generally coincide when comparisons are made across broad regions (e.g. the OECD vs. LDCs in various geographical areas), the discrepancies are very important when we focus on the group of industrialized countries. Another cause for concern is that practically all available data on educational stocks and flows, including UNESCO's enrollment series, present anomalies which, to some extent, raise doubts about their accuracy and consistency. In particular, the schooling levels reported for some countries do not seem very plausible, while others display extremely large changes in attainment levels over periods as short as five years (particularly at the secondary and tertiary levels) or extremely suspicious trends. ${ }^{6}$

To illustrate these problems and to get some feeling for the overall reasonableness of the existing data, in this section we will take a closer look at the most sophisticated data sets within each of the groups of studies identified in the previous section -- i.e. the Barro and Lee (B\&L 1996) and Nehru et al (NSD 1995) data sets. As in the empirical section of the paper, we will concentrate on a sample of OECD countries. One of the main reasons for this choice is that educational statistics for this set of advanced industrial nations are presumably of decent quality. Any deficiencies we find in them are likely to be compounded in the case of poorer countries.

The degree of consistency between the various sources varies a lot depending on the level of aggregation we consider. Table 1, taken from NSD (1995), shows that the overall correlation (computed over common observations) of the different estimates is reasonably high. The correlation between the B\&L and NSD figures over the whole sample, for example, stands at a respectable 0.81. An examination of average figures over different geographic regions and over time also reveals a fairly consistent and reasonable pattern. Industrialized countries and socialist economies display much higher attainment rates than less developed countries. Within this last group, Africa lies at the bottom, while Latin America does fairly well and Southeast Asia presents the largest improvement over the period.

\footnotetext{
${ }^{6}$ Behrman and Rosenzweig (1994) discuss some of the shortcomings of UNESCO's educational data.
} 
Table 1: Correlation among alternative estimates of avge. schooling

Nehru et al (NSD)

NSD $\quad P A \quad B L \quad K y r$

Psch. and Arr. (PA)

1

Barro and Lee (BEL 93)

0.84

0.81

1

Kyriacou (Kyr)

0.89

0.92

0.86

0.89

1

- Source: Nehru et al (1995).

Figure 1: Average years of schooling in1985: B\&L (1996) vs NSD

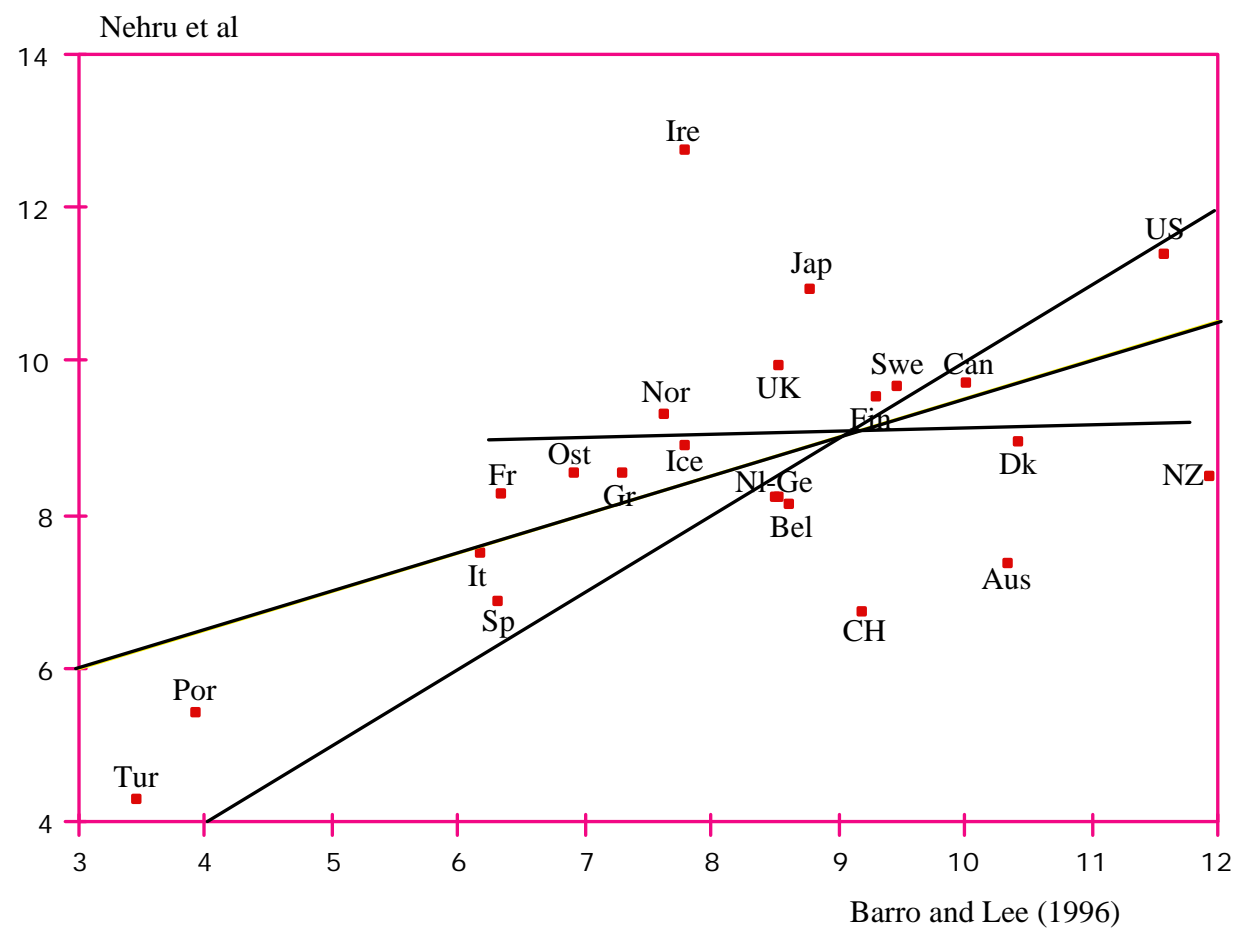

Notes:

- The estimates refer to the population over 15 in the case of Barro and Lee and to the age group 15-64 in Nehru et al.

- The estimated equation is of the form h.nsd $=4.50+0.503 \mathrm{~h} . \mathrm{b} \& \mathrm{l}, \mathrm{t}=3.21, \mathrm{R}^{2}=0.329$. The flatter line in the figure is the regression line fitted after excluding the four countries with the lower schooling levels. The thinest and steepest line is the "diagonal", where all the observations would fall if both sources agreed.

- Legend: $\mathrm{Tu}=$ Turkey; Por = Portugal; $\mathrm{CH}=$ Switzerland; $\mathrm{Sp}=$ Spain; Aus = Australia; It = Italy; Be = Belgium; Ge = West Germany; $\mathrm{Nl}=$ Netherlands; $\mathrm{Fr}=$ France; NZ = New Zealand; Gr = Greece; Ost = Austria; Is = Iceland; Dk = Denmark; Nor = Norway; Fin = Finland; Swe = Sweden; Can = Canada; UK = United Kingdom; Jap = Japan; USA = United States; Ir = Ireland. 
Figure 2: Average years of schooling by level in the OECD: B\&L (1996) vs. NSD
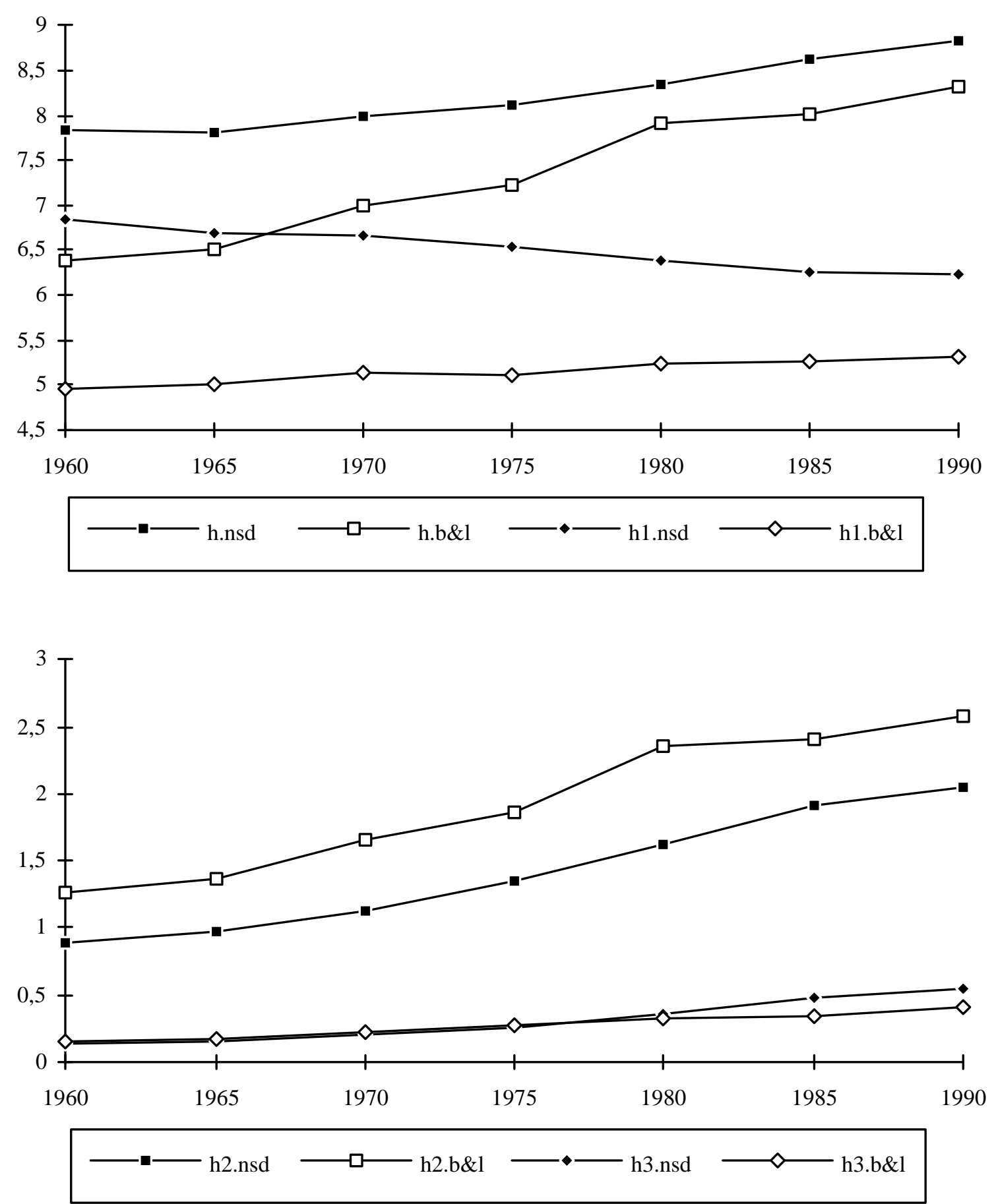

Notes:

- Unweighted averages over the available OECD countries. Neither source reports data for Luxembourg. The sample excludes New Zealand except for average total years of schooling, as NSD only provide data on this variable but not its breakdown by level.

- The data are for the age group 15-64 in the case of NSD and for the population aged 15 and over in Barro and Lee (1996).

- The last year for the NSD series is 1987, rather than 1990. 
This high overall correlation, however, hides significant discrepancies between the two data sets, both over time and across countries. Figure 1 shows B\&L's (1996) and NSD's estimates of the average years of total schooling of the population over 15 for OECD countries in 1985. The correlation for the 23 countries (there are no data for Luxembourg) is now 0.574, but when we exclude the four countries with the lowest levels of schooling in the sample, the correlation drops to zero (0.063). When we disaggregate, the correlation is fairly high at the university level (0.767) and much lower for primary (0.362) and secondary (0.397) attainment.

Figure 2 shows the evolution of the average years of total schooling $(h)$ in the average OECD country and their breakdown by levels ( $h 1, h 2$ and $h 3$ ) according to the same two sources (B\&L vs NSD). If we focus on average years of total schooling, both data sets display an increasing trend, although it is much more marked in the case of B\&L. In terms of their levels, NSD's figures on average attainment are significantly higher, although the difference between the two sets of estimates diminishes over time and becomes minor towards the end of the period. In principle, this discrepancy may be due at least in part to the difference between the age groups considered in the two studies. While B\&L focus on the population aged 15 and over, NSD attempt to measure the educational attainment of the 15 to 64 age group. Since the older cohorts included in the B\&L sample and excluded by NSD are typically less educated than the rest of the population, we would expect Barro and Lee's attainment estimates to be somewhat lower than Nehru et al's.

Significant differences between the two sources emerge when we disaggregate by educational level. In terms of secondary schooling the trend is quite similar in both cases but NSD's estimates are, unexpectedly, lower on average than B\&L's. At the primary level, NSD's attainment figures are implausibly high, exceeding the duration of this school cycle (which is around six years on average), and display a downward trend. This "finding" that primary schooling levels have decreased over time in industrial countries is extremely suspicious, for it implies that new entrants into the labour force have less primary schooling than the older generations -- in spite of the rapid increase of enrollment rates over the period.

For OECD countries we have some alternative sources that can be used to assess the likely accuracy of the B\&L and NSD series. In particular, the OECD has published some reasonably complete educational statistics for most of its member countries. Although these data refer only to the last few years, and are not therefore an alternative to the other sources for the statistical analysis of the impact of education on growth, a comparison of the three sets of figures may perhaps give us some clues as to the possible shortcomings of the B\&L and NSD data sets.

Table 2 summarizes the most relevant data. Notice that although both the year and the age groups differ somewhat across the three sources (see the notes to the table), the figures should be roughly comparable. The breakdown by educational level is also comparable with the one used by Barro and Lee (1996), although the OECD provides more detail. In particular, they disaggregate secondary attainment into two levels and, for most countries, report figures on advanced vocational programmes (ISCED5 level) separately. 
Table 2: B\&L (1996) and NSD vs. OECD (EAG), Educational attainment of the adult population

\begin{tabular}{|c|c|c|c|c|c|c|c|c|c|c|c|c|c|c|c|}
\hline \multirow[b]{2}{*}{ source $=$} & \multirow{2}{*}{$\begin{array}{c}\text { No } \\
\text { school } \\
\text { BEL }\end{array}$} & \multicolumn{2}{|c|}{ PRIMARY } & \multirow{2}{*}{$\begin{array}{l}\text { SEC. I } \\
\text { OECD }\end{array}$} & \multirow{2}{*}{$\begin{array}{l}\text { SEC II } \\
\text { OECD }\end{array}$} & \multicolumn{2}{|c|}{$\begin{array}{l}\text { SECONDARY } \\
\text { TOTAL }\end{array}$} & \multirow{2}{*}{$\begin{array}{c}\text { ISCED } 5 \\
\text { OECD }\end{array}$} & \multicolumn{3}{|c|}{ UNIVERSITY } & \multirow{2}{*}{$\begin{array}{c}\text { app/enr } \\
\text { sec II } \\
\text { OECD }\end{array}$} & \multicolumn{3}{|c|}{$\begin{array}{c}\text { YEARS OF SCHOOLING } \\
(\text { avge }=100)\end{array}$} \\
\hline & & $B \mathcal{E} L$ & OECD & & & $B \mathcal{E} L$ & OECD & & $B \mathcal{E} L$ & $O E C D$ & OECD & & NSD & $B \mathcal{E} L$ & OECD \\
\hline Australia & 2.4 & 26.6 & 11.6 & 30.0 & 25.0 & 48.4 & 55.0 & 21.0 & 22.6 & 10.0 & 31.0 & 0.28 & 84.2 & 116.7 & 105.5 \\
\hline Austria & 2.3 & 42.5 & & 35.0 & 60.0 & 46.9 & 95.0 & 0.0 & 8.4 & 5.0 & 5.0 & 0.37 & 97.0 & 85.8 & 107.6 \\
\hline Belgium & 1.4 & 48.4 & 31.6 & 30.0 & 20.0 & 37.0 & 50.0 & 10.0 & 13.1 & 7.0 & 17.0 & & 92.8 & 100.9 & 91.8 \\
\hline Canada & 1.0 & 15.7 & 13.0 & 14.0 & 41.0 & 62.0 & 55.0 & 15.0 & 21.4 & 15.0 & 30.0 & & 111.0 & 119.2 & 110.6 \\
\hline Denmark & 0.0 & 38.7 & & 43.0 & 40.0 & 41.6 & 83.0 & 7.0 & 19.6 & 10.0 & 17.0 & 0.19 & 101.3 & 129.3 & 108.6 \\
\hline Finland & 0.0 & 49.4 & & 42.0 & 40.0 & 35.3 & 82.0 & 8.0 & 15.4 & 10.0 & 18.0 & 0.03 & 108.7 & 112.9 & 109.0 \\
\hline France & 1.2 & 57.6 & 22.8 & 26.0 & 33.0 & 28.4 & 59.0 & 7.0 & 12.8 & 7.0 & 14.0 & 0.10 & 94.3 & 79.3 & 94.3 \\
\hline W. Germany & 2.6 & 64.9 & & 22.0 & 61.0 & 22.0 & 83.0 & 7.0 & 10.4 & 10.0 & 17.0 & 0.59 & 94.0 & 101.8 & 114.6 \\
\hline Ireland & 4.2 & 40.4 & 32.8 & 25.0 & 23.0 & 43.6 & 48.0 & 7.0 & 11.7 & 7.0 & 14.0 & & 139.4 & 94.0 & 87.6 \\
\hline Italy & 15.3 & 44.1 & 28.7 & 30.0 & 20.0 & 31.7 & 50.0 & 0.0 & 8.9 & 6.0 & 6.0 & & 88.1 & 71.0 & 75.1 \\
\hline Japan & 0.0 & 34.3 & & 30.0 & 48.0 & 44.5 & 78.0 & 8.0 & 21.2 & 13.0 & 21.0 & & 121.8 & 106.1 & 112.5 \\
\hline Netherlands & 4.0 & 34.4 & 15.0 & 26.0 & 36.0 & 45.5 & 62.0 & 13.0 & 16.1 & 6.0 & 19.0 & 0.22 & 93.4 & 98.7 & 99.8 \\
\hline New Zealand & 0.0 & 36.8 & 33.0 & 10.0 & 25.0 & 24.1 & 35.0 & 22.0 & 39.1 & 9.0 & 31.0 & & 98.0 & 128.9 & 100.4 \\
\hline Norway & 2.6 & 49.8 & & 35.0 & 42.0 & 32.2 & 77.0 & 10.0 & 15.4 & 11.0 & 21.0 & & 105.1 & 91.4 & 109.5 \\
\hline Portugal & 24.4 & 58.7 & 64.6 & 4.0 & 2.0 & 11.4 & 6.0 & 2.0 & 5.5 & 4.0 & 6.0 & & 63.5 & 41.6 & 52.1 \\
\hline Spain & 4.5 & 64.4 & 62.5 & 13.0 & 10.0 & 21.3 & 23.0 & 0.0 & 9.8 & 9.0 & 9.0 & & 79.3 & 72.1 & 73.0 \\
\hline Sweden & 2.4 & 35.4 & & 33.0 & 44.0 & 43.9 & 77.0 & 11.0 & 18.4 & 12.0 & 23.0 & & 109.2 & 109.3 & 113.0 \\
\hline Switzerland & 6.3 & 28.5 & & 20.0 & 50.0 & 52.3 & 70.0 & 15.0 & 12.9 & 9.0 & 24.0 & 0.68 & 77.1 & 102.3 & 109.4 \\
\hline UK & 3.6 & 43.9 & & 35.0 & 48.0 & 38.5 & 83.0 & 6.0 & 13.9 & 9.0 & 15.0 & & 113.2 & 100.3 & 108.0 \\
\hline US & 1.2 & 9.1 & 6.8 & 10.0 & 46.0 & 44.4 & 56.0 & 12.0 & 45.2 & 23.0 & 35.0 & & 128.7 & 138.4 & 117.6 \\
\hline Average & 4.0 & 41.2 & & & & 37.8 & 61.4 & & 17.1 & 9.6 & 18.7 & & 9.0 & 8.7 & 10.4 \\
\hline
\end{tabular}

- Notes: Attainment is measured by the fraction of the adult population which has started (but not necessarily completed) each educational level.

- Dates and population groups vary as follows: Barro and Lee: 1990 and population aged 25 and over; NSD: 1987 and population aged 15-64; OECD: 1989 and population aged 25-64.

- The OECD includes apprenticeships programmes as part of secondary (2nd cycle) studies. Level 5 of the international standard classification for education, ISCED 5 , includes relatively short post-secondary programmes which do not lead to a university degree. These are generally advanced vocational prgrammes. University programmes are included in levels 6 and 7 of ISCED. In some countries which do not report data at the ISCED5 level, these programmes are counted either at the university level or as part of secondarylevel vocational programmes. 
The differences across the various sources are quite significant. On the whole, the picture which emerges from the OECD figures seems to be the more plausible one -- at least in the sense of conforming better to common perceptions as to the relative educational levels of different countries. As for the other two sources, both contain rather implausible features and it is difficult to choose between them. Starting with the relative positions of different countries in terms of average total schooling (reported in the last three columns of the table), ${ }^{7}$ we find a number of large discrepancies. Barro and Lee's estimates for Austria, France, Norway and Portugal are much lower than those given in the other sources, while their figure for New Zealand is much higher. On the other hand, NSD give very low figures for Australia, Switzerland and Germany, an extremely high estimate for Ireland (which is probably an error) and an implausibly high number for Greece. ${ }^{8}$ The overall correlation with the OECD estimates is higher for Barro and Lee (0.807) than for NSD (0.531) but this is due to a large extent to the Irish outlier.

In the case of Barro and Lee it is possible to make a detailed comparison by levels of schooling with the OECD data that may give us some clues as to the likely sources of some of their more implausible results. We observe that OECD estimates of secondary attainment are generally higher than Barro and Lee's. ${ }^{9}$ The difference exceeds forty points in Austria, Germany, Finland, Denmark, Norway and the UK, and are quite important for a number of other European countries and for Japan. We think the main reason for the difference has to do with the treatment of apprenticeships and other vocational training programmes, which are included in the OECD data but probably not counted by Barro and Lee. Differences in tertiary attainment are significant as well and also seem to be related to the treatment of (higher-level) vocational programmes. In particular, Barro and Lee seem to report ISCED5 studies as part of university schooling but, even accounting for this, significant differences remain in some cases.

Turning from the cross-section to the time-series dimension of the data, another disturbing feature of the human capital series is the existence of sharp breaks and implausible changes in attainment levels over very short periods. This problem affects the B\&L data set much more than the NSD series, which are much smoother essentially by construction. Figures 3 and 4 below show the evolution of Barro and Lee's (1996) secondary and university attainment rates for the population over 25 in a number of countries that display

\footnotetext{
7 To estimate the average years of schooling on the basis of the OECD data we have used the following durations: Primary, 6 years; Secondary I, 9 years; Secondary II, 12 years; ISCED 5, 14 years; ISCED 6 and 7, 16 years. Since the computation assumes that everybody who started a certain level has completed it, the resulting figures should overstate the true years of schooling but, hopefully, not so much the relative positions of the different countries, which is what we are trying to get at. Our comparisons are based on the standardized attainment figures shown in Table 2, which are constructed by normalizing each estimate of the average years of schooling by the unweighted average of the available contemporaneous observations in each data set.

8 According to NSD the average years of primary schooling in Ireland ranged between 15 in 1960 and just over 11 in 1985. Both figures are much higher than those for any other country and of the order of twice the duration of this level of schooling. Greece does not appear in Table 2 because the OECD reports no data for this country. Greece is ranked by NSD ahead of Switzerland, Australia, Belgium, the Netherlands and France.

${ }^{9}$ Original OECD figures add up to $100 \%$ when we sum primary, secondary and tertirary attainment rates. Since this implies that everybody has received some schooling, we have corrected the figures using Barro and Lee's estimate of the fraction of the population with no schooling. The table reports the original primary attainment figure minus the no schooling fraction from Barro and Lee (1996).
} 
extremely suspicious patterns. In all cases, the sharp break in the series signals in all probability a change of criterion in the elaboration of educational statistics. Similar inconsistencies are present in other countries as well.

Figure 3: Evolution of university attainment levels, Australia, New Zealand and Canada

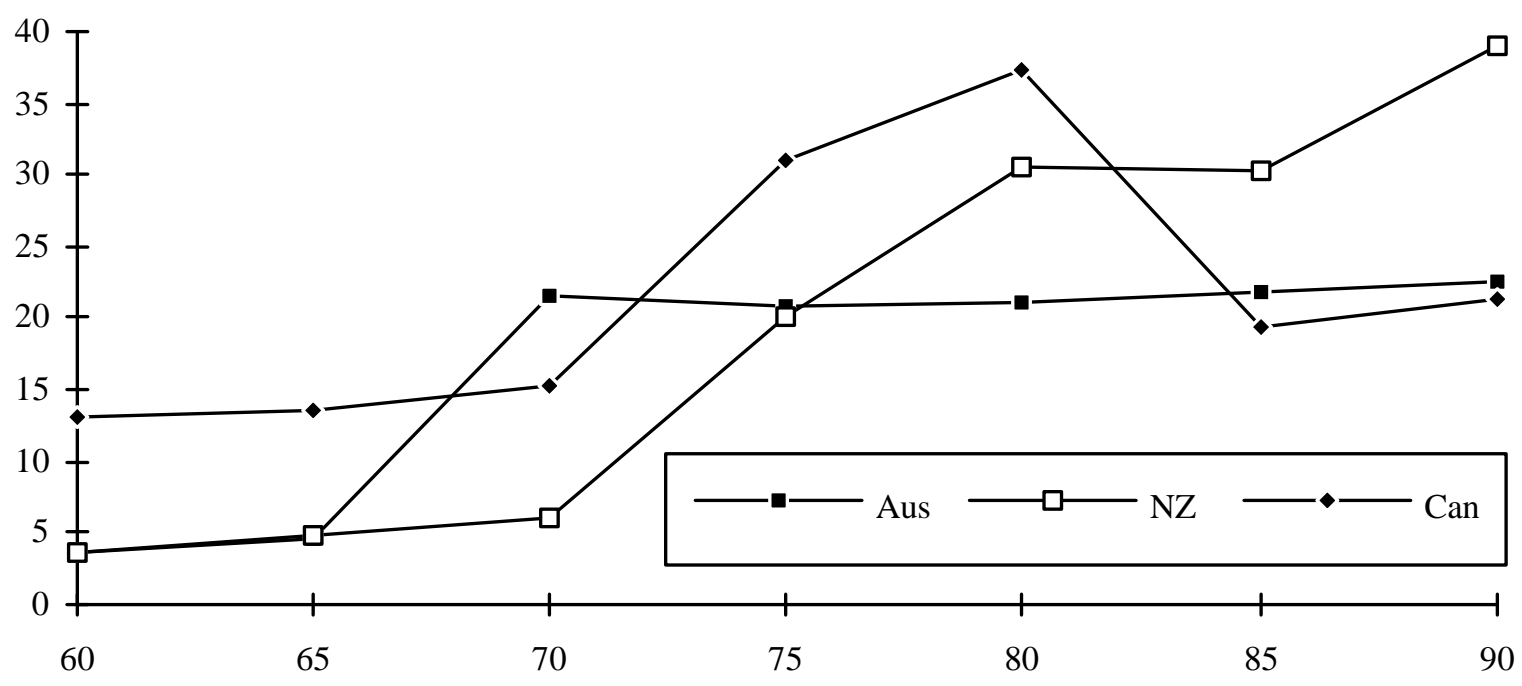

- Source: Barro and Lee (1996). Population aged 25 and over.

Figure 4: Evolution of secondary attainment levels, Netherlands, New Zealand and Canada

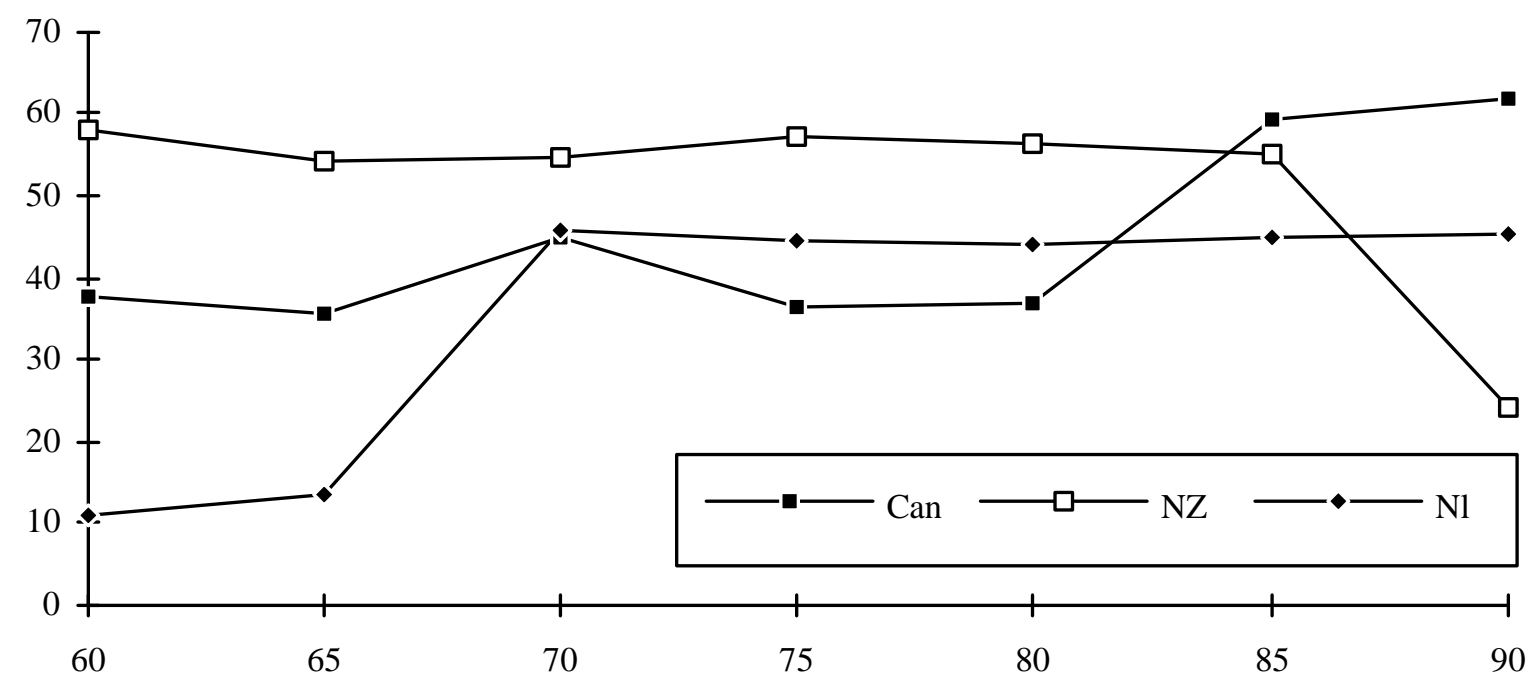

- Source: Barro and Lee (1996). Population aged 25 and over.

The preceding discussion is far from providing an exhaustive list of the suspect features of different educational data sets. On the other hand, it is probably enough to conclude that --despite the fact that recent contributions represent a significant advance in this area-- the available data on human capital stocks are still of dubious quality. Remaining problems are probably due in part to the fact that the primary statistics used in these studies are not consistent, across countries or over time, in their treatment 
of vocational and technical training and other courses of study, ${ }^{10}$ and reflect at times the number of people who have started a certain level of education and, at others, those who have completed it. Additional problems may be traced to the procedure used in the construction of the data and even to computational mistakes. Thus, NSDs neglect of census data probably accounts for their unreasonable results in terms of the overall level and trend of primary and secondary schooling while Barro and Lee's approximation to a perpetual inventory method is probably far from satisfactory. Hence, a fair amount of detailed work remains to be done before we can say with some confidence that we have a reliable and detailed picture of worldwide educational achievement levels or their evolution over time.

To some extent, doubts about the accuracy of existing data sets must raise concerns about the validity of the findings of empirical studies based on them. Concerns about data quality, however, also admit an optimistic interpretation of these results. Since there are no reasons to suspect that the available data contain systematic biases that may lead us to overestimate the contribution of human capital to productivity, the fact that the empirical results are quite favourable in some cases in spite of the dubious quality of the data suggest that improvements in this regard should lead to clearer and more conclusive results about education's contribution to economic growth. We will provide some evidence in this direction below.

\section{Educational attainment in the OECD: A revised set of estimates for 1960-90}

On the basis of our discussion so far we would tentatively conclude that the Barro and Lee (1996) series are probably the best available source on human capital stocks. As we have seen, however, even these data contain a large amount of noise that can be traced largely to inconsistencies of the underlying primary statistics. Trying to reduce this noise, we have constructed a revised version of the Barro and Lee data set for a sample of 21 OECD countries for the period 1960-90. ${ }^{11}$

We aim to provide estimates of the fraction of the population aged 25 and over that has started (but not necessarily completed) each of the levels of education shown in the upper block of Table 3 (illiterates (L0), primary schooling (L1), lower and upper secondary schooling (L2.1 and L2.2) and two levels of higher education (L3.1 and L3.2)). For some countries, however, the available data may refer to a different age group or to the fraction of the population that has completed each schooling level, and it is not always possible to detect when this is the case.

We have tried to include upper-level vocational courses (ISCED 5 studies according to the international standard classification of educational attainment levels, L3.1(5) in our notation) in the first level of higher attainment. For some countries the data is detailed enough to allow us to identify this category separately

\footnotetext{
10 Steedman (1996) documents the existence of important inconsistencies in the way educational data are collected in different countries and argues that this problem can significantly distort the measurement of educational levels. She notes, for example, that countries differ in the extent to which they report qualifications not issued directly (or at least recognized) by the state and that practices differ as to the classification of courses which may be considered borderline between different ISCED levels. The stringency of the requirements for the granting of various completion degrees also seems to vary significantly across countries.

11 The revised series and a detailed description of the estimation procedure are contained in the Appendix. Iceland, Luxembourg, Turkey and recent OECD members are left out because of the scarcity of information
} 
and to recover a narrower, strictly university attainment category (UNIV). ${ }^{12}$ We report L0 only for the four countries where illiteracy rates are significant during the sample period (Portugal, Greece, Spain and Italy). For the rest of the sample, the lowest reported category is L1, and it includes all those who have not reached secondary school.

Table 3: Attainment levels and codes

\begin{tabular}{ll}
\hline code & \\
L0 & Illiterates \\
L1 & Primary schooling \\
L2.1 & Lower secondary schooling \\
L2.2 & Upper secondary schooling \\
L2 & Total secondary schooling = L2.1 + L2.2 \\
L3.1 & Higher education, first cycle or shorter courses \\
L3.2 & Higher education, second cycle or full-length courses \\
L3 & Total higher education = L3.1 + L3.2 \\
L3.1(5) & Upper-level vocational courses (Isced 5 level) \\
L3.1(6) & Shorter university courses or first cycle (included in Isced 6) \\
UNIV & University attainment = L3.1(5) + L3.2
\end{tabular}

Our approach has been to collect all the information we could find on educational attainment in each country, both from international publications and from national sources (census and survey results and national statistical yearbooks), and use it to try to reconstruct a plausible pattern, reinterpreting some of the data if necessary. ${ }^{13}$ For those countries for which reasonably complete series are available, we have relied primarily on national sources. For many of the rest, we start from the most plausible set of attainment estimates available around 1990 (taken generally from OECD sources) and proceed backwards using all the assembled information and trying to avoid unreasonable jumps in the series by choosing the most plausible figure when several are available for the same year, and by reinterpreting some of the data (as referring to broader or narrower schooling categories than the reported one) when it seems sensible to do so. Missing observations are then filled in a variety of ways. Where possible, we interpolate between available observations. Otherwise, we use information on educational attainment by age group in order to make backward projections, or rely on miscellaneous information from a variety of sources in order to construct plausible estimates of attainment levels. We have avoided the use of flow estimates based on enrollment data because they seem to produce implausible time profiles.

Clearly, the construction of our series involves a fair amount of guesswork. Our "methodology" looks decidedly less scientific than the apparently more systematic estimation procedures used by other authors starting from supposedly homogeneous data. As discussed in the previous section, however, even a cursory examination of the data shows that there is no such homogeneity. Hence, we have found it preferable to rely on judgment to try to piece together the available information in a coherent manner than

\footnotetext{
12 We do not report this finer data except in the case of Canada, where our figures for L3 incorporate a tentative estimate of Isced 5 courses that the user may want to change.

13 We would greatly welcome any additional information that may help us improve the quality of our estimates, particularly in the case of the more problematic countries cited in Section 3.2.
} 
to take for granted the accuracy of the primary data. The results do, as we will see, look more plausible than the existing series, at least in terms of their time profile.

\section{1.- An example: the case of higher education in Canada}

To give the reader a flavour for the way our series have been constructed, we will discuss in detail the case of higher education in Canada. This is a country for which there is a considerable amount of information that displays, if taken literally, a rather implausible pattern. It is also one case in which we can partially check the reasonableness of our corrections for part of the sample period against an apparently homogeneous national source for an age group slightly different from our target.

Figure 5: University attainment in Canada, Barro and Lee (1996) vs. this paper

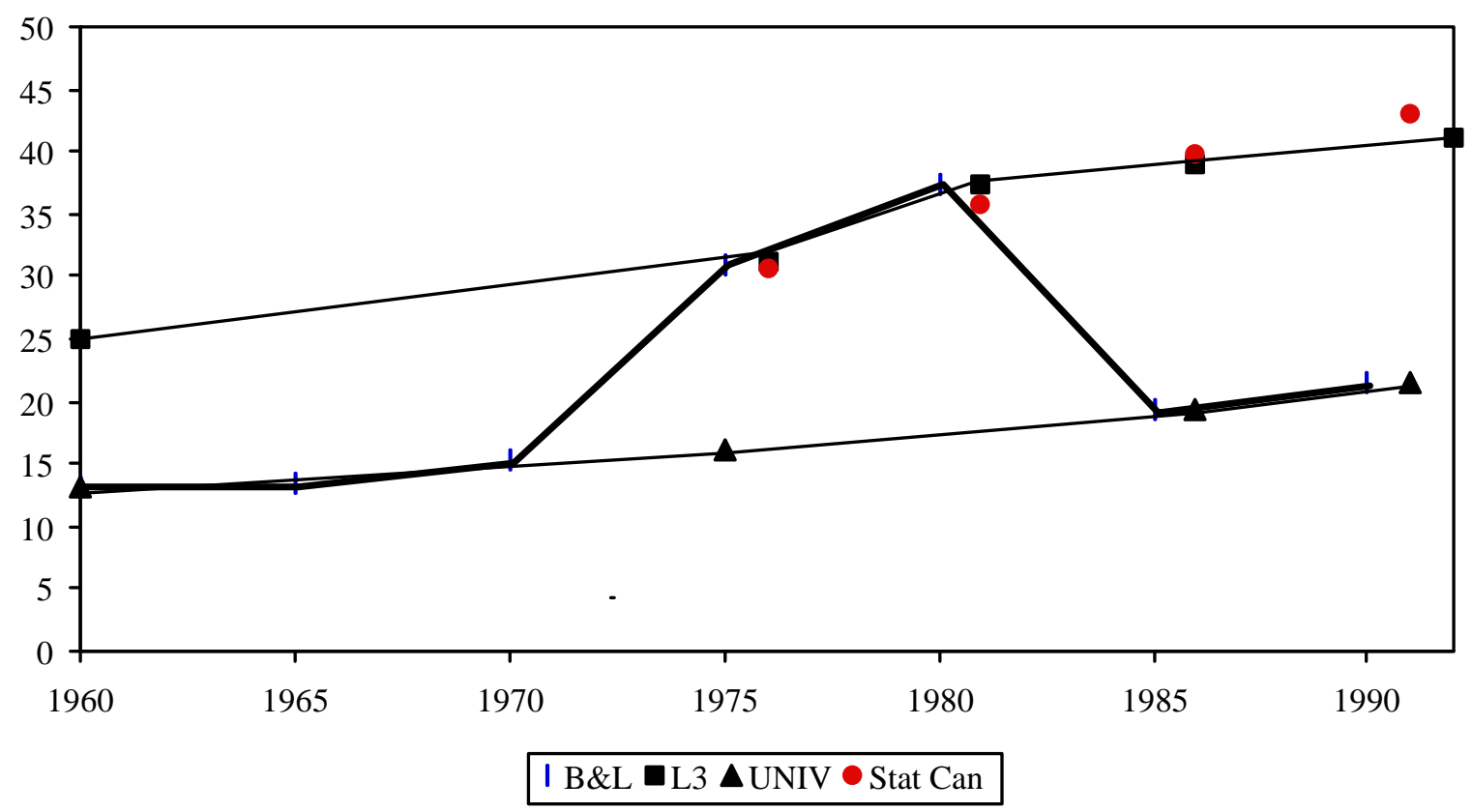

The essence of our approach is captured by Figure 5. The thicker line in the Figure describes Barro and Lee's (1996) higher educational attainment series for the population aged 25 and over, which is based on Unesco and UN data. The implausible hump-shaped pattern of the series strongly suggests that the 1975 and 1980 observations refer to a broader concept of higher attainment than the rest of the data. Our guess is that, unlike the rest, these two atypical observations include upper-level vocational training courses. If we homogenize the series by consistently including or excluding an estimate of this category, we get the more plausible profile described by the two thinner lines shown in the figure. The higher of these lines refers to higher education in a broad sense, and the lower one to strictly university attainment. The dots lying on these two lines represent actual data taken from various sources and attributed to the exact year to which they correspond (and not to the closest multiple of five). For the rest of the years, we complete the series through linear interpolation. 
Table 4: Available data and higher attainment estimates, Canada

\begin{tabular}{|c|c|c|c|c|c|c|c|c|c|c|c|c|c|}
\hline source & rep. level & 1960 & 1965 & 1970 & 1975 & 1976 & 1980 & 1981 & 1985 & 1986 & 1990 & 1991 & 1992 \\
\hline OECD & L3.1 & & & & & & & & & & 15 & 23 & 26,1 \\
\hline OECD & L3.2 & & & & & & & & & & 15 & 17 & 15 \\
\hline Unesco & L3 & 13,1 & & 17,8 & & 31,15 & & 37,4 & & 19,3 & & 21,4 & \\
\hline DY & L3 & 6,5 & & & 16 & & 17,3 & & 19,3 & 19,3 & & 21,4 & \\
\hline census & L3.1 & & & & & & & & & 10,4 & & 11,7 & \\
\hline census & L3.2 & & & & & & & & & 11,5 & & 13,4 & \\
\hline Stat Can & L3.1 & & & & & 24,14 & & 27,65 & & 30,19 & & 31,74 & \\
\hline \multirow[t]{8}{*}{ Stat Can } & L3.2 & & & & & 6,43 & & 8,01 & & 9,57 & & 11,36 & \\
\hline & estimates & 1960 & 1965 & 1970 & 1975 & 1976 & 1980 & 1981 & 1985 & 1986 & 1990 & 1991 & 1992 \\
\hline & L3 & 25,03 & 26,88 & 28,73 & 30,75 & 31,15 & 36,15 & 37,40 & 38,75 & 39,08 & 40,43 & 40,76 & 41,10 \\
\hline & L3.1(5) & 11,93 & 12,82 & 13,70 & 14,66 & 14,85 & 18,65 & 19,60 & 19,75 & 19,78 & 19,45 & 19,36 & \\
\hline & L3.1(6) & 6,60 & 6,87 & 7,14 & 7,49 & 7,56 & 8,20 & 8,36 & 9,01 & 9,17 & 9,81 & 9,98 & \\
\hline & L3.1.(5+6) & & & & & & & & & & & & 26,10 \\
\hline & $\mathrm{L} 3.2$ & 6,50 & 7,20 & 7,90 & 8,60 & 8,74 & 9,30 & 9,44 & 9,99 & 10,13 & 11,17 & 11,42 & 15,00 \\
\hline & $\begin{array}{l}\mathrm{UNIV}= \\
\mathrm{L} 3.1(6)+\mathrm{L} 3.2\end{array}$ & 13,10 & 14,07 & 15,03 & 16,00 & 16,30 & 17,50 & 17,80 & 19,00 & 19,30 & 20,98 & 21,40 & \\
\hline
\end{tabular}

The details of the reconstruction are unavoidably messy. Table 4 contains the available primary data and our reconstructed series, with bold characters used to highlight the information we have selected to construct our estimates. The upper half of the Table summarizes the university attainment data we have found for Canada. The sources are various OECD publications (generally for the age group 25-64), UNESCO's Statistical Yearbook and the UN's Demographic Yearbook (for the population over 25), national census reports and the website of Statistics Canada (for the population over 15). Unesco and the Demographic Yearbook (DYB) report university attainment as a whole (L3), while national sources distinguish between shorter and longer college-level courses (L3.1 and L3.2). The longer available series, provided by Unesco and the UN, show considerable discrepancies in some years and (especially in the case of Unesco) display a rather implausible pattern that strongly suggests changes in classification criteria.

Using these data, we have constructed the estimates shown in the lower part of the table. Since we suspect changes in the classification of upper level vocational courses are behind the jumps in the data, we distinguish between short university courses (L3.1(6)) and advanced vocational training (L3.1(5)) and consider various combinations of the three possible categories that comprise higher education: L3 includes all three of them, while UNIV = L3.1(6) + L3.2 includes only strictly university courses, excluding vocational training.

Using this finer breakdown, we construct our estimates essentially by trying to guess to which of the possible attainment categories the available data refer. We interpret Unesco's 1960, 1986 and 1991 observations, and the DYB observation for 1975 as referring to university attainment in the narrow sense (i.e. excluding ISCED 5 courses). We complete the series for this attainment level by interpolating between available observations. Next, we would like to break down university attainment into its upper (L3.2) and lower (L3.1(6)) cycles. For this, we interpret the 1960 DYB figure as referring to L3.2 and estimate L3.2 in 1986 and 1991 by applying the ratio L3.2/UNIV computed using the census data (which refers to the 
population over 15) to our previous estimate of UNIV. To complete the L3.2 and L3.1(6) series we then interpolate between these three observations.

Finally, we need to estimate the level of attainment in advanced vocational programmes and add it to UNIV to obtain total higher attainment (L3). We observe that Unesco gives extremely high figures for university attainment in 1976 and 1981 that we interpret as estimates of L3 (i.e. assume that they include L3.1(5)). For 1992, OECD (1995) gives a L3 figure that seems compatible with the previous ones. We interpolate L3 between 1981 and 1992 and estimate L3.1(5) as L3 - UNIV, using our previous estimates of these two levels for 1976 onward. To take L3 and L3.1(5) back from 1976, we assume that the ratio UNIV/L3 remains constant at its 1976 value. The estimates constructed in this way seem to fit fairly well with the figures reported in the Statistics Canada website (for 1976 onward and for the population 15+) if we assume that the L3.1 reported in this source includes ISCED 5 courses). These data correspond to the unconnected round dots lying close to the upper line in Figure 5.

\section{2.- Some comments on the estimation procedure and data quality}

A similar approach has been followed for the remainder of the sample, as discussed in the detailed country notes contained in the Appendix. Data availability varies widely across countries. Table 5 shows the fraction of the reported data points that are taken from direct observations and the earliest and latest such observations available for secondary and higher attainment levels. The number of possible observations is typically 21 for each level of schooling (two sublevels and a total times seven quinquennial observations), but it may be larger if the data allow a finer breakdown by sublevel (as in the case of Canada) or if there is no data close to 1990 and we use observations for around 1995 to complete the series (in which case there is one more time period to consider). In the case of Italy, there seem to be no short higher education courses, so the number of possible observations at the university level drops to seven. We count as direct observations backward projections constructed using detailed census data on educational attainment by age group and the age structure of the population.

As can be seen in the table, for around two thirds of the countries we have enough primary information to reconstruct reasonable attainment series covering the whole sample period. The more problematic cases are higlighted using bold characters. In the case of Italy, the main problem is that most of the available information refers to the population over six years of age. We are currently exploring ways to correct the likely bias using data on enrollments and the age structure of the population. For Germany and Denmark, the earliest available direct observation refers to 1970 or later. We have projected attainment rates backward to 1960 using the attainment growth rates reported in OECD (1974), but we are unsure of the reliability of this extrapolation. Finally, the number of available observations is rather small in the cases of Australia, the UK and Switzerland. 
Table 5: Some summary measures of data quality

\begin{tabular}{|c|c|c|c|c|c|c|}
\hline & \multicolumn{3}{|c|}{ secondary attainment } & \multicolumn{3}{|c|}{ university attainment } \\
\hline USA & $\begin{array}{c}\text { direct/tot. } \\
\text { observ. } \\
21 / 21\end{array}$ & $\begin{array}{c}\text { first } \\
\text { observ. } \\
1960\end{array}$ & $\begin{array}{c}\text { last } \\
\text { observ. } \\
1990\end{array}$ & $\begin{array}{c}\text { direct/tot. } \\
\text { obs. } \\
21 / 21\end{array}$ & $\begin{array}{l}\text { first } \\
\text { observ. } \\
1960\end{array}$ & \begin{tabular}{r}
\multicolumn{1}{c}{ last } \\
observ. \\
1990
\end{tabular} \\
\hline Netherlands & $9 / 21$ & 1960 & 1990 & $9 / 21$ & 1960 & 1990 \\
\hline Italy & $12 / 21$ & 1961 & 1991 & $4 / 7$ & 1960 & 1989 \\
\hline Belgium & $12 / 21$ & 1961 & 1989 & $12 / 21$ & 1960 & 1989 \\
\hline Spain & $12 / 21$ & 1960 & 1991 & $12 / 21$ & 1960 & 1991 \\
\hline Greece & $12 / 21$ & 1961 & 1991 & $12 / 21$ & 1961 & 1991 \\
\hline Portugal & $11 / 21$ & 1960 & 1991 & $8 / 21$ & 1960 & 1991 \\
\hline France & $12 / 21$ & 1960 & 1989 & $12 / 21$ & 1960 & 1990 \\
\hline Ireland & $12 / 21$ & 1961 & 1991 & $12 / 21$ & 1961 & 1991 \\
\hline Sweden & $9 / 24$ & 1960 & 1994 & $9 / 24$ & 1960 & 1994 \\
\hline Norway & $6 / 21$ & 1960 & 1990 & $8 / 21$ & 1960 & 1990 \\
\hline Denmark & $3 / 21$ & 1973 & 1991 & $9 / 21$ & 1973 & 1991 \\
\hline Finland & $7 / 21$ & 1960 & 1990 & $7 / 21$ & 1960 & 1990 \\
\hline Japan & $6 / 21$ & 1960 & 1990 & $7 / 21$ & 1960 & 1990 \\
\hline N. Zealand & $7 / 21$ & 1965 & 1991 & $8 / 21$ & 1965 & 1992 \\
\hline UK & $3 / 21$ & 1960 & 1991 & $5 / 21$ & 1960 & 1991 \\
\hline Switzerland & $3 / 21$ & 1960 & 1991 & $5 / 21$ & 1960 & 1991 \\
\hline Austria & $4 / 21$ & 1961 & 1991 & $7 / 24$ & 1961 & 1995 \\
\hline Australia & $5 / 21$ & 1965 & 1990 & $5 / 21$ & 1965 & 1990 \\
\hline Germany & $6 / 21$ & 1970 & 1991 & $7 / 21$ & 1970 & 1991 \\
\hline Canada & $5 / 21$ & 1960 & 1991 & $12 / 35$ & 1960 & 1992 \\
\hline
\end{tabular}

A number of countries do not separate primary education from lower secondary schooling and report a single attainment level that comprises all mandatory courses. To preserve the homogeneity of our attainment categories, we have estimated the breakdown of compulsory schooling into L1 and L2.1. For some countries we have assumed that the ratio L1/L2.1 is the same as in some close neighbour. In particular, we have used the value of this ratio in the US to estimate the breakdown in Canada, and applied the Swedish ratio to Norway and Denmark. For those countries for which there is no obvious candidate for this role (Austria, the UK and Switzerland), we have used an ad-hoc regression estimate of the relevant ratio. Using the remainder of the sample (except Japan, where the information on L1 and L2.1 is of dubious quality), we estimate the following equation with pooled data:

(1) $\mathrm{L} 2.1 /(\mathrm{L} 1+\mathrm{L} 2.1)=0.0802+0.0094(\mathrm{~L} 3+\mathrm{L} 2.2)+0.1998(\mathrm{~L} 3 / \mathrm{L} 2.2)-0.0029^{*}$ trend adj. $\mathrm{R}^{2}=0.6207$

$$
\begin{array}{llll}
(0.74) \quad(13.25) & (4.36)
\end{array}
$$

where the numbers in parentheses below each coefficient are $t$ ratios. That is, we hypothesize that those countries that are more "efficient" in getting students into the upper schooling cycles will also have greater accession rates to lower secondary schooling. Hence we specify the the weight of lower secondary schooling relative to primary attainment as a function of university and upper secondary attainment and the ratio of the two, and allow it to vary systematically over time. Since the fit of the equation is reasonably good, we use it to estimate the lower secondary/compulsory attainment ratio in the countries for which this information is not available. 
Table 6: Cumulative years of schooling by educational level

$\begin{array}{lccccc} & \text { L1 } & \text { L2.1 } & \text { L2.2 } & \text { L3.1 } & \text { L3.2 } \\ \text { Australia } & 7 & 11 & 13 & 15 & 16 \\ \text { Austria } & 6 & 9 & 13 & 15 & \mathbf{1 7} \\ \text { Belgium } & 6 & 8 & 12 & 15 & 16 \\ \text { Canada } & 6 & 9 & 12 & 15 & 16 \\ \text { Denmark } & 6 & 9 & 13 & 14 & \mathbf{1 7} \\ \text { Finland } & 6 & 9 & 12 & 14 & 17 \\ \text { France } & 5 & 9 & 12 & 14 & 16 \\ \text { Germany } & 4 & 10 & 13 & 15 & \mathbf{1 7} \\ \text { Greece } & 6 & 9 & 12 & 16 & 16 \\ \text { Ireland } & \mathbf{6} & \mathbf{9} & \mathbf{1 2} & \mathbf{1 4} & \mathbf{1 6} \\ \text { Italy } & 5 & 8 & 13 & 15 & \mathbf{1 8} \\ \text { Japan } & \mathbf{6} & \mathbf{9} & \mathbf{1 2} & \mathbf{1 4} & \mathbf{1 6} \\ \text { Netherlands } & 6 & 10 & 12 & 16 & 17 \\ \text { Norway } & 6 & 9 & 12 & 14 & 16 \\ \text { New Zealand } & 6 & 11 & 13 & 15 & 16 \\ \text { Portugal } & 6 & 8 & 12 & 14 & 16 \\ \text { Spain } & 5 & 8 & 12 & 14 & 17 \\ \text { Sweden } & 6 & 9 & 12 & 14 & 16 \\ \text { Switzerland } & 6 & 9 & 13 & 16 & \mathbf{1 7} \\ \text { UK } & \mathbf{6} & \mathbf{9} & \mathbf{1 2} & \mathbf{1 4} & \mathbf{1 6} \\ \text { USA } & 7 & 10 & 12 & 14 & 16 \\ \text { Mode } & 6 & 9 & 12 & 14 & 16\end{array}$

- Sources: Education at a Glance 1997 (OECD, 1998), except figures in bold type (WDI, World Bank, 1999) and in italics (national sources). These figures are combined with our attainment series to estimate the average number of years of total schooling reported in Table A.4 in the Appendix.

Using our attainment series, we finally construct an estimate of the average years of total schooling for each country and period. The assumed cumulative duration of the different school cycles in each country is shown in Table 6. In constructing these series we are implicitly assuming that everybody who starts a given school cycle does eventually complete it, which is clearly not the case. Hence, our figures will be biased upward and are not strictly comparable with Barro and Lee's average schooling series, which do incorporate estimates of completion rates. ${ }^{14,15}$

\section{3.- A comparison with the BEL data set}

Our results differ from Barro and Lee's original series in two important respects. In the time dimension, the profiles of our attainment series are considerably smoother and more plausible. In the cross section dimension, there are some significant changes in the relative positions of different countries that bring us, on average, closer to the pattern found in the OECD sources reviewed in Section 2.2. A detailed country by country comparison of the two sets of series can be found in Figures A1-A4 in the Appendix.

\footnotetext{
14 The average number of years of schooling in our series (taken across all countries and periods) is 9.29, as compared with 7.56 for Barro and Lee (1996).

15 The available data on completion rates present the same anomalies we have discussed above in connection with attainment and enrollment rates.
} 
Figure 6: Range of the growth rate of avge. years of schooling: B\&L vs. this paper

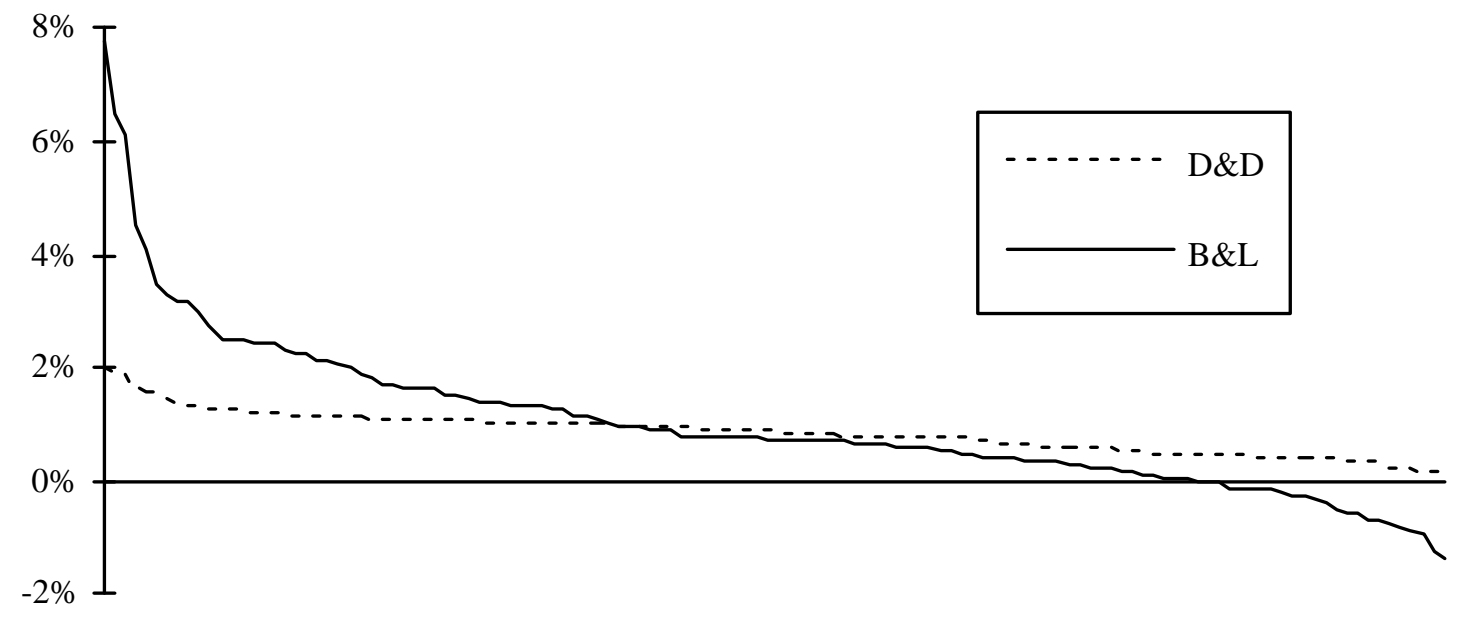

- Note: annual growth rates of average years of schooling for all countries and periods, arranged in decreasing order for each data set. D\&D refers to this paper.

The importance of eliminating sharp breaks in the series is clearly apparent from Figure 6, which has been constructed by arranging the annualized growth rates of the average years of schooling for all periods and years in decreasing order within each data set. The difference in the range of this variable across data sets is enormous: while our annual growth rates (D\&D) range between $0.15 \%$ and $2 \%$, Barro and Lee's go from $-1.35 \%$ to $7.80 \%$; moreover, $15.9 \%$ of their reported growth rates are negative, and $19 \%$ of them exceed $2 \%$. We suspect that the excessive volatility of the Barro and Lee series captured by these figures may be an important part of the reason why these data often generate implausible results in growth regressions, particularly when these are estimated using panel or first difference specifications. The empirical results we report in the following section are, as we will see, consistent with this hypothesis.

As we have already noted, our average years of schooling series is not directly comparable with Barro and Lee's. To examine changes in the cross-section pattern of the data, therefore, we first take averages across periods and then normalize both sets of resulting figures so that the unweighted sample average is set equal to 100 in each case. Figures 7 and 8 summarize the differences across data sets in this normalized measure of average attainment over the sample period. Figure 7 plots our average attainment levels (D\&D) against Barro and Lee's (B\&L). As may be expected, the correlation between the two sets of figures is quite high (0.826). There are, however, important deviations from the "diagonal" (i.e. differences in normalized attainments across data sets) that are reproduced in decreasing order in Figure 8. Relative to Barrro and Lee's estimates, France and Austria gain almost thirty points and surpass Greece in the attainment ranking, while New Zealand, Denmark and Finland experiment sizable downward revisions. Table 7 shows the correlation across data sets of average years of schooling around 1990. Our estimates (D\&D) are slightly closer to the OECD data than to B\&L and display a rather low correlation with NSD's figures. 
Figure 7: Normalized avge. years of schooling: B\&L vs this paper

D\&D normalized years of schooling

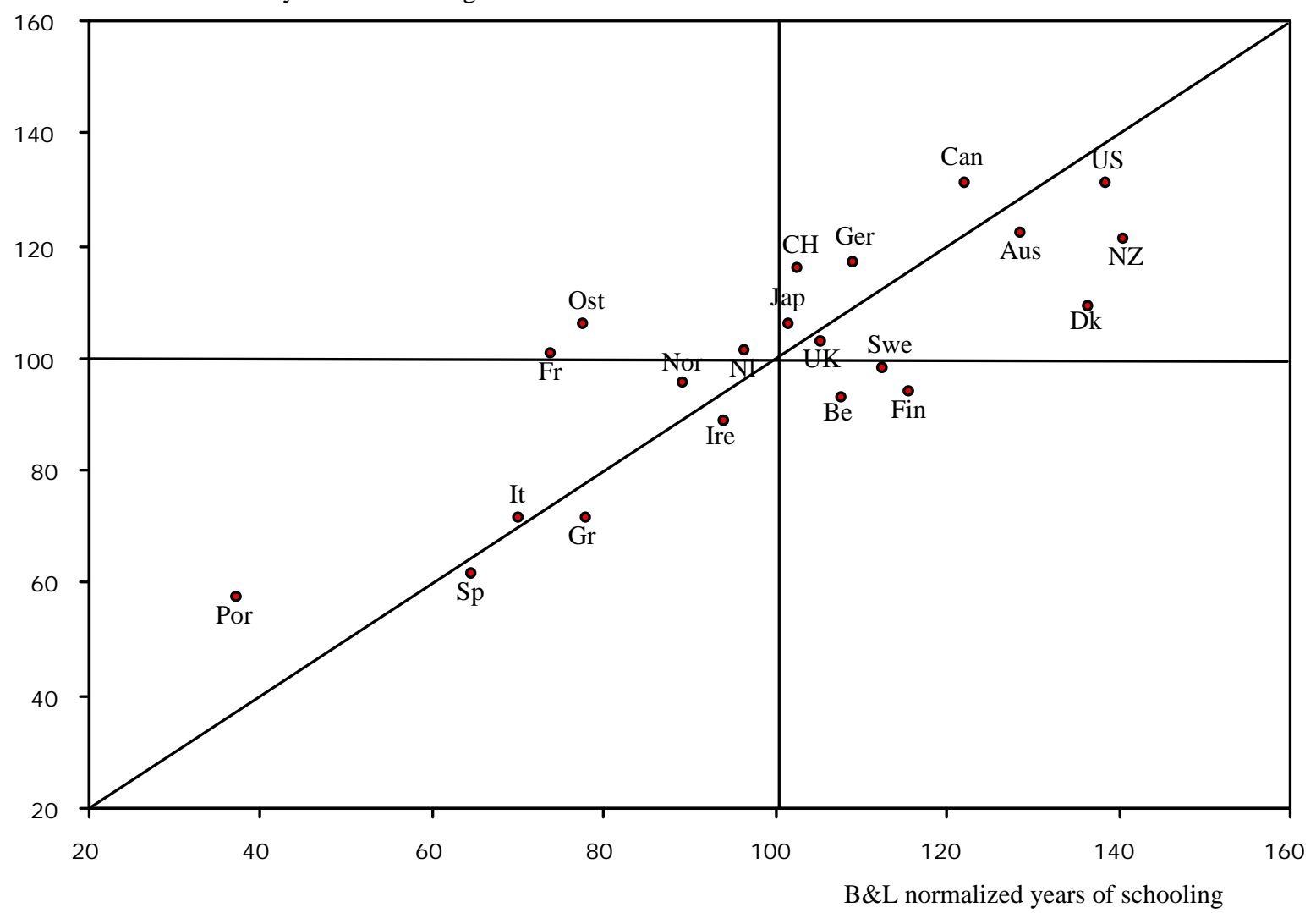

Note: Average number of years of schooling in each country (taken over all periods) are normalized by the unweighted sample average $(=100)$. A regression of our normalized years of schooling on Barro and Lee's gives the following result ( $\mathrm{t}$ values in parentheses):

avge. years $D \& D=35.43+0.646$ avge.years $B \& L \quad R^{2}=0.683$

$$
\text { (3.40) (6.40) }
$$

Figure 8: Change in normalized avge. years of schooling between this paper and B\&L

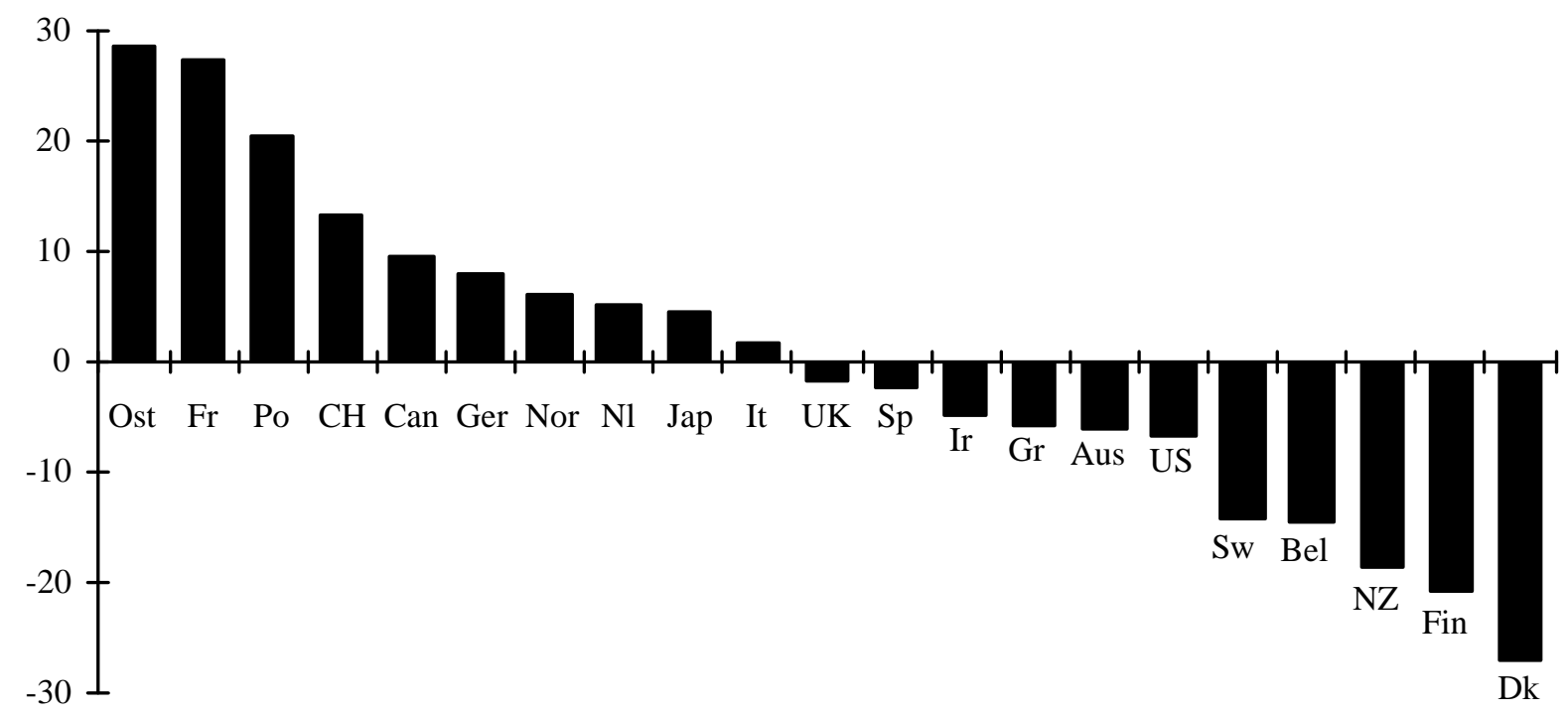


Table 7: Average years of schooling around 1990

Correlation across data sets

\begin{tabular}{llll}
\hline & $N S D$ & $B \mathcal{E} L$ & OECD \\
$B \mathcal{E} L$ & 0.542 & & \\
OECD & 0.531 & 0.807 & \\
$D \mathcal{E} D$ & 0.355 & 0.797 & 0.871
\end{tabular}

- Note: Same data as in Table 2, except for D\&D. Greece is not included for lack of OECD data.

\section{4.- Some empirical results}

In this section we examine the performance of our revised data set and Barro and Lee's and Nehru et al's original series in a number of growth accounting specifications. The results support our hypothesis that the lack of correlation between productivity growth and human capital accumulation reported in some recent studies may be due to data deficiencies. Using the Barro and Lee data, the partial correlation between productivity and educational attainment is only significant in specifications in levels, and the estimated coefficient of human capital in an aggregate production function is quite low in all cases. The results with NSD data are generally even worse: the human capital variable is not significant except in one specification in which its coefficient is negative. With our revised data, in contrast, the coefficient of human capital in an aggregate production function remains positive, significant and large in all the specifications we consider and, unlike in Mankiw, Romer and Weil (1992), survives a simple robustness test. We also explore the possibility that a trends problem may bias the coefficient of human capital in growth regressions and use our preferred specification to investigate the contribution of factor stocks and TFP to cross-country productivity differences.

\section{1.- How much difference does data quality make?}

The first specification we estimate is a constant-returns aggregate production function in levels, which we write in intensive form,

(2) $q_{i t}=\Gamma+\gamma_{i}+\eta_{t}+\alpha k_{i t}+\beta h_{i t}+\varepsilon_{i t}$

where $q_{i t}$ is the $\log$ of output per employed worker in country $i$ at time $t, k$ the $\log$ of the stock of physical capital per worker ${ }^{16}$ and $h$ the log of the average number of years of schooling of the adult population. We use dummy variables to capture fixed time and country effects $\left(\eta_{t}\right.$ and $\left.\gamma_{i}\right)$. In all the results reported below only those country dummies that turn out to be significant are left in the equation. The productivity data are taken from an updated version of Dabán, Doménech and Molinas (1997). We use pooled data at fiveyear intervals starting in 1960 and ending in 1990 for B\&L and D\&D, and in 1985 for NSD.

\footnotetext{
16 See the Appendix for a description of the construction of this variable.
} 
Table 8: A production function in levels

\begin{tabular}{|c|c|c|c|c|c|c|}
\hline human cap. variab. & $\begin{array}{c}{[1]} \\
N S D\end{array}$ & $\begin{array}{c}{[2]} \\
B \mathcal{E} L\end{array}$ & $\begin{array}{c}{[3]} \\
D \mathcal{E} D\end{array}$ & $\begin{array}{c}{[4]} \\
N S D\end{array}$ & $\begin{array}{c}{[5]} \\
B \mathcal{E} L\end{array}$ & $\begin{array}{c}{[6]} \\
D \mathcal{E} D\end{array}$ \\
\hline$\alpha$ & $\begin{array}{c}0.607 \\
(18.23)\end{array}$ & $\begin{array}{c}0.560 \\
(14.73)\end{array}$ & $\begin{array}{c}0.516 \\
(13.92)\end{array}$ & $\begin{array}{c}0.565 \\
(27.21)\end{array}$ & $\begin{array}{c}0.552 \\
(25.95)\end{array}$ & $\begin{array}{c}0.567 \\
(20.53)\end{array}$ \\
\hline$\beta$ & $\begin{array}{l}0.069 \\
(1.69)\end{array}$ & $\begin{array}{l}0.112 \\
(3.21)\end{array}$ & $\begin{array}{l}0.269 \\
(4.88)\end{array}$ & $\begin{array}{l}0.088 \\
(1.80)\end{array}$ & $\begin{array}{l}0.120 \\
(6.48)\end{array}$ & $\begin{array}{l}0.279 \\
(7.52)\end{array}$ \\
\hline $\operatorname{adj} \cdot R^{2}$ & 0.873 & 0.885 & 0.896 & 0.981 & 0.978 & 0.979 \\
\hline std. error reg. & 0.136 & 0.131 & 0.124 & 0.053 & 0.057 & 0.056 \\
\hline country dummies & no & no & no & yes & yes & yes \\
\hline period dummies & yes & yes & yes & yes & yes & yes \\
\hline
\end{tabular}

- Notes: White's heteroscedasticity-consistent $\mathrm{t}$ ratios in parentheses below each coefficient. Only significant country dummies are left in the reported equation. Human capital is measured by the average years of total schooling in each country and period. D\&D refers to this paper.

The pattern of results shown in Table 8 is consistent with our hypothesis about the importance of educational data quality for growth results. For all three data sets, the coefficient of human capital is positive in both specifications in levels (with and without fixed country effects), but the size and significance of the human capital coefficient increases appreciably as we go from the NSD data to the B\&L and D\&D data sets. The differences are even sharper when the estimation is repeated with the data in first differeces, as in equations [1]-[3] in Table 9, where only our revised data produce a significant (although implausibly large) human capital coefficient. The results obtained with the B\&L and NSD data sets are consistent with those reported by Kyriacou (1991), Benhabib and Spiegel (1994) and Pritchett (1995), who find insignificant (and sometimes negative) coefficients for human capital in an aggregate production function estimated in first differences.

Next, we estimate a catch-up specification along the lines of de la Fuente (1996). The estimated equation is of the form ${ }^{17}$

$$
\text { (3) } \Delta q_{i t}=\Gamma_{\mathrm{o}}+\gamma_{i}+\eta_{t}+\alpha \Delta k_{i t}+\beta \Delta h_{i t}+\lambda b_{i t}+\varepsilon_{i t}
$$

\section{We consider an aggregate production function of the form}

$$
Y=K^{\alpha}(A L H)^{\beta}(A L)^{1-\alpha-\beta}
$$

Dividing through by employment, rearranging and taking logarithms, log output per employed worker, $q$, can be written in the form

$$
q=\alpha k+\beta h+(1-\alpha) a
$$

where $\mathrm{k}=\ln (K / L), a=\ln A$ and $h=\ln H$. We can solve this expression for a as a function of productivity and factor stocks

$$
a=\frac{q-\alpha k+\beta h}{1-\alpha}
$$

and take growth rates to obtain

$$
\Delta q=\alpha \Delta k+\beta \Delta h+(1-\alpha) \Delta a .
$$

Finally, we hypothesize that the rate of technical progress is given by

$$
\Delta a_{i t}=\lambda\left(a_{u s, t}-a_{i t}\right)+\mu_{i}+v_{t}
$$

where we have added country and period subindices $\mu_{i}$ and $v_{t}$ are fixed country and period effects. Substituting this last expression into the production function in growth rates, using the above expression for log TFP and simplifying, we obtain equation (3) in the text. Notice that in the presence of technological catch-up $(\lambda>0)$, the technological distance between each country and the leader converges to a constant value. This implies that, asymptotically, all countries display the same rate of technical progress, so the fixed country effects $\mu_{i}$ translate only into differences in TFP levels, and not into permanent differences in growth rates of TFP. 
where $\Delta$ denotes annual growth rates (over the subperiod starting at time $t$ ) and

(4) $b_{i t}=\left(q_{U S, t}-\alpha k_{U S, t}-\beta h_{U S, t}\right)-\left(q_{i t}-\alpha k_{i t}-\beta h_{i t}\right)$

is the Hicks-neutral TFP gap between each country and the US at the beginning of each five-year subperiod. To estimate this specification we substitute (4) into (3) and use NLS with data on both factor stocks and their growth rates. Notice that in this specification the country dummies will pick up permanent cross-country differences in relative TFP levels that will presumably reflect differences in R\&D investment and other omitted variables. The parameter $\lambda$ measures the rate of (conditional) technological convergence.

Table 9: A production function in first differences with and without a catch-up effect

\begin{tabular}{|c|c|c|c|c|c|c|}
\hline human cap. variab. & $\begin{array}{c}{[1]} \\
N S D\end{array}$ & $\begin{array}{c}{[2]} \\
B \mathcal{E} L\end{array}$ & $\begin{array}{c}{[3]} \\
D \mathcal{E} D\end{array}$ & $\begin{array}{c}{[4]} \\
N S D\end{array}$ & $\begin{array}{c}{[5]} \\
B \mathcal{E} L\end{array}$ & $\begin{array}{c}{[6]} \\
D \mathcal{E} D\end{array}$ \\
\hline$\alpha$ & $\begin{array}{l}0.519 \\
(9.66)\end{array}$ & $\begin{array}{l}0.508 \\
(9.51)\end{array}$ & $\begin{array}{l}0.493 \\
(9.21)\end{array}$ & $\begin{array}{l}0.510 \\
(8.30)\end{array}$ & $\begin{array}{l}0.409 \\
(6.12)\end{array}$ & $\begin{array}{l}0.373 \\
(7.15)\end{array}$ \\
\hline$\beta$ & $\begin{array}{l}0.090 \\
(0.80)\end{array}$ & $\begin{array}{l}0.063 \\
(1.03)\end{array}$ & $\begin{array}{l}0.493 \\
(2.04)\end{array}$ & $\begin{array}{c}-0.148 \\
(2.62)\end{array}$ & $\begin{array}{c}-0.057 \\
(0.88)\end{array}$ & $\begin{array}{l}0.271 \\
(2.53)\end{array}$ \\
\hline$\lambda$ & & & & $\begin{array}{l}0.100 \\
(6.98)\end{array}$ & $\begin{array}{l}0.063 \\
(8.27)\end{array}$ & $\begin{array}{l}0.068 \\
(6.34)\end{array}$ \\
\hline $\operatorname{adj} . R^{2}$ & 0.719 & 0.710 & 0.718 & 0.840 & 0.811 & 0.809 \\
\hline std. error reg. & 0.0098 & 0.0097 & 0.0096 & 0.0074 & 0.0079 & 0.0079 \\
\hline country dummies & no & no & no & yes & yes & yes \\
\hline catch-up effect & no & no & no & yes & yes & yes \\
\hline period dummies & yes & yes & yes & yes & yes & yes \\
\hline
\end{tabular}

- Notes: White's heteroscedasticity-consistent $\mathrm{t}$ ratios in parentheses below each coefficient. Only significant country dummies are left in the reported equation.

The results are shown in equations [4]-[6] in Table 9. As in previous specifications, the human capital variable is significant and displays a reasonable coefficient with our revised data, but not with the B\&L series or with the NSD data, which actually produce a negative and significant human capital coefficient. Moreover, the coefficients of the stocks of physical and human capital estimated with the D\&D data are quite plausible, with $\alpha$ only slightly above capital's share in national income and $\beta$ only slightly below Mankiw, Romer and Weil's (1992) preferred estimate of $1 / 3$.

We have checked the robustness of our results by reestimating our preferred specification (the catch-up equation labeled [6] in Table 9) for all the possible subsamples obtained by deleting one country at a time from the original data set. Figure 9 displays the estimated human capital coefficient and the 95\% confidence interval around it, after arranging the coefficient estimates in decreasing order across subsamples. As can be seen in the figure, sample composition does not make a significant difference in terms of the estimated coefficient, and all the estimates remain significantly different from zero at conventional confidence levels. By contrast, Temple (1998) reports that Mankiw, Romer and Weil's (1992) proxy for educational investment looses its significance once a few influential observations are removed. In the OECD subsample, in particular, the removal of Japan suffices to make the coefficient of the human capital variable insignificant (with a t ratio below one). 
Figure 9: Estimated coefficient of human capital and 95\% confidence interval around it when deleting one country at a time from the sample

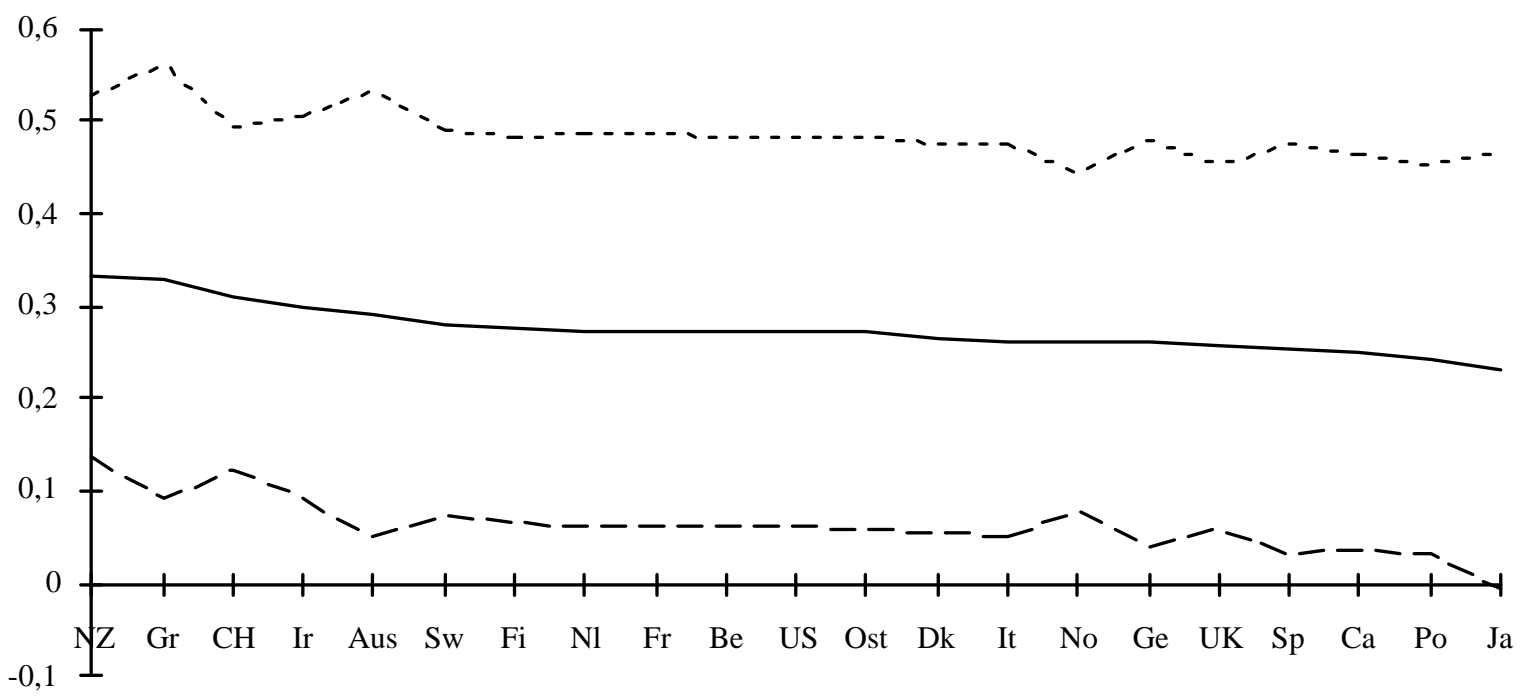

- Note: Catch-up specification with country dummies (equation [6] in Table 9), estimated after excluding the country shown in the horizontal axis.

\section{2.- Is there a trends problem?}

We suspect that the positive trend of human capital investment at a time of slowing productivity growth may have also contributed to the lack of significance of educational variables in growth regressions reported in several studies. As we will see in this section, however, this potential "trends problem" does not appear to be important in our OECD sample with our specification, although we suspect that this result may not be extensible to data sets that include developing countries or to convergence equations. Even in our sample, moreover, we find that the partial correlation between human capital investment and productivity growth is not significant in the pooled data unless we control in some way for other factors that may be responsible for the productivity slowdown. This can be achieved either by including a set of period dummies or by controlling for the remaining variables suggested by our structural model. 
Figure 10: Average growth rates of productivity, per worker factor stocks and the TFP gap and investment rates in physical and human capital
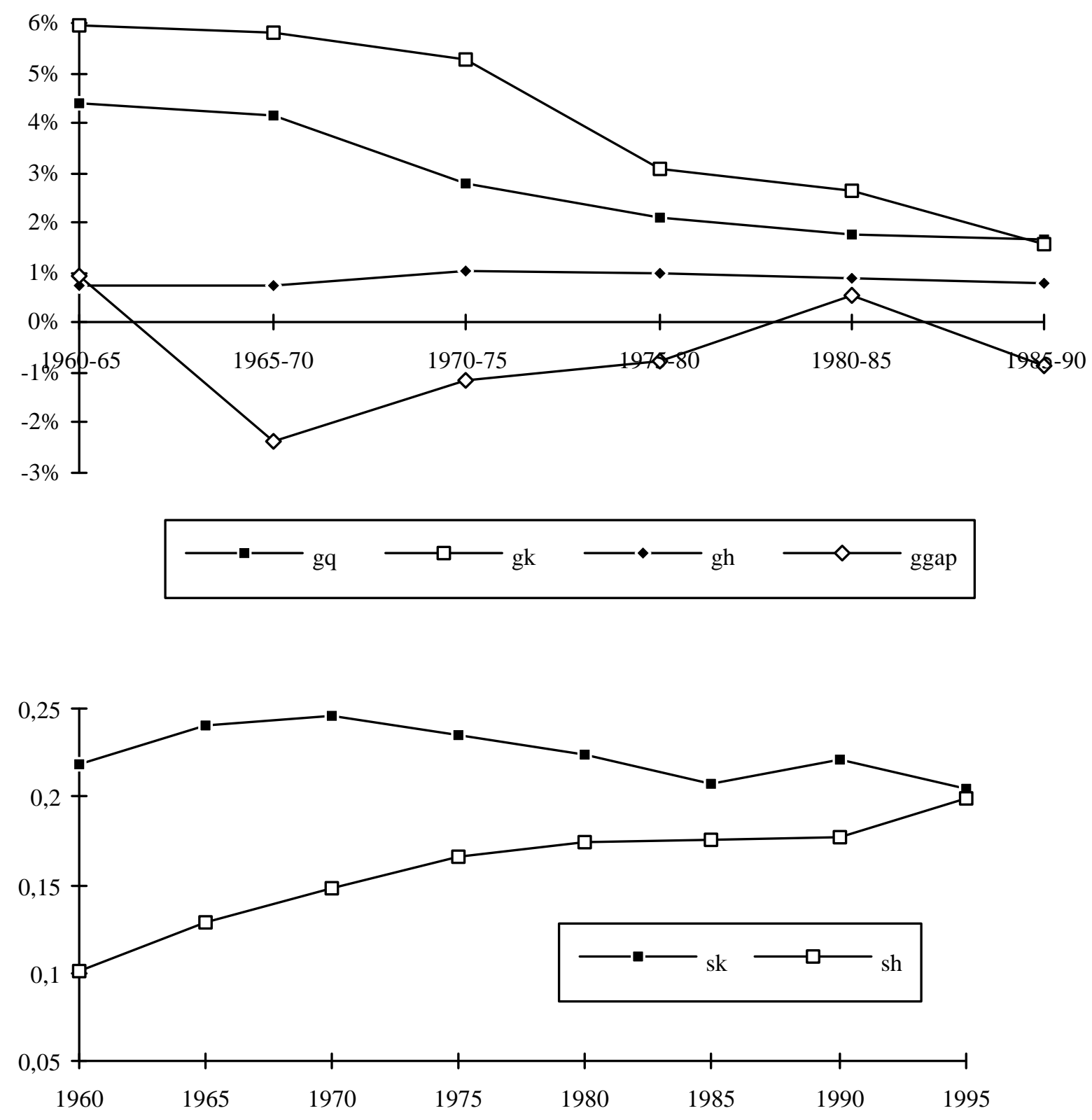

- Note: First panel: annualized growth rates of productivity (gq), the stock of capital per employed worker (gk), average years of education (gh) and the TFP gap relative to the US. Second panel: sk is investment in physical capital as a fraction of GDP; sh is total secondary and university enrollment as a fraction of the population over 15 (from World Development Indicators and UNESCO). All variables are average across countries in each subperiod.

Figure 10 sumarizes the time-series behaviour of the relevant variables. The upper panel of the figure shows the evolution of the average growth rates (taken across countries) of productivity, factor stocks per worker and the TFP gap. As is well known, the growth rate of productivity declines markedly during the period, as does the rate of accumulation of physical capital, while the growth rate of educational attainment is rather stable. The figure suggests that growth accounting regressions will tend to attribute the growth slowdown to the relative decline in investment in physical capital and will not necessarily 
generate a spurious negative human capital coefficient (as it may be the case if the growth rate of this variable displayed an upward trend).

To confirm this hypothesis, we have reestimated several of the specifications in the previous subsection omitting the period dummies, toghether with a simple regression of productivity growth on human capital accumulation with and without fixed period effects. The results are shown in Table 10. When human capital is the only regressor, its coefficient is only significant when we include period dummies (see equations [1] and [2] in Table 10). Once we control for the accumulation of physical capital, however, the educational variable becomes significant even without fixed time effects, except in the specification in first differences without technological catch-up (equation [5]). With this single exception, the results are qualitatively very similar with and without time effects, although the inclusion of period dummies does tend to reduce marginally the coefficient of physical capital and to increase the coefficient of human capital, except in the last equation.

Table 10: Results without period dummies, D\&D data

\begin{tabular}{|c|c|c|c|c|c|c|}
\hline & {$[1]$} & [2] & {$[3]$} & [4] & [5] & [6] \\
\hline human cap. variab. & $D E D$ & $D \mathcal{E} D$ & $D \mathcal{E D}$ & $D \mathcal{E} D$ & $D E D$ & $D \mathcal{E} D$ \\
\hline$\alpha$ & & & $\begin{array}{c}0.579 \\
(24.95)\end{array}$ & $\begin{array}{c}0.604 \\
(38.19)\end{array}$ & $\begin{array}{c}0.544 \\
(11.27)\end{array}$ & $\begin{array}{l}0.294 \\
(6.67)\end{array}$ \\
\hline$\beta$ & $\begin{array}{l}0.683 \\
(1.56)\end{array}$ & $\begin{array}{c}1.21 \\
(3.92)\end{array}$ & $\begin{array}{l}0.236 \\
(4.44)\end{array}$ & $\begin{array}{l}0.247 \\
(6.93)\end{array}$ & $\begin{array}{l}0.090 \\
(0.36)\end{array}$ & $\begin{array}{l}0.328 \\
(3.22)\end{array}$ \\
\hline$\lambda$ & & & & & & $\begin{array}{l}0.076 \\
(7.04)\end{array}$ \\
\hline $\operatorname{adj} . R^{2}$ & 0.011 & 0.396 & 0.894 & 0.977 & 0.664 & 0.785 \\
\hline std. error reg. & 0.018 & 0.014 & 0.125 & 0.058 & 0.0105 & 0.0084 \\
\hline country dummies & no & no & no & yes & no & yes \\
\hline catch-up effect & no & no & no & no & no & yes \\
\hline period dummies & no & yes & no & no & no & no \\
\hline data in & diff. & diff. & levels & levels & diff. & diff. \\
\hline
\end{tabular}

- Notes: White's heteroscedasticity-consistent $\mathrm{t}$ ratios in parentheses below each coefficient. Only significant country dummies are left in the reported equation.

Things are likely to be different, however, with a convergence equation specification à la Mankiw, Romer and Weil (MRW 1992). As shown in the lower panel of Figure 10, the rate of investment in physical capital is relatively stable over the period, while an MRW-style indicator of educational investment (that reflects secondary and university enrollment as a fraction of the adult population) displays a clear positive trend and will tend to be negatively correlated (over time, although not necessarily across countries) with the growth rate of productivity.

\section{3.- Cross-country differences in TFP levels and the explanatory power of the neoclassical model}

A number of authors have recently called attention to the crucial role of technical efficiency in understanding productivity disparities across economies and questioned the capacity of the human capital-augmented neoclassical model with a common technology to explain the international or 
interregional distribution of income. ${ }^{18}$ The catch-up specification we proposed and estimated in a previous section can be seen as a further extension of (the technological components of) an augmented neoclassical model that allows for cross-country differences in TFP levels and for a process of technological diffusion. In this section, we will use this model to explore the relative importance of differences in TFP levels and in factor stocks as sources of international productivity differencials. The exercise is similar to the one performed by Klenow and Rodriguez-Clare (K\&R 1997) but it is conducted using a refined data set that should help improve the quality of TFP estimates and an empirically-based set of production function parameters. In addition, the examination of the relative TFP levels implied by our regression estimates should be helpful as a check on the reasonableness of our results, and on the robustness of recent findings by K\&R (1997) and Jones (1997).

Having estimated our preferred specification (equation [6] in Table 9), we can recover the Hicks-neutral technological gap between each country and a fictional average economy to which we attribute the observed sample averages of $\log$ productivity $(q)$ and $\log$ factor stocks per employed worker $(k$ and $h)$. Thus, we define relative TFP (tfprel) by

(5) tfprel $_{i t}=\left(q_{i t}-\alpha k_{i t}-\beta h_{i t}\right)-\left(q_{a v_{i t}}-\alpha k a v_{i t}-\beta h a v_{i t}\right)=$ qrel $_{i t}-\left(\alpha k r e l_{i t}+\beta h_{r e l} l_{i t}\right)$

where $a v$ denotes sample averages and rel deviations from them.

As may be expected, the correlation between relative productivity and relative TFP is clearly positive. Figures 11 and 12 show the correlation between these two variables in 1960 and 1990 together with the fitted regression line. Relative productivity is measured along the vertical axis so that the country ranking in terms of TFP levels is more readily apparent. Countries lying above the regression line would be those where relatively high factor stocks per worker raise productivity above the level expected on the basis of technical efficiency.

Tables 11 and 12 compare our estimates of relative TFPs with those obtained by K\&R (1997) for 1985 and by Jones (1997) for 1990 and with relative productivity in the same year. ${ }^{19}$ In each table, countries are arranged in decreasing order of relative productivity (qrel), and the rankings induced by the different variables are shown next to their values. We consider suspicious, and highlight using bold italic characters, those cases in which a country's ranking in terms of TFP is five or more positions away from its relative productivity ranking. By this criterion, Jones' estimates yield 10 suspicious cases, K\&R's 7, and D\&D's 4 in 1985 and 5 in 1990. In spite of these differences, Table 12 shows that the correlations across the different TFP estimates and contemporaneous relative productivity levels are reasonably high. This finding may perhaps give us some confidence that, although TFP estimates for a given country should probably not be taken too literally, ${ }^{20}$ the overall picture given by our results is not particularly misleading on average.

18 See for instance Islam (1995), Caselli et al (1996), de la Fuente (1996), Jones (1997), Klenow and Rodriguez (1997) and Prescott (1998).

19 Jones (1997) and K\&R (1997) report TFPs $\left(A_{i}\right)$ expressed in a Harrod-neutral (labour-augmenting) fashion. We have converted them into their Hicks-neutral equivalent, which is the appropiate measure for our calculations, by computing $\left(A_{i}\right)^{1-\alpha}$ with $\alpha$ set to the value used in each of these papers $(1 / 3$ for Jones and 0.30 for $K \& R)$.

20 There are, indeed, some implausible results in all three papers. Perhaps the biggest surprises are Norway, Switzerland and Spain. We suspect that in the case of Spain part of the problem lies in the fact that the educational level of the employed workforce (which is a relatively small fraction of the population due to low participation and 
Figure 11: Relative productivity vs. relative TFP in 1960

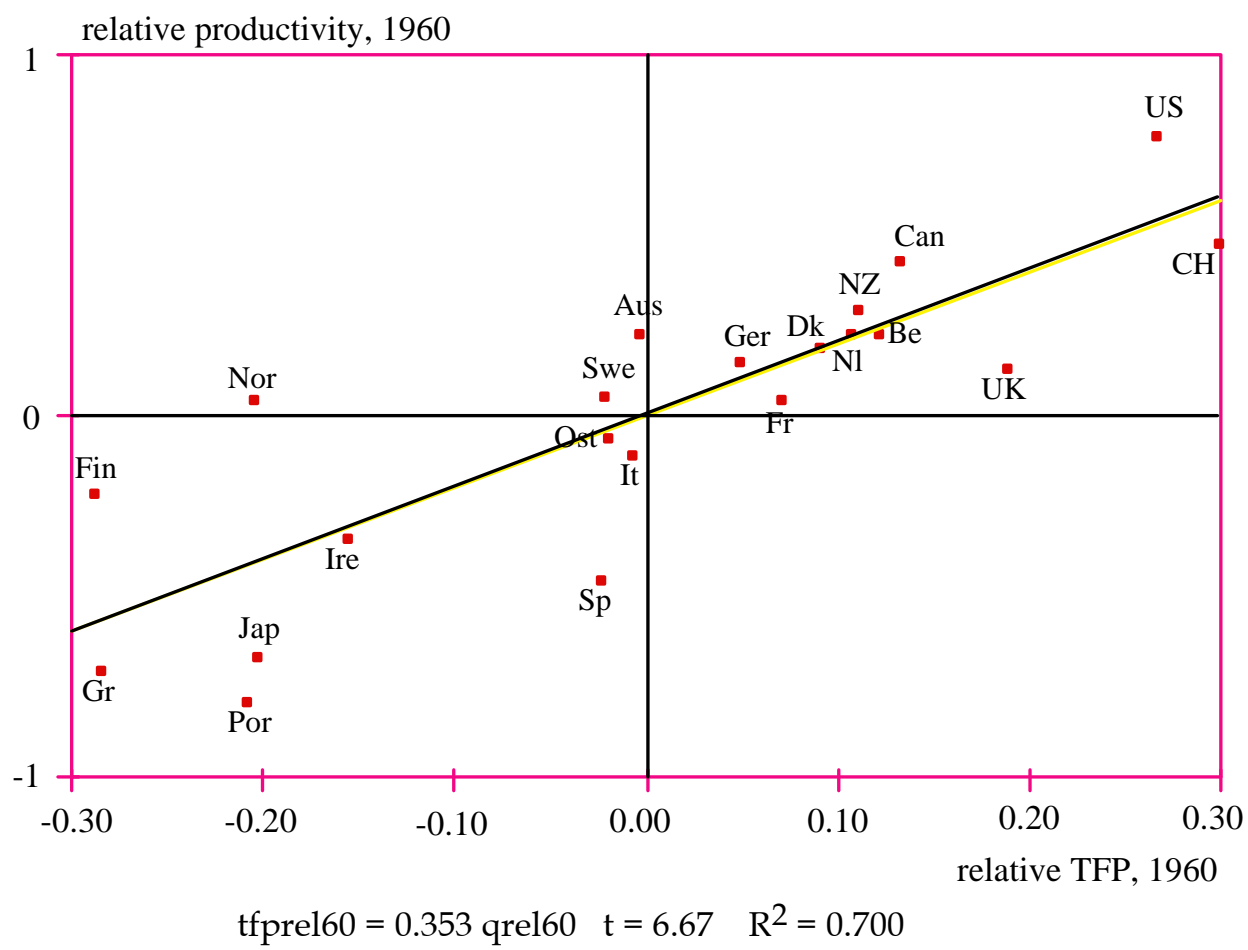

Figure 12: Relative productivity vs. relative TFP in 1990

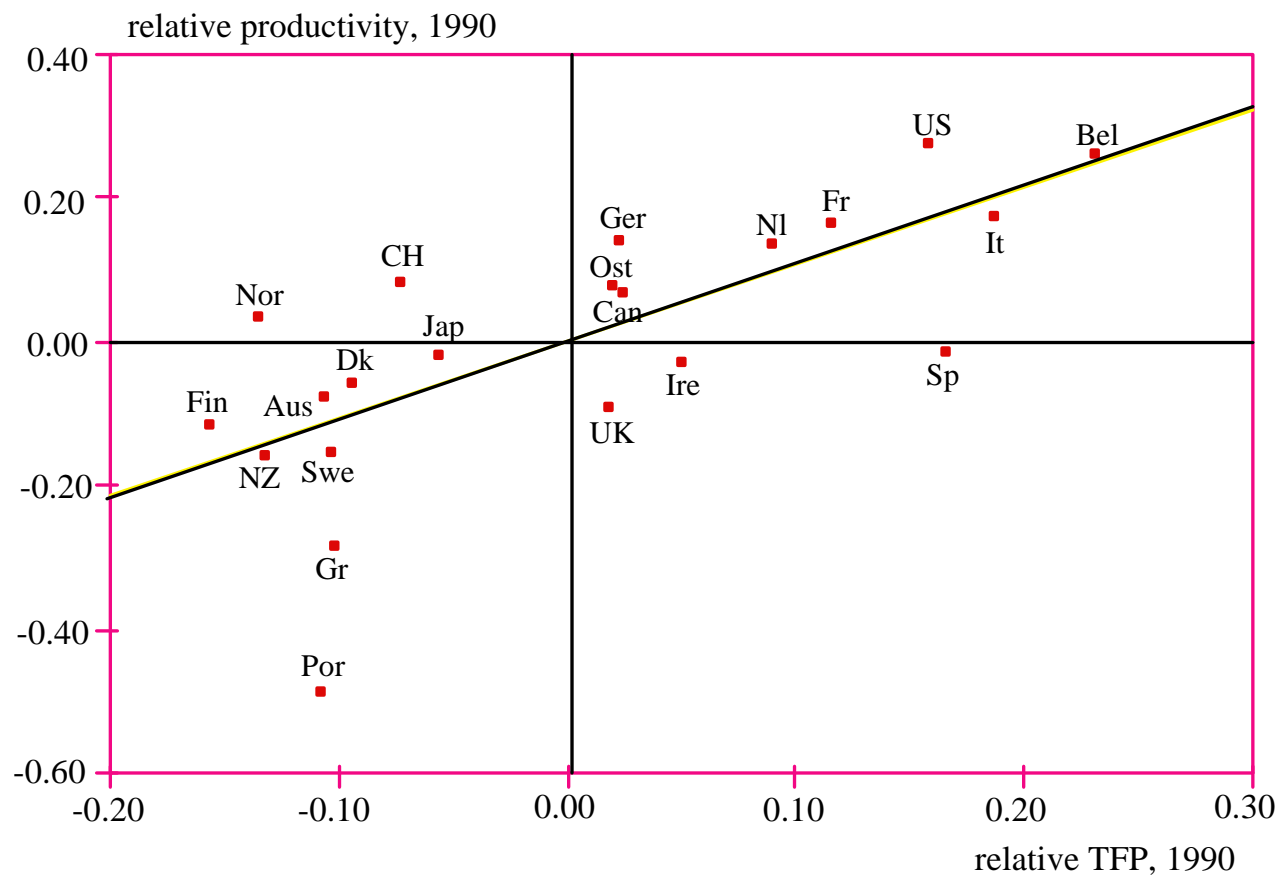

tfprel90 $=0.472$ qrel90 $\quad \mathrm{t}=4.41 \quad \mathrm{R}^{2}=0.506$

high unemployment rates) exceeds that of the adult propulation by a wider margin than in other countries. Hence, we are underestimating the relevant stock of human capital and this biases our estimate of TFP upward. 
Table 11: 1985 relative TFP levels, D\&D vs. K\&R

\begin{tabular}{|c|c|c|c|c|c|c|}
\hline \multirow[b]{3}{*}{$U S$} & \multirow[b]{2}{*}{ qrel } & \multirow[b]{2}{*}{ ranking } & \multicolumn{2}{|c|}{ this paper } & \multicolumn{2}{|c|}{ KER (1997) } \\
\hline & & & Tfprel 85 & ranking & tfprel 85 & ranking \\
\hline & 0.325 & 1 & 0.183 & 2 & 0.152 & 4 \\
\hline $\mathrm{Bel}$ & 0.251 & 2 & 0.203 & 1 & 0.030 & 9 \\
\hline $\mathrm{Nl}$ & 0.179 & 3 & 0.105 & 5 & 0.138 & 5 \\
\hline $\mathrm{CH}$ & 0.164 & 4 & -0.009 & 11 & -0.004 & 10 \\
\hline Ger & 0.135 & 5 & -0.006 & 9 & -0.013 & 12 \\
\hline$F r$ & 0.134 & 6 & 0.083 & 7 & 0.179 & 3 \\
\hline It & 0.133 & 7 & 0.158 & 4 & 0.179 & 2 \\
\hline Can & 0.125 & 8 & 0.088 & 6 & 0.186 & 1 \\
\hline Ost & 0.052 & 9 & -0.008 & 10 & 0.062 & 7 \\
\hline Nor & 0.045 & 10 & -0.110 & 19 & -0.013 & 13 \\
\hline Aust & 0.008 & 11 & -0.055 & 14 & 0.038 & 8 \\
\hline$S p$ & -0.001 & 12 & 0.170 & 3 & 0.101 & 6 \\
\hline$D k$ & -0.021 & 13 & -0.053 & 13 & -0.139 & 17 \\
\hline$U K$ & -0.069 & 14 & 0.032 & 8 & -0.013 & 11 \\
\hline Jap & -0.088 & 15 & -0.090 & 17 & -0.171 & 20 \\
\hline Ire & -0.120 & 16 & -0.047 & 12 & -0.050 & 15 \\
\hline Swe & -0.126 & 17 & -0.081 & 15 & -0.031 & 14 \\
\hline$N Z$ & -0.153 & 18 & -0.098 & 18 & -0.118 & 16 \\
\hline Fin & -0.170 & 19 & -0.194 & 21 & -0.150 & 19 \\
\hline$G r$ & -0.254 & 20 & -0.086 & 16 & -0.150 & 18 \\
\hline Por & -0.545 & 21 & -0.183 & 20 & -0.206 & 21 \\
\hline
\end{tabular}

Table 12: 1990 relative TFP levels, D\&D vs. Jones

\begin{tabular}{|c|c|c|c|c|c|c|}
\hline \multirow[b]{3}{*}{$U S$} & \multirow[b]{2}{*}{ qrel } & \multirow[b]{2}{*}{ ranking } & \multicolumn{2}{|c|}{ this paper } & \multicolumn{2}{|c|}{ Jones (1997) } \\
\hline & & & Tfprel 90 & ranking & tfprel 90 & ranking \\
\hline & 0.281 & 1 & 0.157 & 4 & 0.017 & 11 \\
\hline $\mathrm{Bel}$ & 0.262 & 2 & 0.230 & 1 & 0.087 & 7 \\
\hline It & 0.179 & 3 & 0.186 & 2 & 0.222 & 1 \\
\hline $\mathrm{Fr}$ & 0.167 & 4 & 0.114 & 5 & 0.182 & 3 \\
\hline Ger & 0.145 & 5 & 0.022 & 9 & 0.030 & 10 \\
\hline$N l$ & 0.138 & 6 & 0.089 & 6 & 0.104 & 4 \\
\hline $\mathrm{CH}$ & 0.084 & 7 & -0.074 & 13 & 0.010 & 12 \\
\hline Ost & 0.082 & 8 & 0.018 & 10 & 0.104 & 5 \\
\hline Can & 0.070 & 9 & 0.023 & 8 & 0.050 & 9 \\
\hline Nor & 0.037 & 10 & -0.136 & 20 & -0.140 & 17 \\
\hline$S p$ & -0.011 & 11 & 0.165 & 3 & 0.197 & 2 \\
\hline Jap & -0.018 & 12 & -0.058 & 12 & -0.166 & 19 \\
\hline Ire & -0.026 & 13 & 0.049 & 7 & -0.003 & 13 \\
\hline$D k$ & -0.052 & 14 & -0.096 & 14 & -0.193 & 20 \\
\hline Aust & -0.073 & 15 & -0.107 & 17 & -0.076 & 15 \\
\hline$U K$ & -0.086 & 16 & 0.018 & 11 & 0.081 & 8 \\
\hline Fin & -0.114 & 17 & -0.157 & 21 & -0.140 & 18 \\
\hline Swe & -0.152 & 18 & -0.104 & 16 & -0.024 & 14 \\
\hline$N Z$ & -0.156 & 19 & -0.133 & 19 & -0.324 & 21 \\
\hline$G r$ & -0.281 & 20 & -0.103 & 15 & -0.132 & 16 \\
\hline Por & -0.482 & 21 & -0.109 & 18 & 0.104 & 6 \\
\hline
\end{tabular}


Table 13: Correlations across TFP and productivity measures

\begin{tabular}{lcclcc}
\hline & TFP85DED & TFP85KER & & TFP90D\&D & TFPP90J \\
QREL85 & 0.775 & 0.773 & QREL90 & 0.711 & $\mathbf{0 . 3 7 0}$ \\
TFP85D\&D & & 0.824 & TFP90D\&D & & 0.750 \\
\hline
\end{tabular}

Figure 13: Fraction of the productivity differential with the average explained by the TFP gap in an average country in the sample

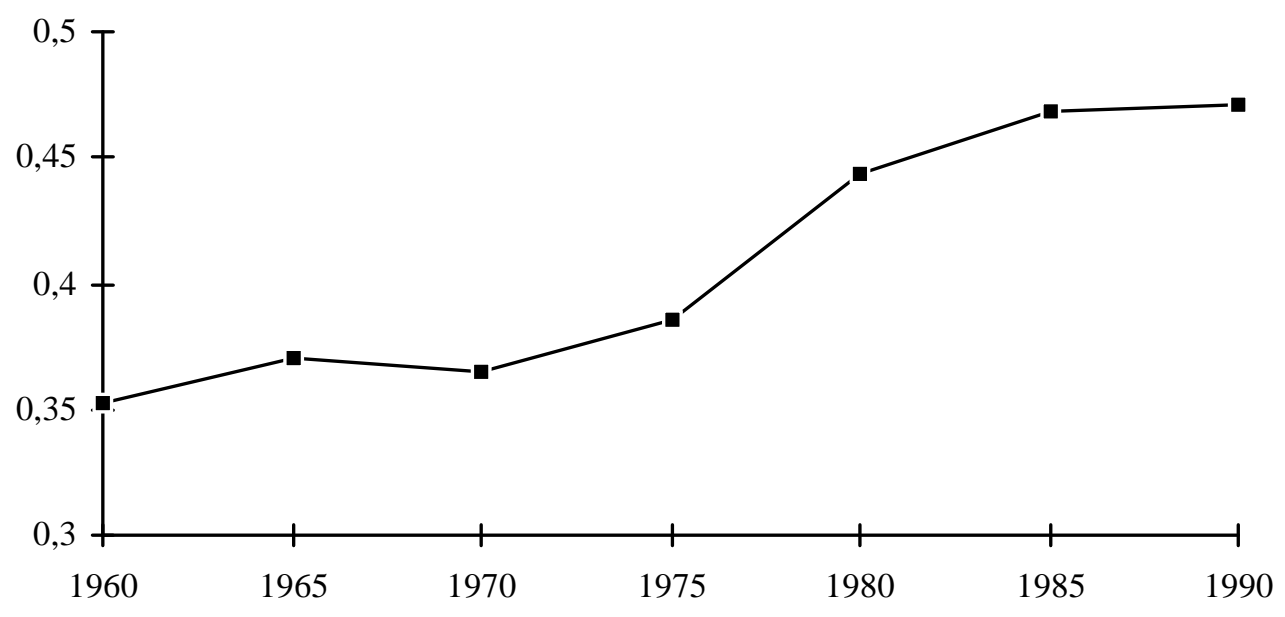

This is important because we would like to use our results to examine the relative contributions of TFP gaps and factor stocks to cross-country productivity differences. To obtain a summary measure of the relative importance of these two factors, we regress relative TFP on relative productivity. (Notice that the regression constant will vanish because both variables are measured in deviations from sample means). The estimated coefficient gives the fraction of the productivity differential with the sample average explained by the TFP gap in a "typical country." Figure 13 shows the evolution of this "average TFP share" in relative productivity. With our data, this coefficient rises consistently over the sample period, from 0.353 in 1960 to 0.472 in 1990. That is, TFP differences seem to have become relatively more important over time in explaining productivity disparities. Equivalently, this result shows that per worker factor stocks have been converging faster than efficiency levels, although the behaviour of both variables has contributed to the narrowing of cross-country productivity differentials.

Towards the end of the sample period, one half of the productivity differential with the sample average can be traced back to differences in technical efficiency, with the other half being attributable to differences in factor stocks. The message is similar if we use K\&R's estimates of the TFP gap, as the TFP share estimated with these data is 0.495 in $1985 .{ }^{21,22}$ This result stands approximately half way between

21 K\&R actually report a higher number (around 2/3), in part because they attribute to TFP differences in factor endowments that are presumably induced by differences in levels of technical efficiency. In practice, their adjustment amounts to working with the TFP gap in its Harrod-neutral form (without multiplying it by 1- $\alpha$ ), which raises its value by about $50 \%$, thereby increasing the share of efficiency in relative productivity. By contrast, we consider only the direct contribution of the TFP gap, without trying to guess its indirect effects through induced factor accumulation. 
those reported by Mankiw (1995), who attributes the bulk of observed income differentials to factor endowments, and those of Caselli et al (1996) and some other recent panel studies of convergence where fixed effects that presumably capture TFP differences account for most of the observed cross-country income disparities. ${ }^{23}$ We view these results as an indication that, while the augmented neoclassical model prevalent in the literature does indeed capture some of the key determinants of productivity, there is a clear need for additional work on the dynamics and determinants of the level of technical efficiency.

\section{5.- Conclusion}

Existing data on educational attainment contain a considerable amount of noise. Due to changes in classification criteria and other inconsistencies in the primary data, the most widely used series on human capital stocks often display implausible time-series and cross-section profiles. After discussing the methodology and contents of these data sets and documenting some of their weaknesses, we have constructed new attainment series for a sample of OECD countries. We have attempted to increase the signal to noise ratio in these data by exploting a variety of sources not used by previous authors, and by eliminating sharp breaks in the series that can only arise from changes in data collection criteria. While our estimates unavoidably involve a fair amount of guesswork, we believe that they provide a more reliable picture of cross-country relative educational attainments and their evolution over time than previously available data sets.

The exercise was originally motivated by the view that weak data was likely to be one of the main reasons for the discouraging results obtained in the recent empirical literature on human capital and growth. Our results clearly support this hypothesis. Unlike Barro and Lee's (1996) or Nehru et al's (1995) original series, our revised data produce positive and theoretically plausible results using a variety of growth specifications and, unlike MRW's original (1992) results for the same sample, our findings survive a simple robustness check.

Our preferred specification is a constant returns production function in first differences with a technological catch-up mechanism and fixed period and country effects. This simple equation explains $80 \%$ of the variation in the growth rate of productivity and yields sensible technological parameters and generally plausible estimates of cross-country relative TFP levels. We have used this model and the underlying data to examine the relative importance of differences in factor stocks and levels of technical efficiency as sources of international productivity differentials. Our results show that the relative importance of TFP differences is considerable and that it has increased over time to account for about one half of the productivity differentials observed at the end of the sample period. These findings reinforce recent calls by a number of authors for better models of technical progress as a key ingredient for

\footnotetext{
22 Things are somewhat different with Jones' estimates, which yield a TFP share of only 0.291 in 1990 (as may have been anticipated by noting the low correlation between Jones' gaps and relative productivity shown in Table 13). In our view, however, many of Jones' TFP estimates look rather implausible, making it dangerous to proceed, as the author does, to use them as the basis for long-term relative income forecasts.

23 If we repeat the exercise with our 1990 data and Caselli et al's most "plausible" estimates of the parameters of the poduction function $(\alpha=0.107$ and $\beta=0.00)$, the share of TFP in relative productivity in our sample is 0.90 .
} 
understanding international income dynamics while preserving an important role for factor stocks as a source of cross-country income disparities. 


\section{References}

Barro, R. and J. W. Lee (1993). "International Comparisons of Educational Attainment." Journal of Monetary Economics 32, pp. 363-94.

Barro, R. and J-W. Lee (1994). "Sources of Economic Growth." Carnegie-Rochester Conference Series on Public Policy 40, pp. 1-46.

Barro, R. and J-W. Lee (1996). "International Measures of Schooling Years and Schooling Quality." American Economic Review Papers and Proceedings 86(2), pp. 218-23.

Behrman, J. and M. Rosenzweig (1994). "Caveat emptor: cross-country data on education and the labor force." Journal of Development Economics 44, pp. 147-71.

Benhabib, J. and M. Spiegel (1994). "The Role of Human Capital in Economic Development: Evidence from Aggregate Cross-Country Data." Journal of Monetary Economics 34, pp. 143-73.

Caselli, F., G. Esquivel and F. Lefort (1996) "Reopening the convergence debate: a new look at crosscountry growth empirics." Journal of Economic Growth, pp. 363-89.

de la Fuente, A. (1996). "On the sources of convergence: A close look at the Spanish regions." CEPR Discussion Paper No. 1543.

de la Fuente, A. (2000). "Human capital and growth: a survey." Mimeo, Instituto de Análisis Económico, Barcelona.

Dabán, T., R. Doménech and C. Molinas (1997). "International and intertemporal comparisons of real product in OECD countries: a growth sensitivity approach," Review of Income and Wealth 43(1), pp. 33-48.

Griliches, Z. (1980). "R\&D and the productivity slowdown." American Economic Review 70 (Papers and Proceedings), pp. 343-48.

Griliches, Z. and J. Hausman (1986). "Errors in variables in panel data." Journal of Econometrics 31, pp. 93118.

Hamilton, J. and J. Monteagudo (1998). "The augmented Solow model and the productivity slowdown." Journal of Monetary Economics 42, pp. 495-509.

Islam, N. (1995). "Growth empirics: a panel data approach." Quarterly Journal of Economics 110, pp. 1127-70.

Jones, Ch. (1997). "Convergence revisited." Journal of Economic Growth 2, pp. 131-53.

Kaneko, M. (1986). "The educational composition of the world's population: a database." Washington DC, the World Bank, Education and Training Department, Report No. EDT 29.

Klenow, P. and A. Rodríguez-Clare (1997). "The neoclassical revival in growth economics: has it gone too far?" in B. Bernanke and J. Rotenberg, editors, Macroeconomics Annual 1997. Cambridge, MA. MIT Press, pp. 73-102..

Knight, M., N. Loayza and D. Villanueva (1993). "Testing the neoclassical theory of economic growth: A panel data approach." IMF Staff Papers 40(3), pp. 512-41.

Kyriacou, G. (1991). "Level and Growth Effects of Human Capital, A Cross-Country Study of the Convergence Hypothesis." Mimeo, NYU.

Lau, L., S. Bhalla and F. Louat (1991). "Human and physical capital stock in developing countries: construction of data and trends." Draft mimeo, World Development Report, World Bank. 
Lau, L, D. Jamison, and F. Louat (1991). "Education and Productivity in Developing Countries: an Aggregate Production Function Approach." Report no. WPS 612, the World Bank.

Mankiw, G., D. Romer and D. Weil (1992). "A Contribution to the Empirics of Economic Growth." Quartely Journal of Economics, pp. 407-37.

Nehru, V., E. Swanson and A. Dubey (1995). "A New Database on Human Capital Stocks in Developing and Industrial Countries: Sources, Methodology and Results." Journal of Development Economics, 46, pp. 379-401.

Nordic Statistical Secretariat (1994). Educational indicators in the nordic countries.

OECD (various years). Education at a Glance. Paris.

OECD (1974). Annuaire des Statistiques de l'Enseignement, Vol. I, Paris.

OECD (1970b). Development of higher education, 1950-67. Statistical Survey. Paris.

OECD (1970a). Statistics of the occupational and educational structure of the labour force in 53 countries. Paris.

OECD (1990). L'Enseignement dans les Pays de l'OCDE, 1987-88. Recueil d'informations statistiques. Paris.

OECD (1995). OECD Education Statistics 1985-92. Paris.

Prescott, E. (1998). "Needed: A theory of total factor productivity." International Economic Review 39(3), pp. $525-51$.

Pritchett, L. (1995). "Where has all the education gone?" Mimeo, World Bank.

Psacharopoulos, G. and A. Arriagada (1986). "The educational composition of the labour force: an international comparison," International Labour Review, 125(5), Sept.-Oct., pp. 561-74.

Steedman, H. (1996). "Measuring the quality of educational outputs: a note." Center for Economic Performance, Discussion Paper no. 302, LSE.

Temple, J. (1998). "Robustness tests of the augmented Solow model." Journal of Applied Econometrics 13, pp. $361-75$.

UNESCO (1993). Statistics of Educational Attainment and Illiteracy, 1970-80. Division of Statistics on Eduation. UNESCO, Paris.

UNESCO (various years). Statistical Yearbook, Paris.

United Nations (various years). Demographic Yearbook, New York. 


\section{Appendix}

Our revised attainment data are available at the following web site: http://iei.uv.es/ rdomenec /human.html.

\section{1.- Detailed country notes}

\section{United States}

- Source: U.S. Bureau of the Census (website) for 1960, 1965, 1970, 1975, 1980, 1985, 1990 and 1995.

- Population: $25+$

- Attainment categories: L1 = 4 years of schooling or less; L2.1 = 5-8 years; L2.2 = 9-12 years; L3.1 = 1-2 years of college; L3.2 = more than two 2 years of college.

\section{Netherlands}

- Source: Dutch Statistical Yearbooks with data for 1960, 1971 and 1990.

- Population: labour force in 1960; population over 14 not attending school rest of the years.

- Attainment categories (when not obvious how they correspond with our scheme): L2.1 = advanced elementary level (1960); L2.2 = secondary level (1960); L3.1 = semi-higher level (1960) and vocational colleges (1990).

- Other notes: We use linear interpolation to fill in the missing observations.

\section{Italy}

- Source: For secondary schooling, Italian Statistical Yearbooks with census data for 1961, 1981 and 1991, and DYB for 1970 (1971, 25+) . For university: Unesco for 1960, DYB for 1971 and 1981 and EAG for 1989. For illiterates, Statistical Yearbook for 1961, 1981 and 1991, and World Development Indicators for 1970 and 1975.

- Population: National yearbooks, 6+; Unesco and DYB, 25+.

- Other notes:

- We do not use the information in the national yearbook for university attainment because this source refers to the population over 6 years of age and will therefore underestimate attainment (especially at this level).

- For 1970, DYB provides only the total secondary attainment. To estimate L2.1 and L2.2, we interpolate the ratio L2.2/L2 between 1961 and 1981 and apply it to the total. The rest of the missing observations are estimated by linear interpolation.

\section{Belgium}

- Source: For secondary schooling, Belgian Statistical Yearbook with census data for 1961, 1970 and 1981 and EAG for 1989. For university: EAG for 89, with breakdown by level and UNESCO 1960 and 1970 (25+) interpreted as L3.2.

- Population: non-student population over 15 in Yearbooks; population 25-64 in EAG; 20+ in Unesco 1960. 
- Other notes: Because it refers to the non-student population over 15, we do not use the Yearbook data for university attainment. We do, however, use the ratio L3.2/L3 in these data to estimate L3 from available data on L3.2 in 1960 and 1970, and from the estimate of this number (by interpolation) in 1980.

\section{Spain}

- Source: National census data for 1960, 1970, 1981 and 1991.

- Population: $25+$

- Other notes: The 1960 census does not give very detailed information or a breakdown of results by age group, and its results appear implausible in the light of latter data. Hence, we do not use this source (except for illiterates), and construct attainment estimates for 1960 using the 1970 census (which gives a very fine breakdown by age), and the actual age structure of the population in 1960. We interpolate to estimate missing observations.

\section{Greece}

- Source: National census data for $(1961,1971), 1981$ and 1991.

- Population: $25+$.

- Attainment categories: L3.1 = with certificate of intermediate school + attended a higher or intermediate school; L2.1 = have finished at least the third degree of secondary education; L1 = complete or incomplete primary or no schooling but literate; $\mathrm{L} 0=$ illiterate.

- Other notes: The 1981 census has a finer breakdown by age and level than the previous ones. We project it backward using the observed age structures in 1961 and 1971. The results are compatible with the original census data for those years but more detailed. We interpolate to estimate missing observations.

\section{Portugal}

- Sources: For university: Unesco in 1960, 1970 and 1981 (25+) interpreted as L3.2; OECD (1995) for 1991 and DYB for 1960 interpreted as L3. For secondary educaton: Unesco in 1960 interpreted as L2.2; DYB in 1960 and Unesco in 1970, 1981 and 1991 for L2. For illiterates (L0), World Development Indicators (WDI). - Population: 15+ in WDI, 25-64 in OECD (1995) and25+ in Unesco and DYB.

- Other notes:

- University: We have observations for both L3.1 and L3.2 in 1960 and 1991. We calculate the ratio L3.2/L3 in these two years and interpolate it to 1970 and 1981, where we have Unesco observations that we interpret as L3.2. Using the interpolated ratio and these observations, we estimate L3.1 and L3. Finally, we interpolate for the rest of the years.

- Secondary: We have an observation for L2.1 and L2.2 in 1960, and can obtain another one in 1991 applying the ratio L2.2/L2 in OECD (1995) to the total L2 given in Unesco (which refers to the desired age group). We interpolate the ratio L2.2/L2 between 1960 and 1991 and apply it to available data on L2 to estimate its breakdown. We interpolate for the rest of the years.

\section{France}

- Sources: National census for (1960), 1968, 1975 and 1990 and EAG (for 1989). 
- Population: 25+ not attending school in census data and pop. 25-64 in EAG.

- Attainment categories in 1968. L2.1 = CEP, examen de fin d'apprentissage artisanal or certificat de fin de stage de la FPA; L2.2 = BEPC, BE, BEPS, CAP, BEI, BEC, BES, BEH, BEA, etc; 23.1 = bac ou brevet superieur, brevet des ENP, brevet de technicien, etc., autres diplomes; L3.2 = superieur au bac complet.

- Other notes: Data for 1960 are backward projections using 1968 attainments by age group and the 1960 population structure. The 1990 Census seems to be missing secondary vocational qualifications, so we use EAG for 1989 instead at the secondary level.

\section{Ireland}

- Sources: 1966 national census; Unesco for 1981 and 1991. OECD (1995) for ratios L2.2/L2 and L3.2/L3.

- Population: 25+ except OECD (1995) where it is 25-64.

- Other notes:

- Figures for 1961 are estimated by a backward projection of the 1966 census data on attainment by age group. Since we do not have the age structure of the population in 1961, we estimate it from the 1966 distribution using age-specific survival probababilities (for 1981) taken from the DYB. To compute the average survival probability, we assume 40\% of population is urban in 1961 (around 55\% in 1981) to average death rates over rural and urban populations.

- Census and survey information does not allow a breakdown of L3 and L2 into first and second cycles. We estimate this breakdown using data from OECD (1995). For L2 we have L2.1 and L2.2 in 1991 from Unesco. OECD (1995) gives this ratio by age group; we observe that the ratio L2.1/L2.2 stabilizes for the older age groups around 0.54 , which we take as the 1960 value, then we interpolate this ratio between the two observations and apply the result to our L2 series to recover L2.1 and then L2.2. To recover L3.1 and L3.2 we proceed in a similar way, we use the ratio L3.1/L3 in OECD 1995. Since this ratio does not change much with age in this source, we keep its value constant over time.

- The remaining missing observations are filled in by interpolation. The figures for 1960 are extrapolations from 1960 and 1966 estimates.

\section{Sweden}

- Sources: National Statistical Yearbook for 1970 and 1994, Education in Nordic Countries for ratio L3.1/L3 en 1988.

- Population: 25+ (est.) in 1970 and 25-75 in 1994.

- Other notes:

- The earliest available disaggregated data is for 1970 and refers to the population aged 25-60. We want to use this information (and census data on the age structure of the population) to estimate attainment in the same year and in 1960 for the population 25+. First, we extrapolate attainment rates to older cohorts in 1970 as follows. Let F3544 and F4559 be the fraction of the population aged 35-44 and 45-59 which has attained a given level of education. Then, we estimate F6075 and F75+ as follows:

$$
\begin{aligned}
& F 6075=F 4559+0.5^{*}(F 4559-F 3544) \\
& F 75+=F 4559+(F 4559-F 3544) .
\end{aligned}
$$


With this, we can estimate attainments for ages 25+ in 1970, using the age structure of the population in that year. Next, we estimate 1960 using the same information and the age structure in 1960.

- Breakdown for tertiary into L3.1 and L3.2: We have data on the two cycles and therefore on the ratio L3.1/L3 for 1960, 1970 and 1994 from the Statistical Yearbook and for 1988 from Education in Northern Countries. For the rest of the years we interpolate this ratio and total L3, and use these two numbers to estimate L3.1 and L3.2.

\section{Norway}

- Source: Statistics Norway website for 1960, 1970, 1975, 1980, 1985 and 1990.

- Population: $16+$

- Other notes:

- Statistics Norway does not disaggregate compulsory education into L1 and L2.1 or tertiary achievement into L3.1 and L3.2. We use information from Sweden and Education in Nordic Countries (1994) to estimate these categories as follows.

- To estimate L3.1 and L3.2: We have data on these two categories in 1988 for all Scandinavian countries from Education in Nordic Countries. We compute the quotient L3.1/L3 for Norway and Sweden and the ratio between them. We then apply this ratio to the Swedish L3.1/L3 ratio to estimate the Norwegian ratio for all years and use it to recover L3.1 and L3.2.

- To estimate L1 and L2.1,we use the ratio L1/L1+L2.1 for Sweden.

\section{Denmark}

- Sources: Danish Statistical Yearbooks with data for 1983, 1988 and 1991 and OECD (1974) for attainment growth rates between 1960 and 1971.

- Population: 25-62 or 25-65.

- Other notes:

- National sources and OECD report only L1+L2.1 (compulsory education). To separate them we use the ratio L1/L1+L2.1 for Sweden.

- Figures for 1973 are a backward projection using attainment data by age in 1983 and the age structure of the population in 1971. We then extrapolate back to 1970 using the 1973 and 1983 observations. Finally, we use the annual growth rate of attainment between 1960 and 1971 reported in OECD (1974) to estimate 1960 levels of L3 and L2 (We use the growth rate of attainments, which is recovered from the original data on average years of schooling by level. It coincides with the original for L3 but not for L2 since people with university schooling also have secondary training and we have to subtract them from the total to get those whose maximum attainment level is secondary). L2.1 in 1960 is obtained from the 1970 value and the growth rate for secondary, for all other years we use the Swedish ratio L2.1/L1+L2.1.

- Backward projection for 1973: The 1983 disaggregation by age stops with the group 60-62. We estimate attainments for the 63-64 population by extrapolating the change between the previous two age groups amd weighting it for the "length of the period", and reconstruct attainment for the 60-64 age group. Then we extrapolate backwards again from consecutive age groups of the same length but assuming that at each step the change in the achievement ratios drops to one half for each category (This is half way between 
extrapolating and attributing to the oldest group in the population the achievement of the last observed age subgroup).

- 1988 Statistical Yearbook secondary attainment figures look implausible and are ignored.

- Tertiary is broken down into three groups: post-secondary vocational (isced5), short university courses and full-length university degrees. We report the sum of the first two groups as L3.1.

\section{Finland}

- Sources: For university, Unesco in 1960, 1970, 1980, 1985 and 1990 (all for L3); Education in Nordic Countries for ratio L3.2/L3 in 1988. For secondary, in 1960 DYB for L2 and Unesco interpreted as L2.1, in 1970 Unesco interpreted as L2.2, in 1980 Unesco gives breakdown of L2 into L2.1 and L2.2, in 1990 Unesco interpreted as L2.2.

- Population: 20+ in 1980, and 25+ in 1990. We need to check the rest.

- Other notes:

- Most sources do not separate L3.1 and L3.2. Those that do (towards the end of the period) give extremely similar values. We take the 1988 ratio from Education in Nordic Countries and assume that it remains constant throughout the whole sample period. We use this ratio to recover L3.1 and L3.2.

- Secondary: we interpolate and extrapolate L2 to recover missing observations and the ratio L2.2/L2 to separate the first and second cycle.

\section{Japan}

- Sources: For higher education, DYB for 1960 (25+) and 1970 (25+), Unesco for 1980 and 1990, Unesco for 1970 interpreted as L3.2, and EAG for ratio L3.1/L3 in 1990. For secondary attainment, in 1960 and 1965 Unesco interpreted as L2.2. For 1960 and 1970 we recover an estimate of L2 from the data on average years of secondary schooling in OECD (1974). In 1990, Unesco, interpreted as L2.2.

- Population: Unesco and DYB, 25+; EAG, 25-64.

- Other notes:

- Tertiary attainment: In 1990, we use ratio L3.1/L3.2 from EAG for 1989 to estimate L3.1 and L3.2. We interpolate and extrapolate the ratio L3.1/L3.2 from available years (1970 and 1990) to estimate L3.1 and L3.2 in the rest of the period.

- Secondary attainment: We interpolate L2.2 between available observations to recover the complete series. Then, we compute the ratio L2.1/L2.2 for 1960 and 1970 and extrapolate it forward to 1980 and 1990 (assuming the increase between each two decades drops to one half its previous value at each stage). We use this ratio to estimate L2.1 and add it to L2.2 to obtain L.2. Remaining missing observations are filled by interpolation.

\section{New Zealand}

- Sources: Higher education: Statistical Yearbook for 1965 and 1970, interpreted as L3.2 and for 1975 and 1981, interpreted as L3; OECD (1995) for 1992 with full breakdown. Secondary schooling: Statistical Yearbook for 1965; for 1981 we use the DYB and add to this source's reported L2.2 part of Barro and Lee's 
L3, as explained below. For 1992 we use OECD (1995), adding to L2.2 part of Barro and Lee's L3.1, as above.

- Population: 25+ except OECD (1995).

- Other notes:

- Higher education: We interpolate L3.2 between 1970 and 1992, compute the ratio L3.2/L3 for 1975 onwards and extrapolate this ratio back to recover L3 and its breakdown in 1965 and 1970. Finally, we extrapolate backward L3 and the ratio L3.2/L3 to estimate attainments in 1960. We assume the difference between Barro and Lee's L3 and our estimate is part of L2.2 and add it to that category.

- Secondary education: For L2, we interpolate between 1965, 1981 and 1991, and extrapolate backward to 1960. We compute the ratio L2.2/L2 in 1981 and 1991 and interpolate it between these years. We assume this ratio remains constant for all years before 1981 and use it to break down L2 into its upper and lower levels.

\section{UK}

- Sources: For higher education, in 1960 Unesco interpreted as L3.2; in 1975 (1976), Unesco for L3; in 1991 EAG93 for L3.1 and L3.2. For secondary attainment: Unesco for 1960 and 1970 interpreted as L2.2, EAG93 gives L2.2 for 1991.

- Population: Unesco 1976, 25-69. EAG, 25-64. UNESCO 25+.

- Other notes:

- Higher education: We interpolate L3.2 between 1960 and 1991 to recover the full series. Then, we compute the ratio L3.2/L3 in 1975 and 1991, interpolate it between these years and extrapolate it backward to 1960. Using this ratio, we estimate L3.1 and L3 in 1960. Then we interpolate between these years.

- Secondary education: We interpolate between available observations to complete the L2.2 series. To construct L2.1, we use a regression estimate of the ratio L2.1/L2.2 (see the body of the paper).

- Double check Unesco 1970.

\section{Switzerland}

- Sources: Higher education: for 1960, Unesco as L3; for 1970, Unesco interpreted as L3.2; for 1991, EAG for L3.1 and L3.2. For secondary education: In 1960, Unesco interpreted as L2.2; in 1980, Kaneko (as reported in Barro and Lee's appendix) interpreted as L2.2; and in 1991, EAG for L2.2.

- Population: $25+$

- Other notes:

- Higher education: We interpolate L3 and L3.2 between available observations, compute the ratio L3.2/L3, extrapolate it back to 1960 and use it to estimate L3.1 and L3.2 in that year. In all years, L3.1 is computed as the difference between the estimated values of L3 and L3.2.

- Secondary education: We interpolate between available observations to recover the L2.2 series. We use a regression estimate of the ratio L2.1/L2.2 to estimate L2.1. 


\section{Austria}

- Sources: University, Unesco for 1961, 1971, 1981 and 1991 interpreted as L3.2 and 1995 Microcensus for L3.1 and L3.2. Secondary, L2.2 from the Austrian Statistical Yearbook for 1961, 1971, 1981 and 1991 and the 1995 Microcensus.

- Population: Unesco, 25+; microcensus, check; Austrian Statistical Yearbook, 16+.

- Other notes:

- University: We use the ratio L3.1/L3.2 from the 1995 microcensus (which does not vary significantly across age groups) to estimate L3.1 in years before 1995. Our guess for L3.1 in the 1995 microcensus is called "secondary technical and vocational" and lasts 5 years, two more than other upper secondary categories. We don't use the Austrian Statistical Yearbook series for university schooling because it refers to the population $16+$ and will tend to underestimate tertiary attainment.

- Secondary: For 1961-91, we guess that reported L2.2 includes our estimate of L3.1, so we subtract it from reported L2.2 to obtain the final estimate. For L2.2, we interpolate between available observations and extrapolate backward from 1961 to 1960. To estimate L2.1, we use a regression estimate of the ratio L2.1/L2.2.

\section{Australia}

- Sources: University, in 1965 Unesco (as reported in Barro and Lee) interpreted as L3.2; in 1970 (1971) Unesco (as reported in Barro and Lee) as L3, and in 1990, EAG for L3.1 and L3.2. Secondary: For 1965 we use as L2 Unesco minus our estimate of L3.1; for 1970 Unesco as L2, for 1990, we have L2.1 and L2.2 from EAG.

\section{- Population: $25+$}

- Other notes:

- University: We interpolate between 1965 and 1990 to estimate L3.2, and between 1970 and 1990 to estimate L3.1. Then, we compute the ratio L3.2/L3 and extrapolate it backward to 1965 and 1960. We use the estimated ratio to recover L3 (and hence L3.1) in 1965. For 1960, first we extrapolate L3.2 backward and then proceed in the same way.

- Secondary: We interpolate L2 for missing years after 1965 and use the ratio L2.2/L2 from EAG in 1990 (assumed constant over time) to recover L2.1 and L2.2. For 1960, we first extrapolate L2 backwards and then use the same ratio.

- EAG gives the same figures for 1989 and 1993, so we use the same number for 1990 without "periodification."

\section{Germany}

- Sources: University: EAG for 1991; in 1970 DYB interpreted as L3; in1970 Unesco, 1975 and 1980 (in fact 1978 and 1982) Statistiches Jahrbuch as reported in Barro and Lee, all interpreted as L3.2. From 1970 backward we use the growth rate of attainment recovered from OECD (1974). Secondary: OECD (1974) for 1960 and 1970 as L2; for 1970 and 1980 DYB interpreted as L2.2 and for 1991 EAG gives L2.2 and L2.1.

- Population: Unesco and DYB, 25+; EAG, 25-64.

- Other notes: 
- University: We interpolate between available observations for 1970 on. To extrapolate backward from 1970 we use the growth rate of university attainment given in OECD (1974).

- Secondary schooling: We use the ratio L2.1/L2 from 1970 to estimate L2.1 in other years, given L2. In 1991 this gives a number for L2+L3 slightly larger than 100, so we accept the L2.1 ratio for that year given by EAG, and the implication that L1 is zero.

\section{Canada}

- Sources: Higher education: We interpret Unesco's 1960, 1986 and 1991 observations, and the DYB observation for 1975 as referring to university attainment in the narrow sense (i.e. UNIV = L3 - L3.1(5)). We interpret the 1960 DYB figure as referring to L3.2. We interpret Unesco for 1976 and 1981 and OECD (1995) for 1992 as L3. We use National Census figures for the ratio L3.1(6)/L3.2 in 1986 and 1991. Secondary schooling: Unesco for 1960 interpreted as L2.2; Statistics Canada website for L2.2 in 1976, 1981, 1986 and 1991.

- Population: National Census, 15+; Unesco and DYB, 25+; OECD, 25-64.

- Other notes:

- University: see the discussion in the text.

- Secondary: For L2.2, we fill in missing observations by interpolation. No data are reported for L2.1, which seems to be grouped together with L2.1 as a single category. We estimate L2.1 by using de L1/(L1+L2.1) ratio for the United States.

\section{2.- Data tables}

Tables A1-A3 contain our estimates of attainment levels (in percentages) for the adult population. We report higher and secondary attainment for all countries in the sample, and an illiteracy series for four countries (Spain, Italy, Greece and Portugal). For the remaining countries, illiteracy rates are extremely low and are therefore ignored. Primary attainment can be obtained as L1 = 100 - L3 - L2 (- L0). Character types are used to indicate data quality as indicated in the note to Table A.1.

Table A4 contains an estimate of the average number of years of total schooling. This is constructed by combining the attainment series with the cumulative durations by educational level and country given in Table 6 in the text.

Tables A6-A8 give the data sources and summarize the estimation method used to obtain each observation. See the notes to Table A6 for a key to the notation used in these tables. Notice that interpolations are generally constructed taking into account the exact year to which the original observation refers, rather than bringing them to the beginning or the end of the quinquenium.

Figures A1-A4 plot our attainment and years of schooling series together with Barro and Lee's to facilitate country-by-country comparisons between the two data sets. 


\section{3.- Estimation of the stock of physical capital}

We construct series of stocks of physical capital in the OECD countries for the period 1950-97 using a perpetual inventory procedure with an assumed annual depreciation rate of $5 \%$. To estimate the initial capital stock we modify the procedure proposed by Griliches (1980) to take into account the fact that the economies in our sample may be away from their steady states.

The growth rate of the stock of capital, $g k$, can be written in the form

$$
g_{k}=\frac{I}{K}-\delta
$$

where I is investment, $\delta$ the depreciation rate and $\mathrm{K}$ the stock of capital. Solving this expression for $\mathrm{K}$ and assuming that the growth rate of investment is a good approximation to the growth rate of the capital stock (i.e. $g_{\mathrm{I}} \cong \mathrm{g}_{\mathrm{K}}$ ), we obtain an expression that can be used to estimate the initial capital stock using data on investment flows:

$$
\text { (A.1) } K=\frac{I}{g_{k}+\delta} \cong \frac{I}{g_{I}+\delta} \text {. }
$$

When implementing this approach, it is common to use the level of investment in the first year in the sample period and the growth rate of the same variable over the entire period. In our case, however, this does not seem to be the best way to proceed because i) investment may be subject to transitory disturbances that make it dangerous to rely on a single observation and ii) rates of investment and factor accumulation will tend to vary over time in a systematic way as countries approach their steady states.

To try to control for these factors, we use the growth rate of investment over the period 1950-60 and the HP-filtered level of investment in 1955. Hence, our version of equation (A.1) is of the form:

$$
\text { (A.2) } K_{55} \cong \frac{I_{h p 55}}{g_{I, 50-60}+0.05},
$$

where $I_{h p}$ is the Hodrick-Prescott trend of investment (with a smoothing parameter $\lambda=10$ ). We use 1955 as the base year instead of 1950 because it is known that this filter may displays anomalies at sample endpoints. ${ }^{24}$ Our investment data are corrected for differences in PPP and are taken from the OECD National Accounts and Economic Outlook starting in 1960. Prior to that date, we use IMF data and price deflators and, for some countries where no information is available, we extrapolate investment backward using the growth rates of the capital stocks provided by Summers and Heston in the PWT 5.6.

\footnotetext{
24 Due to data limitations and other anomalies we have used a different base year for some countries. In particular, we use 1953 for Canada and Norway and 1960 for the UK, Greece and Ireland.
} 
Table A1: University attainment levels

\begin{tabular}{|c|c|c|c|c|c|c|c|c|c|}
\hline Country & level & 1960 & 1965 & 1970 & 1975 & 1980 & 1985 & 1990 & 1995 \\
\hline USA & L3 & 16.50 & 18.30 & 21.20 & 26.30 & 31.90 & 35.70 & 39.20 & 47.80 \\
\hline USA & L3.1 & 8.80 & 8.90 & 10.20 & 12.40 & 14.90 & 16.30 & 17.90 & 24.80 \\
\hline USA & L3.2 & 7.70 & 9.40 & 11.00 & 13.90 & 17.00 & 19.40 & 21.30 & 23.00 \\
\hline Neth. & L3 & 3.30 & 4.64 & 5.97 & 8.22 & 10.70 & 13.18 & 15.66 & \\
\hline Neth. & L3.1 & 1.90 & 3.11 & 4.32 & 5.92 & 7.62 & 9.32 & 11.02 & \\
\hline Neth. & L3.2 & 1.40 & 1.53 & 1.65 & 2.30 & 3.08 & 3.86 & 4.64 & \\
\hline Italy & $\mathrm{L} 3.2=\mathrm{L} 3$ & 2.10 & 2.81 & 3.51 & 4.19 & 4.87 & 5.50 & 6.13 & \\
\hline Belgium & L3 & 8.27 & 9.19 & 10.10 & 13.13 & 16.16 & 18.30 & 20.43 & \\
\hline Belgium & L3.1 & 4.27 & 4.44 & 4.60 & 6.45 & 8.30 & 9.24 & 10.19 & \\
\hline Belgium & L3.2 & 4.00 & 4.75 & 5.50 & 6.68 & 7.87 & 9.05 & 10.24 & \\
\hline Spain & L3 & 3.07 & 3.53 & 3.98 & 5.41 & 6.84 & 8.17 & 9.48 & \\
\hline Spain & L3.1 & 1.59 & 1.85 & 2.11 & 2.77 & 3.43 & 4.08 & 4.73 & \\
\hline Spain & L3.2 & 1.48 & 1.68 & 1.87 & 2.64 & 3.42 & 4.09 & 4.75 & \\
\hline Greece & L3 & 3.71 & 4.31 & 4.92 & 6.56 & 8.45 & 9.73 & 10.86 & \\
\hline Greece & L3.1 & 1.13 & 1.31 & 1.49 & 2.43 & 3.56 & 3.41 & 2.93 & \\
\hline Greece & $\mathrm{L} 3.2$ & 2.58 & 3.00 & 3.43 & 4.12 & 4.89 & 6.33 & 7.94 & \\
\hline Portugal & L3 & 1.50 & 1.70 & 1.90 & 3.18 & 4.46 & 5.51 & 6.50 & \\
\hline Portugal & L3.1 & 0.40 & 0.45 & 0.50 & 0.82 & 1.15 & 1.41 & 1.65 & \\
\hline Portugal & L3.2 & 1.10 & 1.25 & 1.40 & 2.35 & 3.31 & 4.10 & 4.85 & \\
\hline France & L3 & 9.41 & 10.43 & 11.79 & 13.68 & 16.43 & 19.17 & 21.92 & \\
\hline France & L3.1 & 6.83 & 7.54 & 8.32 & 9.19 & 11.48 & 13.76 & 16.05 & \\
\hline France & L3.2 & 2.58 & 2.89 & 3.48 & 4.49 & 4.95 & 5.41 & 5.87 & \\
\hline Ireland & L3 & 4.03 & 4.36 & 5.36 & 6.51 & 7.67 & 10.58 & 13.93 & \\
\hline Ireland & L3.1 & 2.05 & 2.22 & 2.73 & 3.31 & 3.90 & 5.38 & 7.09 & \\
\hline Ireland & L3.2 & 1.98 & 2.14 & 2.63 & 3.20 & 3.77 & 5.20 & 6.84 & \\
\hline Sweden & L3 & 4.83 & 5.74 & 6.65 & 9.71 & 12.77 & 15.83 & 18.89 & 21.34 \\
\hline Sweden & L3.1 & 2.10 & 2.41 & 2.71 & 4.27 & 5.83 & 7.39 & 8.95 & 10.20 \\
\hline Sweden & L3.2 & 2.73 & 3.34 & 3.94 & 5.44 & 6.94 & 8.44 & 9.94 & 11.14 \\
\hline Norway & L3 & 4.20 & 5.45 & 6.70 & 8.70 & 11.10 & 13.60 & 15.70 & \\
\hline Norway & L3.1 & 2.00 & 2.50 & 3.00 & 3.99 & 5.22 & 6.56 & 7.86 & \\
\hline Norway & $\mathrm{L} 3.2$ & 2.20 & 2.95 & 3.70 & 4.71 & 5.88 & 7.04 & 7.84 & \\
\hline Denmark & L3 & 7.08 & 9.93 & 12.79 & 14.79 & 16.78 & 18.26 & 19.31 & \\
\hline Denmark & L3.1 & 5.26 & 7.39 & 9.52 & 11.19 & 12.87 & 14.01 & 14.61 & \\
\hline Denmark & $\mathrm{L} 3.2$ & 1.81 & 2.55 & 3.28 & 3.60 & 3.92 & 4.25 & 4.70 & \\
\hline Finland & L3 & 4.10 & 5.10 & 6.10 & 9.00 & 11.90 & 13.80 & 15.40 & \\
\hline Finland & L3.1 & 1.84 & 2.29 & 2.74 & 4.04 & 5.34 & 6.20 & 6.92 & \\
\hline Finland & $\mathrm{L} 3.2$ & 2.26 & 2.81 & 3.36 & 4.96 & 6.56 & 7.60 & 8.48 & \\
\hline Japan & L3 & 6.30 & 7.87 & 9.43 & 11.87 & 14.30 & 17.75 & 21.20 & \\
\hline Japan & L3.1 & 2.63 & 3.28 & 3.93 & 4.82 & 5.70 & 6.89 & 8.08 & \\
\hline Japan & L3. 2 & 3.67 & 4.59 & 5.50 & 7.05 & 8.60 & 10.86 & 13.12 & \\
\hline
\end{tabular}


Table A1: University attainment levels (continued)

\begin{tabular}{llrrrrrrrr}
\hline Country & level & 1960 & 1965 & 1970 & 1975 & 1980 & 1985 & 1990 & 1995 \\
N. Zealand & L3 & 11,96 & 14,08 & 16,20 & $\mathbf{1 8 , 9 0}$ & $\mathbf{2 1 , 4 4}$ & 22,55 & $\mathbf{2 3 , 3 0}$ & \\
N. Zealand & L3.1 & 7.86 & 9.11 & 10.31 & 11.83 & 13.19 & 13.14 & $\mathbf{1 2 . 6 9}$ & \\
N. Zealand & L3.2 & 4.09 & 4.97 & 5.89 & 7.07 & 8.25 & 9.41 & $\mathbf{1 0 . 6 1}$ & \\
UK & L3 & 3.88 & 6.25 & 8.63 & $\mathbf{1 1 . 0 0}$ & 12.88 & 14.75 & $\mathbf{1 6 . 6 3}$ & \\
UK & L3.1 & 2.08 & 3.13 & 4.18 & 5.23 & 5.78 & 6.34 & $\mathbf{6 . 8 9}$ & \\
UK & L3.2 & $\mathbf{1 . 8 0}$ & 3.12 & 4.45 & 5.77 & 7.09 & 8.41 & $\mathbf{9 . 7 4}$ & \\
Switzerland & L3 & $\mathbf{9 . 4 0}$ & 11.11 & 12.82 & 14.53 & 16.24 & 17.95 & $\mathbf{1 9 . 6 6}$ & \\
Switzerland & L3.1 & 7.96 & 8.94 & 9.92 & 10.65 & 11.39 & 12.12 & $\mathbf{1 2 . 8 5}$ & \\
Switzerland & L3.2 & 1.44 & 2.17 & $\mathbf{2 . 9 0}$ & 3.88 & 4.85 & 5.83 & $\mathbf{6 . 8 0}$ & \\
Austria & L3 & 4.12 & 4.50 & 4.88 & 6.03 & 7.36 & 9.23 & 11.24 & $\mathbf{1 2 . 4 0}$ \\
Austria & L3.1 & 1.96 & 2.14 & 2.32 & 2.87 & 3.50 & 4.39 & 5.35 & $\mathbf{5 . 9 0}$ \\
Austria & L3.2 & $\mathbf{2 . 1 6}$ & 2.36 & $\mathbf{2 . 5 6}$ & 3.16 & 3.86 & 4.84 & 5.89 & $\mathbf{6 . 5 0}$ \\
Australia & L3 & 15.66 & 18.79 & $\mathbf{2 1 . 5 0}$ & 23.88 & 26.25 & 28.63 & $\mathbf{3 1 . 0 0}$ & \\
Australia & L3.1 & 12.02 & 14.09 & 15.74 & 17.06 & 18.37 & 19.69 & $\mathbf{2 1 . 0 0}$ & \\
Australia & L3.2 & 3.64 & $\mathbf{4 . 7 0}$ & 5.76 & 6.82 & 7.88 & 8.94 & $\mathbf{1 0 . 0 0}$ & \\
Germany & L3 & 6.64 & 7.57 & $\mathbf{8 . 5 0}$ & 12.21 & 14.93 & 18.14 & $\mathbf{2 1 . 3 6}$ & \\
Germany & L3.1 & 4.22 & 4.81 & 5.40 & 6.71 & 8.03 & 9.38 & $\mathbf{1 0 . 7 3}$ & \\
Germany & L3.2 & 2.42 & 2.76 & $\mathbf{3 . 1 0}$ & 5.50 & $\mathbf{6 . 9 0}$ & 8.76 & $\mathbf{1 0 . 6 3}$ & \\
Canada & L3 & 25.03 & 26.88 & 28.73 & $\mathbf{3 0 . 7 5}$ & $\mathbf{3 6 . 1 5}$ & 38.75 & $\mathbf{4 0 . 4 3}$ & \\
Canada & L3.1(5) & 11.93 & 12.82 & 13.70 & 14.66 & 18.65 & 19.75 & 19.45 & \\
Canada & L3.1(6) & 6.60 & 6.87 & 7.14 & 7.49 & 8.20 & $\mathbf{9 . 0 1}$ & $\mathbf{9 . 8 1}$ & \\
Canada & L3.2 & $\mathbf{6 . 5 0}$ & 7.20 & 7.90 & 8.60 & 9.30 & $\mathbf{9 . 9 9}$ & $\mathbf{1 1 . 1 7}$ & \\
Canada & UNIV & $\mathbf{1 3 . 1 0}$ & 14.07 & 15.03 & $\mathbf{1 6 . 0 0}$ & 17.50 & $\mathbf{1 9 . 0 0}$ & $\mathbf{2 0 . 9 8}$ & \\
& & & & & & & & &
\end{tabular}

- Note: Character types are used to indicate the quality of the data. A bold character indicates a direct census or survey observation (or interpolation from census or survey data no more than two years away in time). Bold italic indicates that we are using census or survey data (usually from Unesco or DYB compilations) after reinterpreting it as an attainment category slightly different from the one reported in the original source. Italics are used for educated guesses based on census or survey information (e.g. when we apply ratios from a census source to census totals to break down an attainment category into subcategories). The rest of the observations are interpolations or more uncertain estimates. 
Table A2: Secondary attainment levels

\begin{tabular}{|c|c|c|c|c|c|c|c|c|c|}
\hline country & level & 1960 & 1965 & 1970 & 1975 & 1980 & 1985 & 1990 & 1995 \\
\hline USA & L.2 & 75.20 & 74.90 & 73.50 & 69.50 & 64.80 & 61.60 & 58.40 & \\
\hline USA & L2.1 & 31.40 & 26.20 & 22.40 & 17.70 & 14.10 & 11.20 & 8.80 & \\
\hline USA & L2.2 & 43.80 & 48.70 & 51.10 & 51.80 & 50.70 & 50.40 & 49.60 & \\
\hline Neth. & L. 2 & 40.60 & 46.00 & 51.39 & 55.18 & 58.57 & 61.96 & 65.35 & \\
\hline Neth. & L2.1 & 33.50 & 37.81 & 42.13 & 40.12 & 36.52 & 32.93 & 29.34 & \\
\hline Neth. & L2.2 & 7.10 & 8.18 & 9.26 & 15.07 & 22.05 & 29.03 & 36.01 & \\
\hline Italy & L2 & 12.73 & 18.30 & 23.87 & 29.06 & 34.25 & 40.88 & 47.87 & \\
\hline Italy & L2.1 & 8.82 & 12.59 & 16.34 & 19.74 & 23.13 & 26.56 & 30.00 & \\
\hline Italy & L2.2 & 3.91 & 5.71 & 7.53 & 9.32 & 11.12 & 14.32 & 17.87 & \\
\hline Belgium & L2 & 27.55 & 31.05 & 34.55 & 40.07 & 45.59 & 48.345 & 50.414 & \\
\hline Belgium & L2.1 & 22.14 & 23.14 & 24.13 & 25.99 & 27.85 & 29.11 & 30.223 & \\
\hline Belgium & L2.2 & 5.41 & 7.91 & 10.41 & 14.07 & 17.74 & 19.235 & 20.191 & \\
\hline Spain & L2 & 4.20 & 5.03 & 5.85 & 9.21 & 12.57 & 19.74 & 27.86 & \\
\hline Spain & L2.1 & 2.17 & 2.71 & 3.24 & 5.21 & 7.18 & 10.95 & 15.17 & \\
\hline Spain & L2.2 & 2.03 & 2.32 & 2.61 & 4.00 & 5.39 & 8.79 & 12.69 & \\
\hline Greece & L2 & 12.53 & 13.75 & 14.97 & 16.89 & 19.00 & 22.30 & 25.89 & \\
\hline Greece & L2.1 & 4.31 & 4.58 & 4.86 & 5.34 & 5.87 & 6.10 & 6.24 & \\
\hline Greece & L2.2 & 8.22 & 9.17 & 10.11 & 11.56 & 13.13 & 16.20 & 19.65 & \\
\hline Portugal & L2 & 6.40 & 6.60 & 6.80 & 8.53 & 10.25 & 12.28 & 14.38 & \\
\hline Portugal & L2.1 & 2.90 & 3.07 & 3.24 & 4.19 & 5.13 & 6.30 & 7.53 & \\
\hline Portugal & L2.2 & 3.50 & 3.53 & 3.56 & 4.34 & 5.12 & 5.98 & 6.85 & \\
\hline France & L2 & 47.45 & 53.99 & 59.28 & 62.70 & 61.38 & 60.06 & 58.74 & \\
\hline France & L2.1 & 36.18 & 40.31 & 41.40 & 37.95 & 33.68 & 29.41 & 25.15 & \\
\hline France & L2.2 & 11.27 & 13.69 & 17.89 & 24.75 & 27.70 & 30.64 & 33.59 & \\
\hline Ireland & L2 & 23.21 & 26.00 & 30.09 & 34.50 & 38.92 & 42.36 & 45.56 & \\
\hline Ireland & L2.1 & 12.55 & 13.50 & 14.86 & 16.32 & 17.79 & 18.49 & 19.00 & \\
\hline Ireland & L2.2 & 10.66 & 12.50 & 15.23 & 18.18 & 21.13 & 23.87 & 26.56 & \\
\hline Sweden & L2 & 30.22 & 33.80 & 37.38 & 40.68 & 43.97 & 47.27 & 50.56 & 53.20 \\
\hline Sweden & L2.1 & 7.25 & 8.39 & 9.53 & 9.84 & 10.14 & 10.45 & 10.76 & 11.00 \\
\hline Sweden & L2.2 & 22.97 & 25.41 & 27.85 & 30.84 & 33.83 & 36.82 & 39.81 & 42.20 \\
\hline Norway & L2 & 24.28 & 29.14 & 34.00 & 38.86 & 44.06 & 49.99 & 53.23 & \\
\hline Norway & L2.1 & 7.98 & 9.04 & 10.10 & 11.36 & 11.96 & 11.69 & 11.83 & \\
\hline Norway & L2.2 & 16.30 & 20.10 & 23.90 & 27.50 & 32.10 & 38.30 & 41.40 & \\
\hline Denmark & L2 & 38.73 & 40.83 & 42.93 & 46.41 & 49.64 & 51.83 & 52.44 & \\
\hline Denmark & L2.1 & 6.05 & 6.79 & 7.54 & 8.29 & 8.79 & 9.56 & 10.70 & \\
\hline Denmark & L2.2 & 32.68 & 34.04 & 35.40 & 38.12 & 40.85 & 42.27 & 41.75 & \\
\hline
\end{tabular}


Table A2: Secondary attainment levels (continued)

\begin{tabular}{|c|c|c|c|c|c|c|c|c|c|}
\hline country & level & 1960 & 1965 & 1970 & 1975 & 1980 & 1985 & 1990 & 1995 \\
\hline Finland & L2 & 27.80 & 29.13 & 30.47 & 33.68 & 36.90 & 40.59 & 44.28 & \\
\hline Finland & L2.1 & 6.00 & 6.23 & 6.47 & 7.08 & 7.70 & 8.39 & 9.08 & \\
\hline Finland & $\mathrm{L} 2.2$ & 21.80 & 22.90 & 24.00 & 26.60 & 29.20 & 32.20 & 35.20 & \\
\hline Japan & L2 & 38.70 & 43.43 & 48.30 & 52.54 & 56.77 & 60.87 & 64.96 & \\
\hline Japan & L2.1 & 7.80 & 10.43 & 13.07 & 15.07 & 17.07 & 18.77 & 20.46 & \\
\hline Japan & $\mathrm{L} 2.2$ & 30.90 & 33.00 & 35.23 & 37.47 & 39.70 & 42.10 & 44.50 & \\
\hline N.Zealand & $\mathrm{L} 2$ & 53.82 & 54.80 & 55.78 & 56.77 & 57.75 & 58.70 & 59.63 & \\
\hline N.Zealand & $\mathrm{L} 2.1$ & 21.11 & 21.49 & 21.88 & 22.27 & 22.65 & 18.71 & 13.52 & \\
\hline N.Zealand & $\mathrm{L} 2.2$ & 32.71 & 33.31 & 33.90 & 34.50 & 35.10 & 39.99 & 46.11 & \\
\hline UK & $\mathrm{L} 2$ & 39.38 & 43.58 & 47.24 & 53.18 & 58.05 & 62.26 & 65.57 & \\
\hline UK & L2.1 & 14.88 & 16.88 & 18.34 & 19.49 & 19.58 & 19 & 17.53 & \\
\hline UK & $\mathrm{L} 2.2$ & 24.50 & 26.70 & 28.90 & 33.69 & 38.47 & 43.26 & 48.04 & \\
\hline Switzerl. & $\mathrm{L} 2$ & 41.68 & 47.77 & 53.27 & 58.16 & 62.38 & 67.94 & 72.15 & \\
\hline Switzerl. & L2.1 & 19.88 & 20.79 & 21.12 & 20.83 & 19.88 & 17.49 & 13.74 & \\
\hline Switzerl. & $\mathrm{L} 2.2$ & 21.80 & 26.98 & 32.15 & 37.33 & 42.50 & 50.45 & 58.41 & \\
\hline Austria & $\mathrm{L} 2$ & 47.9 & 49.65 & 50.05 & 53.8 & 57.99 & 61.58 & 64.63 & \\
\hline Austria & $\mathrm{L} 2.1$ & 16.14 & 17.08 & 16.67 & 17.24 & 17.66 & 17.82 & 17.53 & \\
\hline Austria & $\mathrm{L} 2.2$ & 31.76 & 32.57 & 33.38 & 36.56 & 40.33 & 43.76 & 47.10 & 51.5 \\
\hline Australia & $\mathrm{L} 2$ & 37.92 & 43.11 & 48.30 & 49.98 & 51.65 & 53.33 & 55.00 & \\
\hline Australia & L2.1 & 20.69 & 23.52 & 26.35 & 27.26 & 28.17 & 29.09 & 30.00 & \\
\hline Australia & $\mathrm{L} 2.2$ & 17.24 & 19.60 & 21.95 & 22.72 & 23.48 & 24.24 & 25.00 & \\
\hline Germany & $\mathrm{L} 2$ & 53.60 & 55.70 & 57.80 & 64.75 & 71.70 & 74.57 & 77.43 & \\
\hline Germany & L2.1 & 14.28 & 14.84 & 15.40 & 17.25 & 19.10 & 18.60 & 18.10 & \\
\hline Germany & $\mathrm{L} 2.2$ & 39.32 & 40.86 & 42.40 & 47.50 & 52.60 & 55.96 & 59.33 & \\
\hline Canada & $\mathrm{L} 2$ & 67.22 & 66.26 & 65.62 & 64.35 & 60.03 & 57.66 & 55.93 & \\
\hline Canada & L2.1 & 29.32 & 26.44 & 23.88 & 20.68 & 16.30 & 14.89 & 13.36 & \\
\hline Canada & $\mathrm{L} 2.2$ & 37.90 & 39.82 & 41.74 & 43.67 & 43.73 & 42.77 & 42.57 & \\
\hline
\end{tabular}

Table A.3: Illiteracy rates

\begin{tabular}{llrrrrrrr}
\hline country & level & 1960 & 1965 & 1970 & 1975 & 1980 & 1985 & 1990 \\
Italy & L0 & $\mathbf{8 . 5 8}$ & 7.29 & $\mathbf{6 . 0 0}$ & $\mathbf{5 . 1 0}$ & $\mathbf{3 . 4 1}$ & 2.698 & $\mathbf{2 . 2 3}$ \\
Spain & L0 & $\mathbf{1 1 . 2 0}$ & 10.63 & 10.05 & 9.48 & $\mathbf{8 . 9 0}$ & 7.01 & $\mathbf{4 . 7 9}$ \\
Greece & L0 & $\mathbf{2 3 . 9 2}$ & 20.81 & $\mathbf{1 7 . 6 9}$ & 14.78 & $\mathbf{1 1 . 9 2}$ & 10.35 & $\mathbf{9 . 0 9}$ \\
Portugal & L0 & 34.00 & 30.20 & $\mathbf{2 6 . 4 0}$ & $\mathbf{2 2 . 6 0}$ & $\mathbf{1 8 . 3 0}$ & $\mathbf{1 5 . 7 0}$ & $\mathbf{1 2 . 8 0}$ \\
\hline
\end{tabular}


Table A.4: Average years of schooling

\begin{tabular}{lrrrrrrr}
\hline & 1960 & 1965 & 1970 & 1975 & 1980 & 1985 & 1990 \\
Australia & 10.15 & 10.67 & 11.15 & 11.43 & 11.71 & 12.00 & 12.28 \\
Austria & 9.12 & 9.24 & 9.33 & 9.68 & 10.09 & 10.53 & 10.95 \\
Belgium & 7.55 & 7.81 & 8.07 & 8.61 & 9.16 & 9.47 & 9.76 \\
Canada & 11.54 & 11.74 & 11.96 & 12.16 & 12.54 & 12.69 & 12.80 \\
Denmark & 9.09 & 9.46 & 9.83 & 10.21 & 10.58 & 10.84 & 10.93 \\
Finland & 7.88 & 8.05 & 8.22 & 8.68 & 9.13 & 9.50 & 9.87 \\
France & 8.13 & 8.57 & 9.04 & 9.57 & 9.86 & 10.16 & 10.45 \\
Germany & 9.17 & 9.46 & 9.74 & 10.76 & 11.66 & 12.32 & 12.99 \\
Greece & 5.56 & 5.87 & 6.18 & 6.62 & 7.09 & 7.51 & 7.91 \\
Ireland & 7.38 & 7.55 & 7.84 & 8.17 & 8.49 & 8.94 & 9.41 \\
Italy & 5.42 & 5.83 & 6.25 & 6.63 & 7.05 & 7.52 & 8.01 \\
Japan & 8.67 & 9.01 & 9.37 & 9.79 & 10.21 & 10.73 & 11.24 \\
Netherlands & 8.11 & 8.48 & 8.85 & 9.35 & 9.88 & 10.42 & 10.95 \\
Norway & 7.60 & 7.97 & 8.35 & 8.78 & 9.29 & 9.88 & 10.25 \\
New Zealand & 10.46 & 10.72 & 10.98 & 11.30 & 11.60 & 11.86 & 12.11 \\
Portugal & 4.37 & 4.62 & 4.87 & 5.29 & 5.73 & 6.06 & 6.41 \\
Spain & 4.97 & 5.08 & 5.19 & 5.53 & 5.87 & 6.45 & 7.10 \\
Sweden & 8.04 & 8.30 & 8.57 & 9.03 & 9.49 & 9.96 & 10.42 \\
Switzerland & 9.08 & 9.64 & 10.20 & 10.73 & 11.24 & 11.91 & 12.53 \\
USA & 11.44 & 11.69 & 11.93 & 12.24 & 12.53 & 12.74 & 12.91 \\
UK & 8.26 & 8.67 & 9.06 & 9.60 & 10.07 & 10.51 & 10.94 \\
\hline
\end{tabular}


Table A.6: Data sources and construction, university attainment

\begin{tabular}{|c|c|c|c|c|c|c|c|c|c|c|c|c|c|c|c|c|}
\hline country & level & 1960 & 1961 & 1965 & 1966 & 1968 & 1970 & 1971 & 1975 & 1980 & 1981 & 1985 & 1989 & 1990 & 1991 & 1995 \\
\hline USA & L3.1 & $\mathrm{NC}$ & & $\mathrm{NC}$ & & & $\mathrm{NC}$ & & $\mathrm{NC}$ & $\mathrm{NC}$ & & $\mathrm{NC}$ & & $\mathrm{NC}$ & & $\mathrm{NC}$ \\
\hline USA & L3.2 & $\mathrm{NC}$ & & $\mathrm{NC}$ & & & $\mathrm{NC}$ & & $\mathrm{NC}$ & $\mathrm{NC}$ & & $\mathrm{NC}$ & & $\mathrm{NC}$ & & $\mathrm{NC}$ \\
\hline Netherlands & L3.1 & $\mathrm{NC}$ & & int & & & int & $\mathrm{NC}$ & int & int & & int & & $\mathrm{NC}$ & & \\
\hline Netherlands & L3.2 & $\mathrm{NC}$ & & int & & & int & $\mathrm{NC}$ & int & int & & int & & $\mathrm{NC}$ & & \\
\hline Italy & L3.2 & UNE & & int & & & DYB & & int & DYB & & int & EAG & ext & & \\
\hline Belgium & L3 & est & & int & & & est (NC) & & int & est (NC) & & int & EAG & ext & & \\
\hline Belgium & L3.1 & est & & int & & & est (NC) & & int & est (NC) & & int & EAG & ext & & \\
\hline Belgium & L3.2 & UNE & & int & & & DYB & & int & int & & int & EAG & ext & & \\
\hline Spain & L3.1 & BP & & int & & & $\mathrm{NC}$ & & int & int & $\mathrm{NC}$ & int & & int & $\mathrm{NC}$ & \\
\hline Spain & L 3.2 & $\mathrm{BP}$ & & int & & & $\mathrm{NC}$ & & int & int & $\mathrm{NC}$ & int & & int & $\mathrm{NC}$ & \\
\hline Greece & L3.1 & ext & $\mathrm{BP}$ & int & & & int & $\mathrm{BP}$ & int & int & $\mathrm{NC}$ & int & & int & $\mathrm{NC}$ & \\
\hline Greece & L3.2 & ext & $\mathrm{BP}$ & int & & & int & $\mathrm{BP}$ & int & int & $\mathrm{NC}$ & int & & int & $\mathrm{NC}$ & \\
\hline Portugal & L3 & DYB & & int & & & est & & int & & est & int & & int & OECD95 & \\
\hline Portugal & L3.1 & est & & int & & & est & & int & & est & int & & int & OECD95 & \\
\hline Portugal & L3.2 & UNE & & int & & & UNE & & int & int & UNE & int & & int & OECD95 & \\
\hline France & L3 & BP & & int & & $\mathrm{NC}$ & int & & $\mathrm{NC}$ & int & & int & & $\mathrm{NC}$ & & \\
\hline France & L3.1 & $\mathrm{BP}$ & & int & & $\mathrm{NC}$ & int & & $\mathrm{NC}$ & int & & int & & $\mathrm{NC}$ & & \\
\hline France & L3.2 & BP & & int & & $\mathrm{NC}$ & int & & $\mathrm{NC}$ & int & & int & & $\mathrm{NC}$ & & \\
\hline Ireland & L3 & ext & $\mathrm{BP}$ & int & $\mathrm{NC}$ & & int & & int & int & UNE & int & & int & UNE & \\
\hline Ireland & L3.1 & ext & est & int & est & & int & & int & int & est & int & & int & $\begin{array}{c}\text { est } \\
\text { (OECD95) }\end{array}$ & \\
\hline Ireland & L3.2 & ext & est & int & est & & int & & int & int & est & int & & int & $\begin{array}{c}\text { est } \\
\text { (OECD95) }\end{array}$ & \\
\hline
\end{tabular}


Table A.6: Data sources and construction, university attainment (continued)

\begin{tabular}{|c|c|c|c|c|c|c|c|c|c|c|c|c|c|c|c|}
\hline country & level & 1960 & 1965 & 1970 & 1973 & 1975 & 1980 & 1981 & 1983 & 1985 & 1988 & 1990 & 1991 & 1992 & 1994 \\
\hline Sweden & L3 & $\mathrm{BP}$ & int & $\mathrm{NC}$ & & int & int & & & int & & int & & & $\mathrm{NC}$ \\
\hline Sweden & L3.1 & BP & est & $\mathrm{NC}$ & & est & est & & & est & & est & & & $\mathrm{NC}$ \\
\hline Sweden & L3.2 & BP & est & $\mathrm{NC}$ & & est & est & & & est & & est & & & $\mathrm{NC}$ \\
\hline Norway & L3 & $\mathrm{NC}$ & int & $\mathrm{NC}$ & & $\mathrm{NC}$ & $\mathrm{NC}$ & & & $\mathrm{NC}$ & & $\mathrm{NC}$ & & & \\
\hline Norway & L3.1 & est & int & est & & est & est & & & est & & est (EdNC) & & & \\
\hline Norway & L3.2 & est & int & est & & est & est & & & est & & est (EdNC) & & & \\
\hline Denmark & L3 & $\begin{array}{c}\text { est } \\
\text { (OECD74) }\end{array}$ & int & ext & $\mathrm{BP}$ & int & int & & $\mathrm{NC}$ & int & $\mathrm{NC}$ & int & $\mathrm{NC}$ & & \\
\hline Denmark & L3.1 & est & int & ext & BP & int & int & & $\mathrm{NC}$ & int & $\mathrm{NC}$ & int & $\mathrm{NC}$ & & \\
\hline Denmark & L3.2 & est & int & ext & $\mathrm{BP}$ & int & int & & $\mathrm{NC}$ & int & $\mathrm{NC}$ & int & $\mathrm{NC}$ & & \\
\hline Finland & L3 & UNE & int & UNE & & int & UNE & & & UNE & & UNE & & & \\
\hline Finland & L3.1 & est & int & est & & int & est & & & est & & $\mathrm{Ed}$ in $\mathrm{NC}$ & & & \\
\hline Finland & L3.2 & est & int & est & & int & est & & & est & & $\mathrm{Ed}$ in $\mathrm{NC}$ & & & \\
\hline Japan & L3 & DYB & int & DYB & & int & UNE & & & int & & UNE & & & \\
\hline Japan & L3.1 & est & int & est & & int & est & & & int & & EAG89 & & & \\
\hline Japan & L3.2 & est & int & UNE & & int & est & & & int & & EAG89 & & & \\
\hline New Zealand & L3 & ext & ext & ext & & $\mathrm{NC}$ & int & $\mathrm{NC}$ & & int & & int & & OECD95 & \\
\hline New Zealand & L3.1 & est & est & est & & est & est & est & & est & & est & & OECD95 & \\
\hline New Zealand & L3.2 & est & $\mathrm{NC}$ & $\mathrm{NC}$ & & int & int & int & & int & & int & & OECD95 & \\
\hline UK & L3 & est & int & int & & UNE & int & & & int & & int & EAG91 & & \\
\hline UK & L3.1 & est & int & int & & est & int & & & int & & int & EAG91 & & \\
\hline UK & L3.2 & UNE & int & int & & int & int & & & int & & int & EAG91 & & \\
\hline
\end{tabular}


Table A.6: Data sources and construction, university attainment (continued)

\begin{tabular}{|c|c|c|c|c|c|c|c|c|c|c|c|c|c|c|c|c|}
\hline country & level & 1960 & 1961 & 1965 & 1970 & 1971 & 1975 & 1976 & 1980 & 1981 & 1985 & 1986 & 1990 & 1991 & 1992 & 1995 \\
\hline Switzerland & L3 & UNE & & int & int & & int & & int & & int & & int & EAG91 & & \\
\hline Switzerland & L3.1 & est & & est & est & & est & & est & & est & & est & EAG91 & & \\
\hline Switzerland & L3.2 & est & & est & UNE & & int & & int & & int & & int & EAG91 & & \\
\hline Austria & L3 & ext & est & int & int & est & int & & int & est & int & & int & est & & $\mathrm{NC}$ \\
\hline Austria & L3.1 & ext & est & int & int & est & int & & int & est & int & & int & est & & $\mathrm{NC}$ \\
\hline Austria & L3.2 & ext & UNE & int & int & UNE & int & & int & UNE & int & & int & UNE & & $\mathrm{NC}$ \\
\hline Australia & L3 & est & & est & UNE & & int & & int & & int & & EAG & & & \\
\hline Australia & L3.1 & est & & est & est & & est & & est & & est & & EAG & & & \\
\hline Australia & L3.2 & ext & & UNE & int & & int & & int & & int & & EAG & & & \\
\hline Germany & L3 & $\begin{array}{c}\text { est } \\
\text { (OECD74) }\end{array}$ & & est & DYB & & int & & int & & int & & int & EAG91 & & \\
\hline Germany & L3.1 & est & & est & est & & est & & est & & est & & est & EAG91 & & \\
\hline Germany & L3.2 & est & & est & UNE & & SJ & & SJ & & int & & int & EAG91 & & \\
\hline Canada & L3 & est & & est & est & & est & UNE & int & UNE & int & int & int & int & OECD95 & \\
\hline Canada & L3.1(5) & est & & est & est & & est & est & int & & int & est & int & est & & \\
\hline Canada & UNIV* & UNE & & int & int & & int & DYB & int & & int & UNE & int & UNE & & \\
\hline Canada & L3.1(6) & est & & est & est & & est & est & int & & int & est & int & est & & \\
\hline Canada & L3.2 & DYB & & int & int & & int & int & int & & int & $\mathrm{NC}$ & int & $\mathrm{NC}$ & & \\
\hline
\end{tabular}

$\left(^{*}\right)$ UNIV = university attainment, excluding upper level vocational training (isced 5) = L3.1(6) + L3.1.

- Key: NC = national census or survey data, or national statistical yearbook; DYB = UN Demographic Yearbook; UNE = Unesco Yearbook; EAG = OECD,

Education at a Glance; OECD95 = OECD (1995); B\&L = Barro and Lee (1996); EdinNC = Educational indicators in the nordic countries (1974); SJ = Statistiches Jahrbuch, as reported in Barro and Lee.

int = interpolation between available observations; ext = extrapolation (forward or backward); est = indirect estimate; BP = Backward projection using census or survey data disaggregated by age. 
Table A.7: Data sources and construction, secondary attainment

\begin{tabular}{|c|c|c|c|c|c|c|c|c|c|c|c|c|c|c|c|c|}
\hline country & level & 1960 & 1961 & 1965 & 1966 & 1968 & 1970 & 1971 & 1975 & 1980 & 1981 & 1985 & 1989 & 1990 & 1991 & 1995 \\
\hline USA & L2.1 & $\mathrm{NC}$ & & $\mathrm{NC}$ & & & $\mathrm{NC}$ & & $\mathrm{NC}$ & $\mathrm{NC}$ & & $\mathrm{NC}$ & & $\mathrm{NC}$ & & $\mathrm{NC}$ \\
\hline USA & L2.2 & $\mathrm{NC}$ & & $\mathrm{NC}$ & & & $\mathrm{NC}$ & & $\mathrm{NC}$ & $\mathrm{NC}$ & & $\mathrm{NC}$ & & $\mathrm{NC}$ & & $\mathrm{NC}$ \\
\hline Neth & L2.1 & $\mathrm{NC}$ & & int & & & int & $\mathrm{NC}$ & int & int & & int & & $\mathrm{NC}$ & & \\
\hline Neth & $\mathrm{L} 2.2$ & $\mathrm{NC}$ & & int & & & int & $\mathrm{NC}$ & int & int & & int & & $\mathrm{NC}$ & & \\
\hline Italy & $\mathrm{L} 2$ & ext & $\mathrm{NC}$ & int & & & DYB & int & int & int & $\mathrm{NC}$ & int & & int & $\mathrm{NC}$ & \\
\hline Italy & L2.1 & ext & $\mathrm{NC}$ & int & & & est & int & int & int & $\mathrm{NC}$ & int & & int & $\mathrm{NC}$ & \\
\hline Italy & L2.2 & ext & $\mathrm{NC}$ & int & & & est & int & int & int & $\mathrm{NC}$ & int & & int & $\mathrm{NC}$ & \\
\hline Belgium & L2.1 & ext & $\mathrm{NC}$ & int & & & $\mathrm{NC}$ & int & int & int & $\mathrm{NC}$ & int & EAG & ext & & \\
\hline Belgium & L2.2 & ext & $\mathrm{NC}$ & int & & & $\mathrm{NC}$ & int & int & int & $\mathrm{NC}$ & int & EAG & ext & & \\
\hline Spain & L2.1 & BP & & int & & & $\mathrm{NC}$ & & int & int & $\mathrm{NC}$ & int & & int & $\mathrm{NC}$ & \\
\hline Spain & L2.2 & BP & & int & & & $\mathrm{NC}$ & & int & int & $\mathrm{NC}$ & int & & int & $\mathrm{NC}$ & \\
\hline Greece & L3.1 & ext & $\mathrm{BP}$ & int & & & int & $\mathrm{BP}$ & int & int & $\mathrm{NC}$ & int & & int & $\mathrm{NC}$ & \\
\hline Greece & L3.2 & ext & BP & int & & & int & BP & int & int & $\mathrm{NC}$ & int & & int & $\mathrm{NC}$ & \\
\hline Portugal & $\mathrm{L} 2$ & DYB & & int & & & UNE & & int & & UNE & int & & int & UNE & \\
\hline Portugal & L2.1 & est & & int & & & est & & int & & est & int & & int & $\begin{array}{c}\text { est } \\
\text { (OECD) }\end{array}$ & \\
\hline Portugal & L2.2 & UNE & & int & & & est & & int & int & est & int & & int & $\begin{array}{c}\text { est } \\
\text { (OECD) }\end{array}$ & \\
\hline France & L2 & BP & & int & & $\mathrm{NC}$ & int & & $\mathrm{NC}$ & int & & int & EAG & ext & & \\
\hline France & L2.1 & BP & & int & & $\mathrm{NC}$ & int & & $\mathrm{NC}$ & int & & int & EAG & ext & & \\
\hline France & L2.2 & $\mathrm{BP}$ & & int & & $\mathrm{NC}$ & int & & $\mathrm{NC}$ & int & & int & EAG & ext & & \\
\hline Ireland & L2 & ext & $\mathrm{BP}$ & int & $\mathrm{NC}$ & & int & & int & int & UNE & int & & int & UNE & \\
\hline Ireland & L2.1 & ext & est & int & est & & int & & int & int & est & int & & int & $\begin{array}{c}\text { est } \\
\text { (OECD) }\end{array}$ & \\
\hline Ireland & $\mathrm{L} 2.2$ & ext & est & int & est & & int & & int & int & est & int & & int & $\begin{array}{c}\text { est } \\
\text { (OECD) }\end{array}$ & \\
\hline
\end{tabular}


Table A.7: Data sources and construction, secondary attainment (continued)

\begin{tabular}{|c|c|c|c|c|c|c|c|c|c|c|c|c|c|}
\hline country & level & 1960 & 1965 & 1970 & 1973 & 1975 & 1980 & 1981 & 1983 & 1985 & 1990 & 1991 & 1994 \\
\hline Sweden & $\mathrm{L} 2$ & $\mathrm{BP}$ & int & $\mathrm{NC}$ & & int & int & & & int & int & & $\mathrm{NC}$ \\
\hline Sweden & $\mathrm{L} 2.1$ & $\mathrm{BP}$ & int & $\mathrm{NC}$ & & int & int & & & int & int & & $\mathrm{NC}$ \\
\hline Sweden & $\mathrm{L} 2.2$ & $\mathrm{BP}$ & int & $\mathrm{NC}$ & & int & int & & & int & int & & $\mathrm{NC}$ \\
\hline Norway & $\mathrm{L} 2$ & est & est & est & & est & est & & & est & est & & \\
\hline Norway & L2.1 & est & est & est & & est & est & & & est & est & & \\
\hline Norway & $\mathrm{L} 2.2$ & $\mathrm{NC}$ & int & $\mathrm{NC}$ & & $\mathrm{NC}$ & $\mathrm{NC}$ & & & $\mathrm{NC}$ & $\mathrm{NC}$ & & \\
\hline Norway & $\mathrm{L} 1+\mathrm{L} 2.1$ & $\mathrm{NC}$ & int & $\mathrm{NC}$ & & $\mathrm{NC}$ & $\mathrm{NC}$ & & & $\mathrm{NC}$ & $\mathrm{NC}$ & & \\
\hline Denmark & $\mathrm{L} 2$ & $\begin{array}{c}\text { est } \\
\text { (OECD74) }\end{array}$ & int & est & est & int & int & & est & int & int & est & \\
\hline Denmark & $\mathrm{L} 2.1$ & est & int & est & est & int & int & & est & int & int & est & \\
\hline Denmark & $\mathrm{L} 2.2$ & est & int & ext & BP & int & int & & $\mathrm{NC}$ & int & int & $\mathrm{NC}$ & \\
\hline Denmark & $\mathrm{L} 1+\mathrm{L} 2.1$ & est & int & ext & $\mathrm{BP}$ & int & int & & $\mathrm{NC}$ & int & int & $\mathrm{NC}$ & \\
\hline Finland & L2 & DYB & int & est & & int & UNE & & & int & est & & \\
\hline Finland & L2.1 & UNE & int & est & & int & UNE & & & int & est & & \\
\hline Finland & L2.2 & est & int & UNE & & int & UNE & & & int & UNE & & \\
\hline Japan & L2 & OECD74 & int & OECD74 & & int & est & & & est & est & & \\
\hline Japan & L2.1 & est & est & est & & int & est & & & est & est & & \\
\hline Japan & $\mathrm{L} 2.2$ & UNE & UNE & int & & int & UNE & & & int & UNE & & \\
\hline New Zealand & $\mathrm{L} 2$ & ext & $\mathrm{NC}$ & int & & int & int & DYB+ & & int & int & OECD95+ & \\
\hline New Zealand & $\mathrm{L} 2.1$ & est & est & est & & est & est & DYB & & int & est & OECD95 & \\
\hline New Zealand & $\mathrm{L} 2.2$ & est & est & est & & est & est & DYB+ & & int & est & OECD95+ & \\
\hline UK & $\mathrm{L} 2.2$ & UNE & int & UNE & & int & int & & & int & int & EAG91 & \\
\hline UK & L2.1 & regr & regr & regr & & regr & regr & & & regr & regr & & \\
\hline
\end{tabular}


Table A.7: Data sources and construction, secondary attainment (continued)

\begin{tabular}{|c|c|c|c|c|c|c|c|c|c|c|c|c|c|c|c|}
\hline country & level & 1960 & 1961 & 1965 & 1970 & 1971 & 1975 & 1976 & 1980 & 1981 & 1985 & 1986 & 1990 & 1991 & 1995 \\
\hline Switzerland & L2 & est & & est & est & & est & & est & & est & & est & & \\
\hline Switzerland & L2.1 & regr & & regr & regr & & regr & & regr & & regr & & regr & & \\
\hline Switzerland & L2.2 & UNE & & int & int & & int & & Kaneko & & int & & int & EAG91 & \\
\hline Austria & L2.2 & ext & $\mathrm{NC}$ & int & int & $\mathrm{NC}$ & int & & int & $\mathrm{NC}$ & int & & int & $\mathrm{NC}$ & $\mathrm{NC}$ \\
\hline Austria & L2.1 & regr & & regr & regr & & regr & & regr & & regr & & regr & & \\
\hline Australia & L2 & ext & & UNE+ & UNE & & int & & int & & int & & EAG & & \\
\hline Australia & L2.1 & ext & & est & est & & est & & est & & est & & EAG & & \\
\hline Australia & L2.2 & ext & & est & est & & est & & est & & est & & EAG & & \\
\hline Germany & L2 & OECD74 & & int & OECD74 & & int & & int & & int & & int & EAG91 & \\
\hline Germany & L2.1 & est & & est & est & & est & & est & & est & & est & EAG91 & \\
\hline Germany & L2. 2 & est & & est & DYB & & int & & DYB & & int & & int & EAG91 & \\
\hline Canada & $\mathrm{L} 2$ & est & & est & est & & est & & est & & est & & est & & \\
\hline Canada & L2.1 & est & & est & est & & est & & est & & est & & est & & \\
\hline Canada & L2.2 & UNE & & int & int & & int & $\mathrm{NC}$ & int & $\mathrm{NC}$ & int & $\mathrm{NC}$ & int & $\mathrm{NC}$ & \\
\hline
\end{tabular}

- Notes: same notation as above, plus Kaneko (1986) and OECD (1974); regr = regression estimate of the ratio L2.1/L2.2; (+) indicates that the given source has been corrected in some way using other information.

Table A.8: Data sources and construction, illiterates (L0)

\begin{tabular}{lccccccccccc}
\hline & 1960 & 1961 & 1965 & 1970 & 1971 & 1975 & 1980 & 1981 & 1985 & 1990 & 1991 \\
Spain & NC & & int & int & & int & int & NC & int & int & NC \\
Italy & ext & NC & int & WDI & & WDI & int & NC & int & int & NC \\
$\begin{array}{l}\text { Portugal } \\
\text { Greece }\end{array}$ & ext & & ext & WDI & & WDI & WDI & & WDI & WDI & int \\
ext & BP & int & int & BP & int & int & NC & int & NC \\
\hline
\end{tabular}

- WDI = World Bank, World Development Indicators1999, Washington D.C. 1999. 
Percentage of population 25 years and over with primary education.
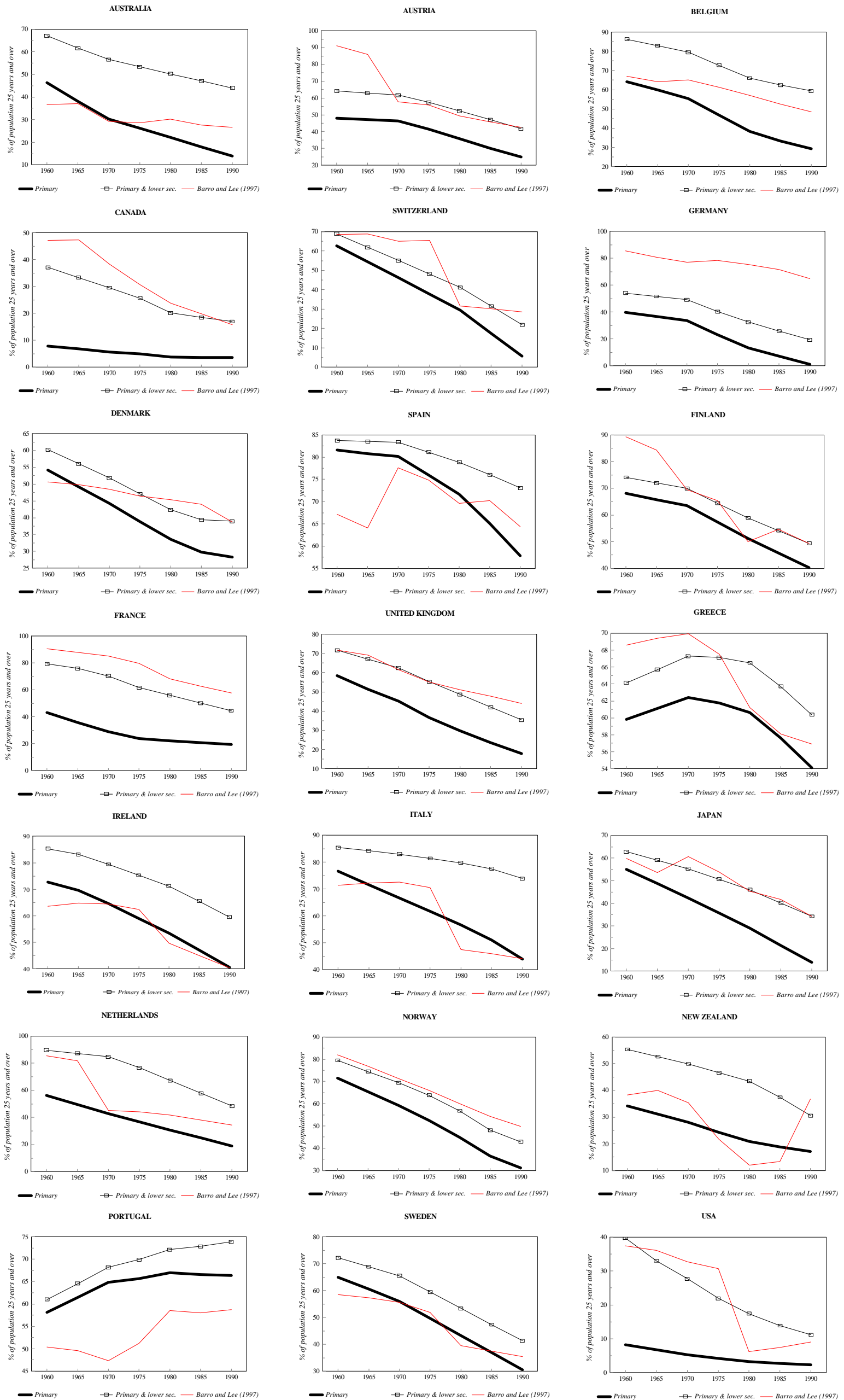
Percentage of population 25 years and over with secondary education.

AUSTRALIA

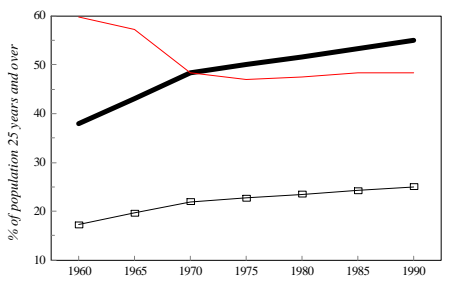

CANADA

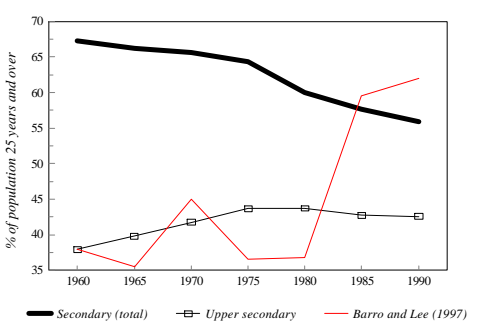

DENMARK

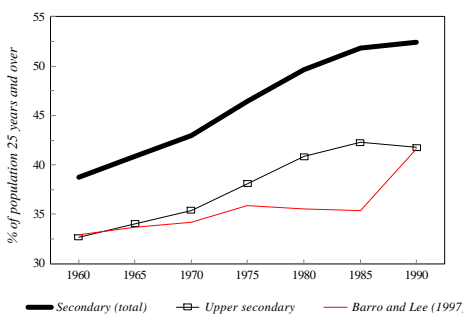

FRANCE

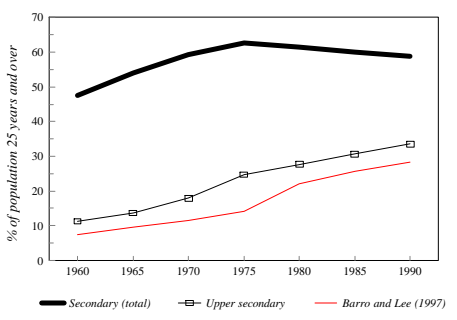

IRELAND
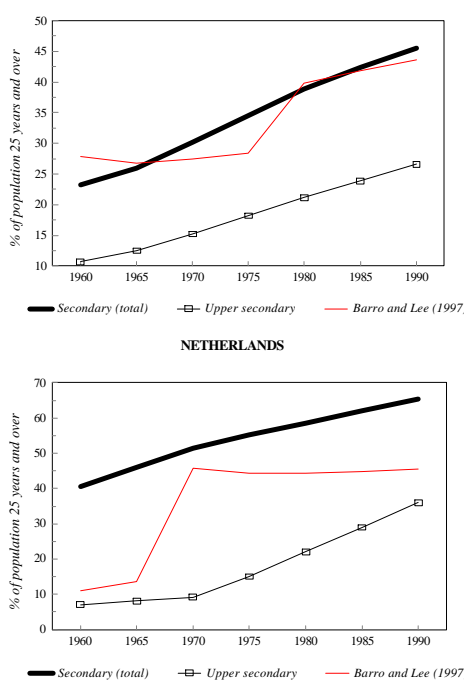

PORTUGAL

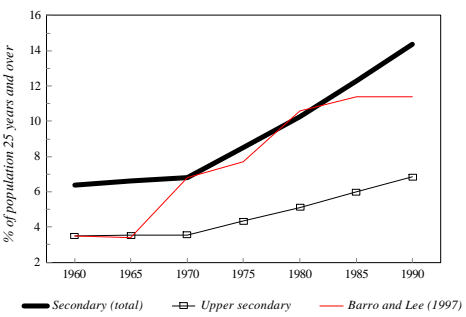

AUSTRIA

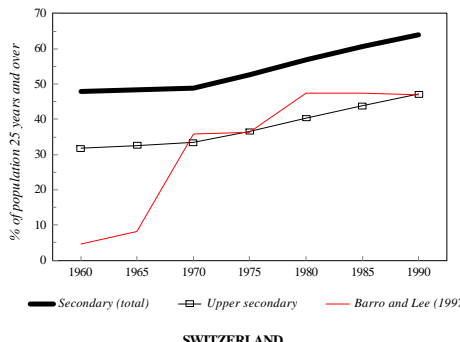

SWITZERLAND

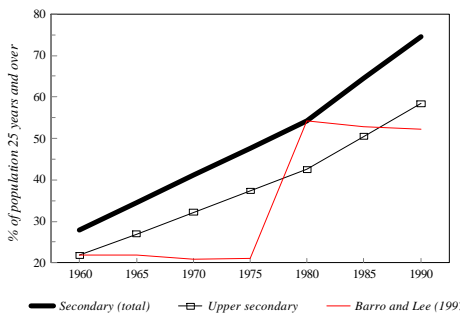

SPAI

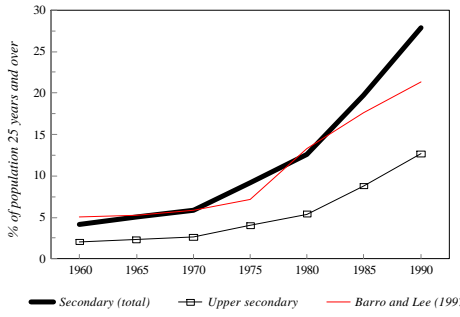

UNITED KINGDOM

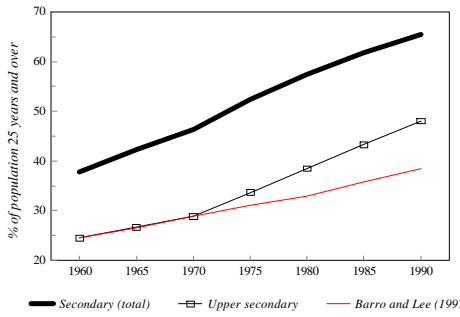

TाM

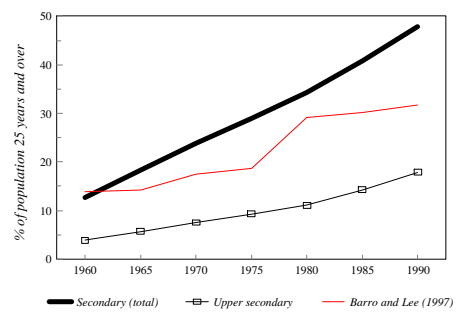

NORWAY

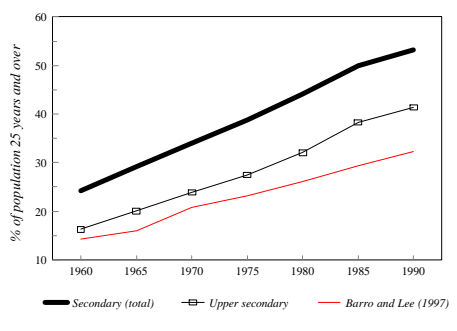

SWEDEN

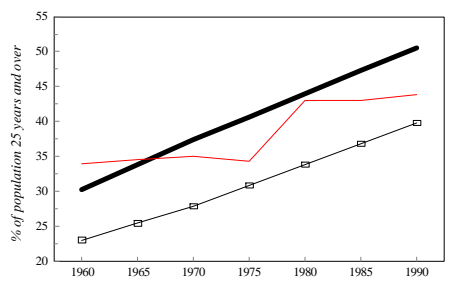

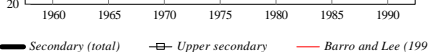

BELGIUM

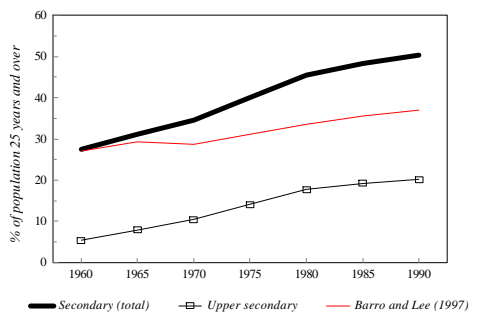

GERMANY

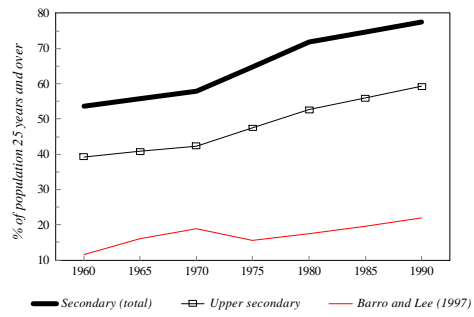

FINLAND
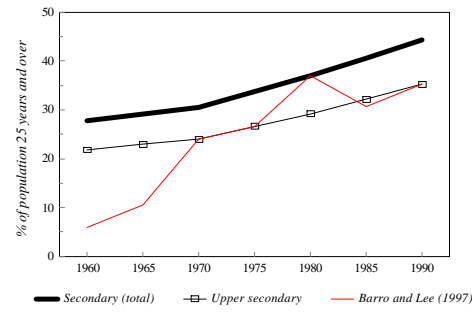

GREECE

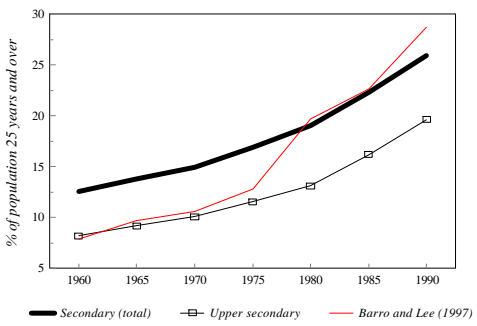

JPPAN

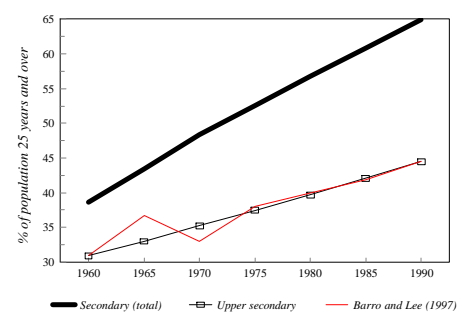

NEW ZEALAND
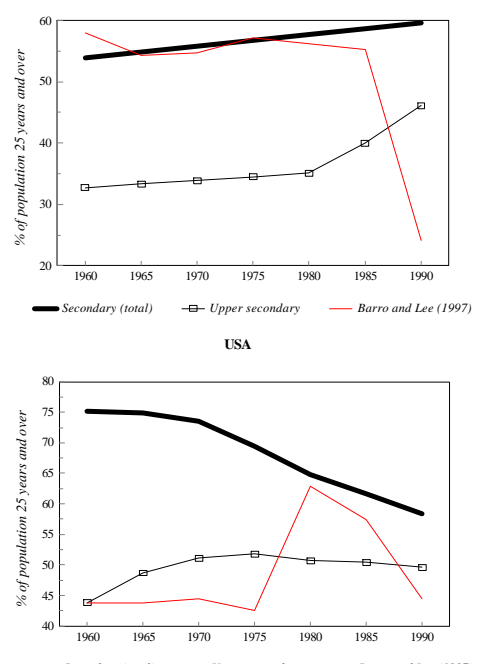
Percentage of population 25 years and over with higher education.
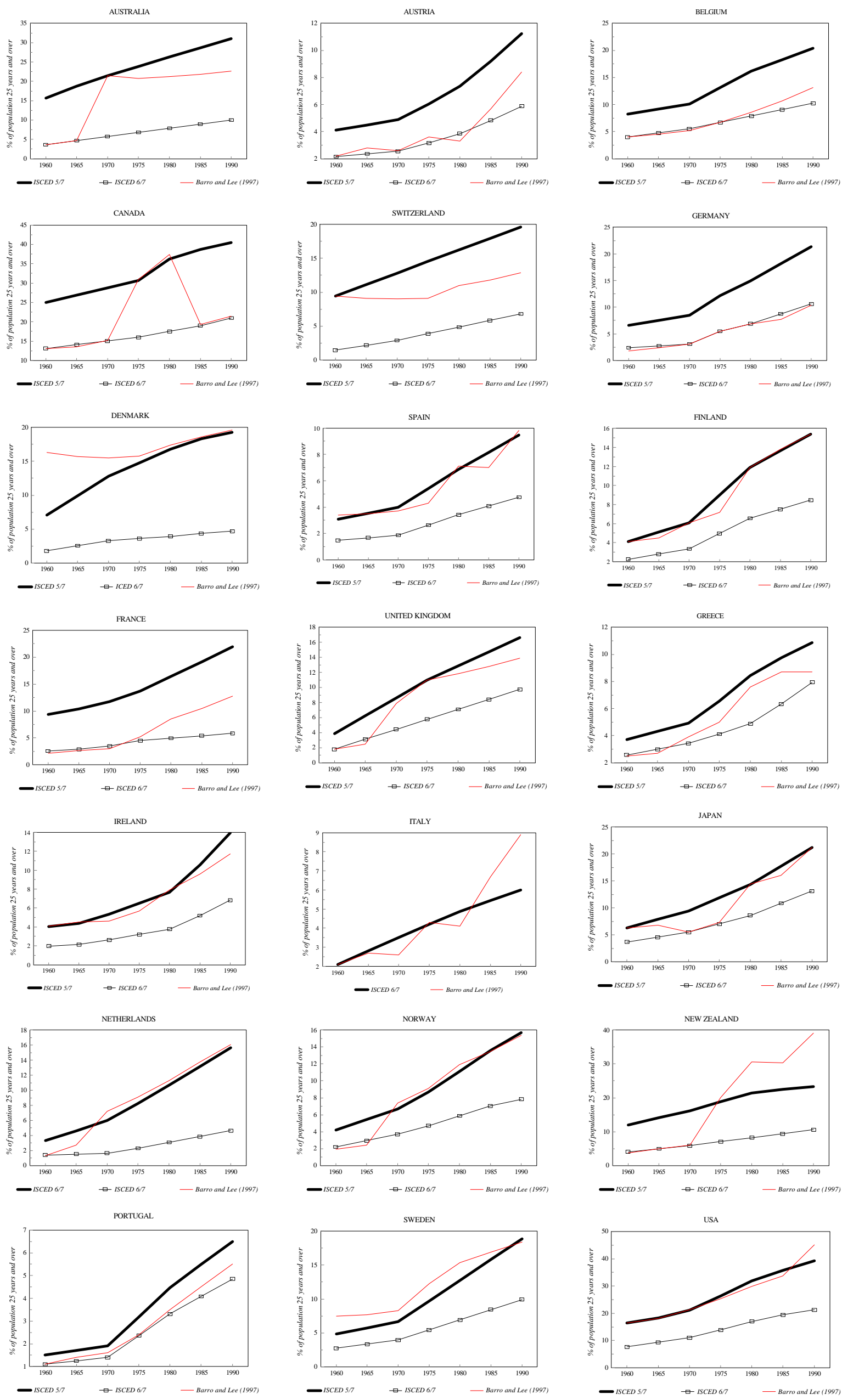
Average years of schooling of population 25 years and over.

AUSTRALIA

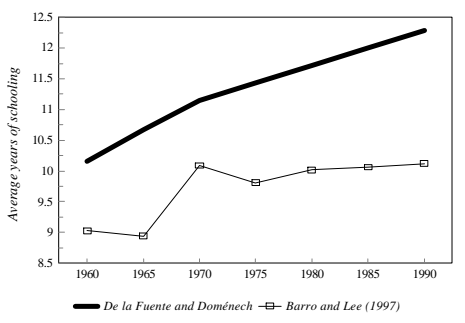

CANADA

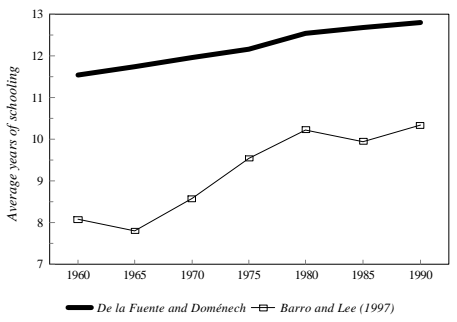

DENMARK

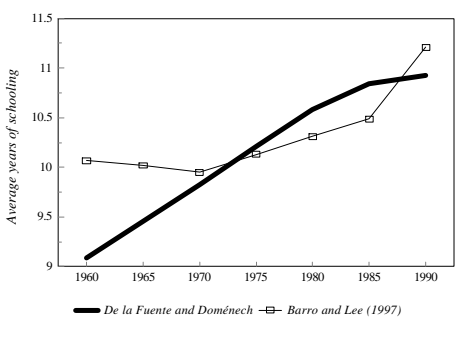

FRANCE

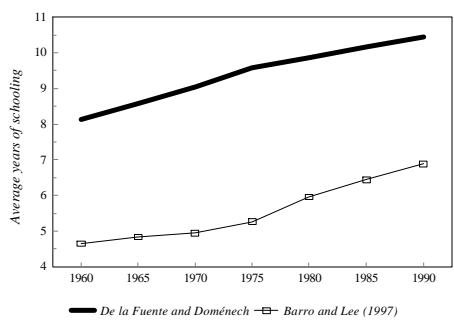

IRELAND
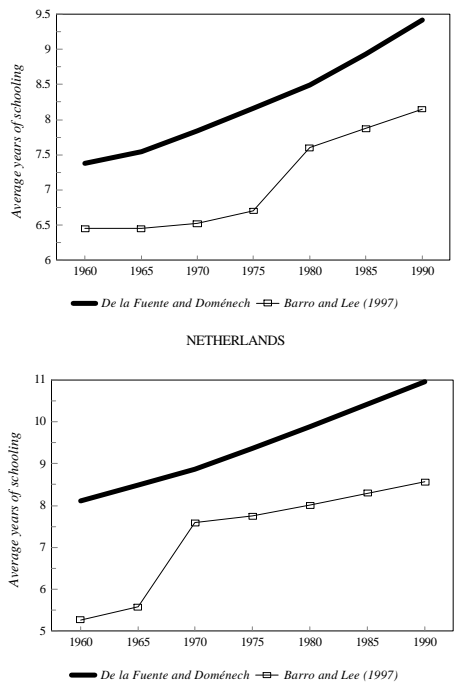

PORTUGAL

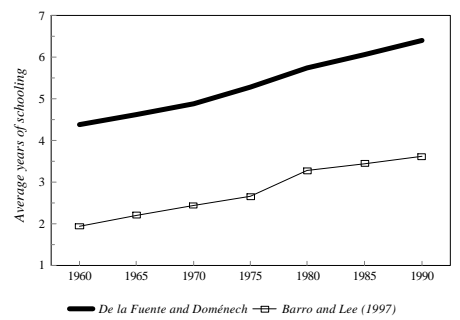

AUSTRIA

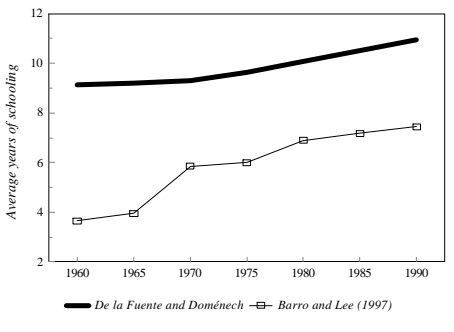

SWITZERLAND

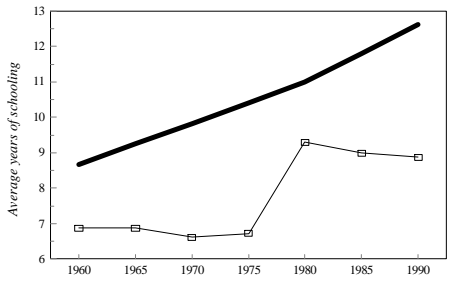

—De la Fuente and Doménech $\square$ Barro and Lee (1997)

SPAIN

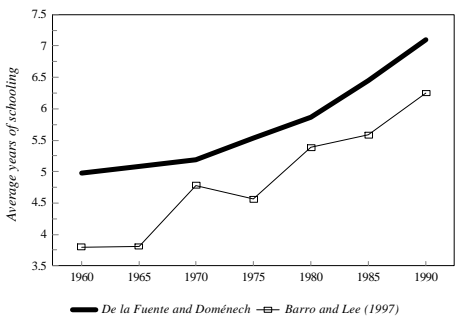

UNITED KINGDOM

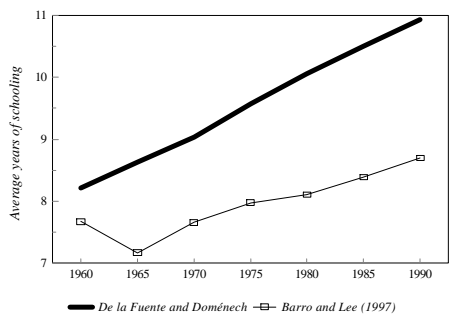

ITALY

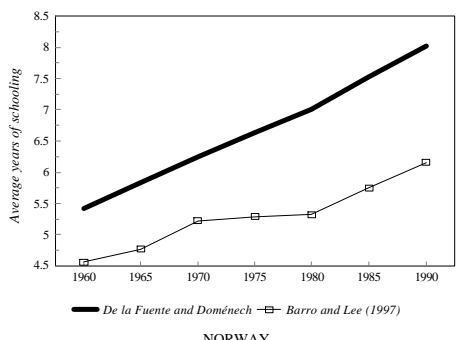

NORWAY

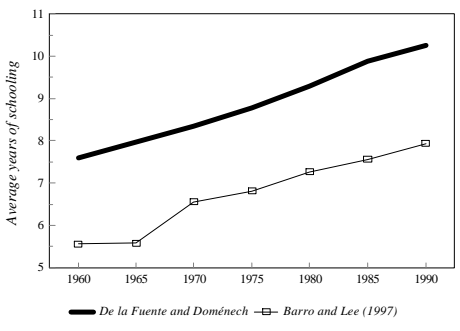

SWEDEN

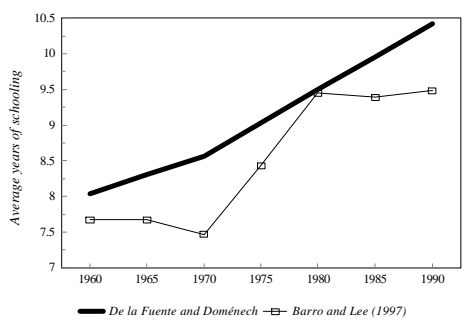

BELGIUM

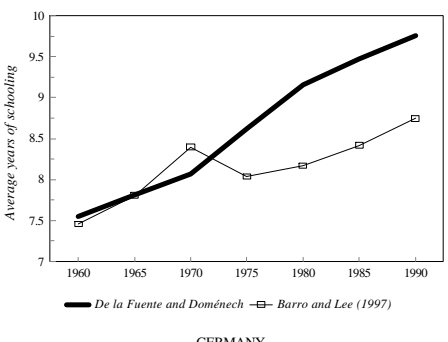

GERMANY

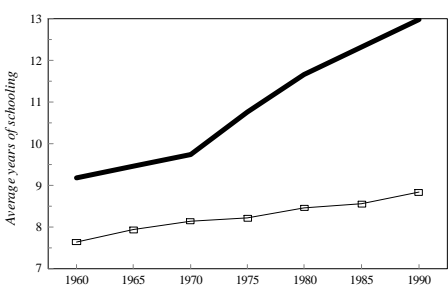

— De la Fuente and Domenenech —-Barro and Lee (1997)

FINLAND

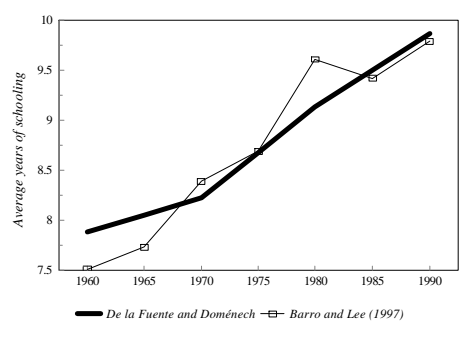

GREFCE

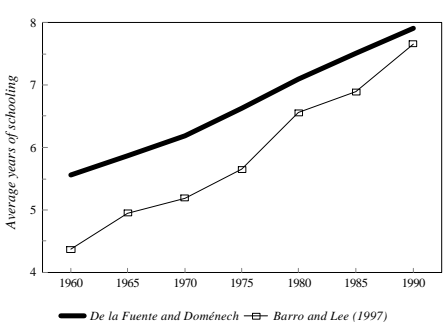

JAPAN

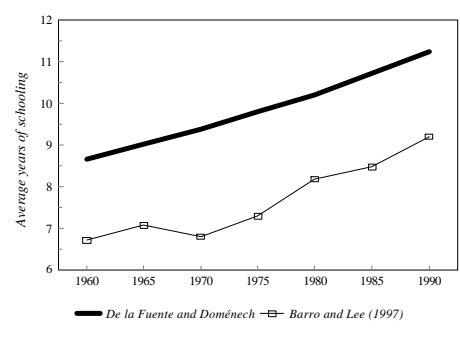

NEW ZEALAND

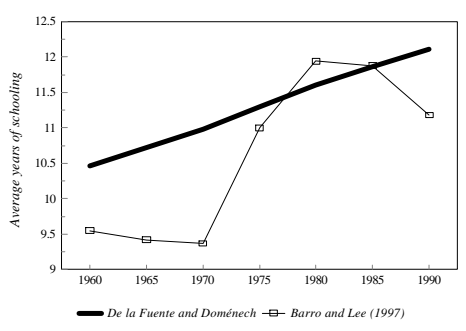

UNITED STATES

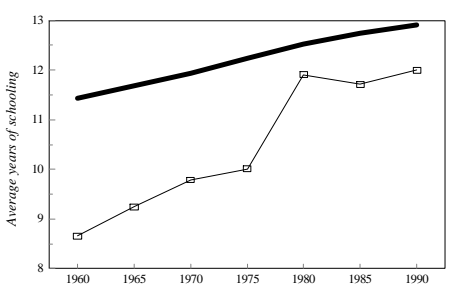

De la Fuente and Doménech $\rightarrow$ Barro and Lee (1997) 